Conceptual Soundness, Metric Development, Benchmarking, and Targeting for PATH Subprogram Evaluation

Prepared for the U.S. Department of Housing and Urban Development (HUD) Partnership for Advancing Technology in Housing

Gail Mosey, Elizabeth Doris, and Charles Coggeshall National Renewable Energy Laboratory

Matt Antes, Jennifer Ruch, and John Mortensen Energetics

Technical Report NREL/TP-6A2-43822 January 2009 


\section{Conceptual Soundness, Metric Development, Benchmarking, and Targeting for PATH Subprogram Evaluation}

Prepared for the U.S. Department of Housing and Urban Development (HUD) Partnership for Advancing Technology in Housing

Gail Mosey, Elizabeth Doris, and Charles Coggeshall National Renewable Energy Laboratory

Matt Antes, Jennifer Ruch, and John Mortensen Energetics

Prepared under Task No. WF1K.1000 and Subcontract No. KLCX-4-44453-19

National Renewable Energy Laboratory 1617 Cole Boulevard, Golden, Colorado 80401-3393 303-275-3000 • www.nrel.gov

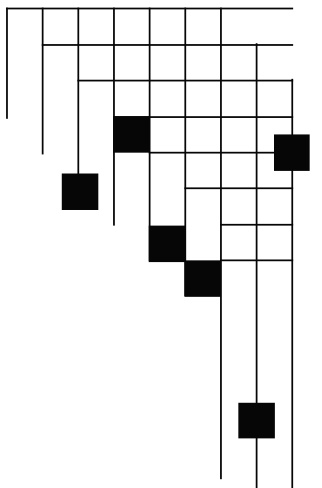




\section{NOTICE}

This report was prepared as an account of work sponsored by an agency of the United States government. Neither the United States government nor any agency thereof, nor any of their employees, makes any warranty, express or implied, or assumes any legal liability or responsibility for the accuracy, completeness, or usefulness of any information, apparatus, product, or process disclosed, or represents that its use would not infringe privately owned rights. Reference herein to any specific commercial product, process, or service by trade name, trademark, manufacturer, or otherwise does not necessarily constitute or imply its endorsement, recommendation, or favoring by the United States government or any agency thereof. The views and opinions of authors expressed herein do not necessarily state or reflect those of the United States government or any agency thereof.

Available electronically at http://www.osti.gov/bridge

Available for a processing fee to U.S. Department of Energy and its contractors, in paper, from:

U.S. Department of Energy

Office of Scientific and Technical Information

P.O. Box 62

Oak Ridge, TN 37831-0062

phone: 865.576 .8401

fax: 865.576 .5728

email: mailto:reports@adonis.osti.gov

Available for sale to the public, in paper, from:

U.S. Department of Commerce

National Technical Information Service

5285 Port Royal Road

Springfield, VA 22161

phone: 800.553 .6847

fax: 703.605.6900

email: orders@ntis.fedworld.gov

online ordering: http://www.ntis.gov/ordering.htm 


\section{Table of Contents}

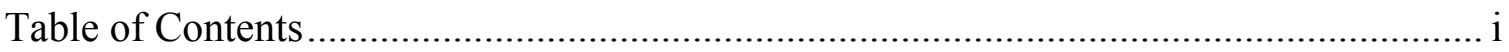

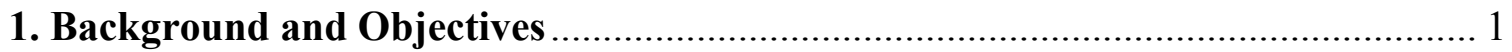

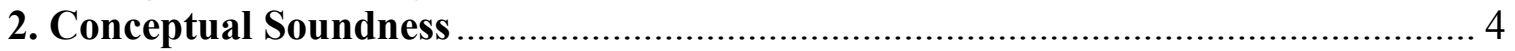

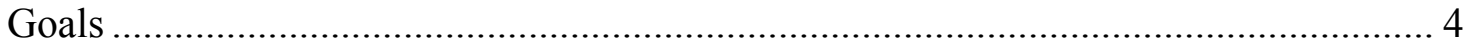

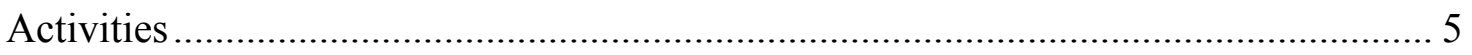

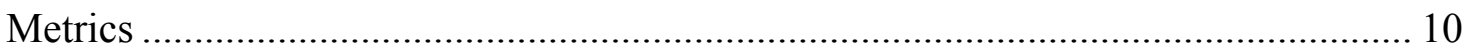

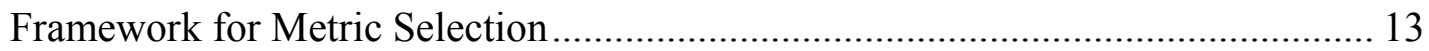

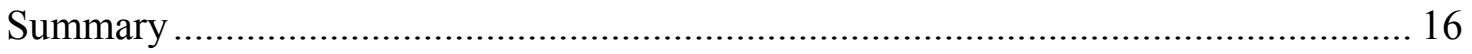

3. Recommended Metrics for PATH's Concept Home............................................... 17

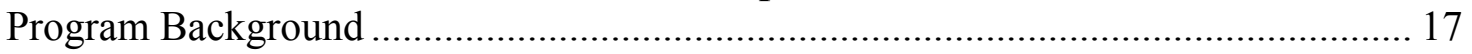

Which PATH Goal(s) Does This Program Address? ………....................................... 17

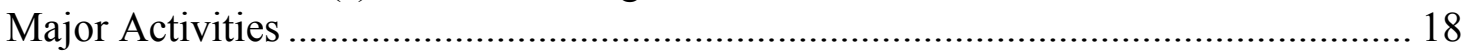

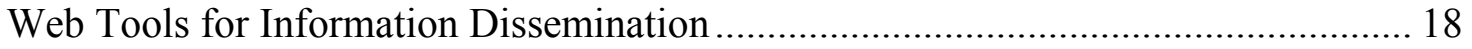

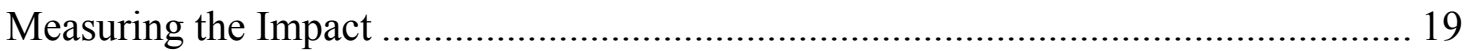

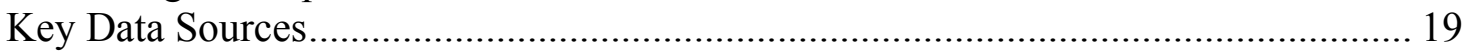

Approach for Identifying and Recommending Performance Metrics........................... 20

Recommended Metrics .................................................................................... 21

Additional Recommended Metrics …………………............................................ 24

4. Recommended Metrics for PATH's ToolBase Program …………………............ 25

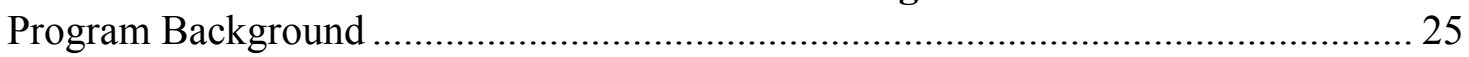

Which PATH Goal(s) Does This Program Address? ................................................ 26

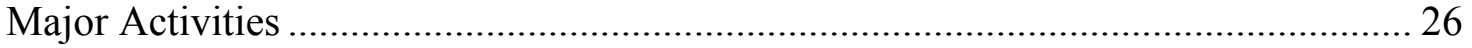

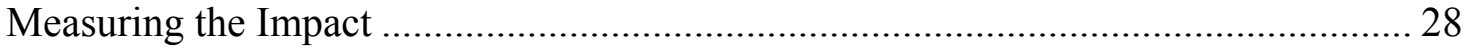

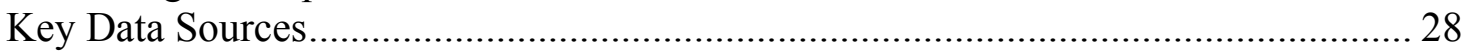

Approach for Identifying and Recommending Performance Metrics........................... 29

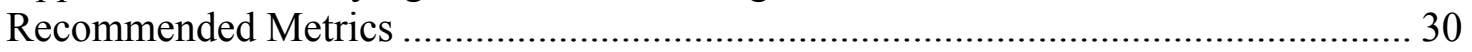

Additional Recommended Metrics …………………................................................. 35

5. Recommended Metrics for PATH's Structural Insulated Panels Program.......... 36

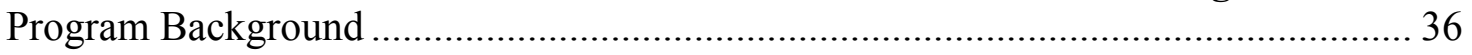

Which PATH Goal(s) Does This Program Address? ………………………….......... 36

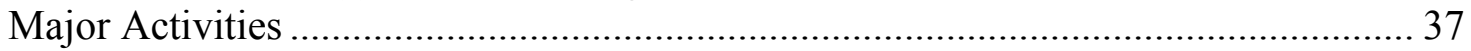

Web Tools for Information Dissemination ............................................................... 37

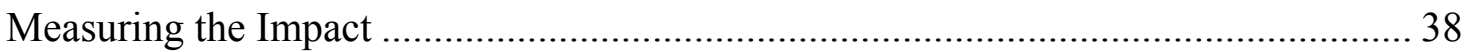

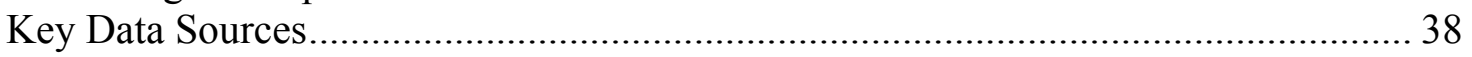

Approach for Identifying and Recommending Performance Metrics........................... 39

Recommended Metrics ............................................................................................. 40

Additional Recommended Metrics ……................................................................ 43

6. Recommended Metrics for PATH's Steel Framing Program.................................. 44

Program Background .............................................................................................. 44

Which PATH Goal(s) Does This Program Address? ………...................................... 44

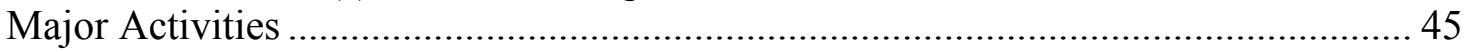

Web Tools for Information Dissemination .................................................................. 46

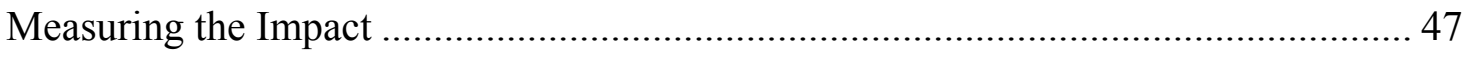

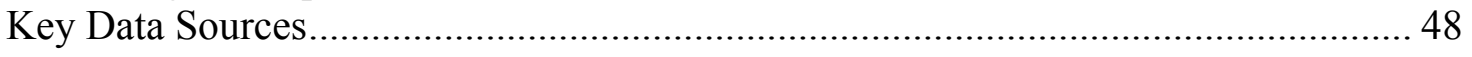


Approach for Identifying and Recommending Performance Metrics........................ 48

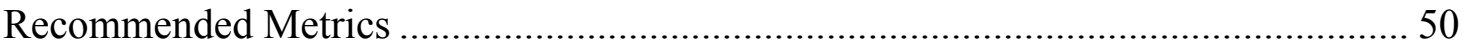

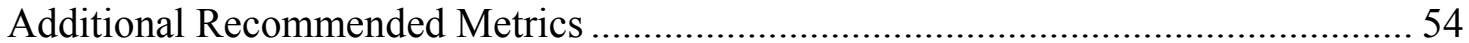

7. Recommended Metrics for PATH's Insulating Concrete Forms Program........... 55

Program Background .................................................................................. 55

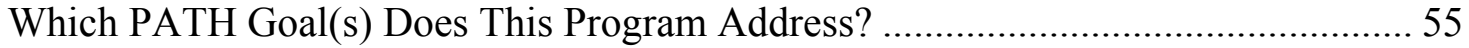

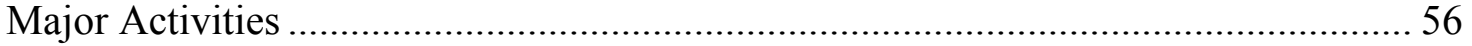

Web Tools for Information Dissemination ........................................................... 57

Measuring the Impact ..................................................................................... 57

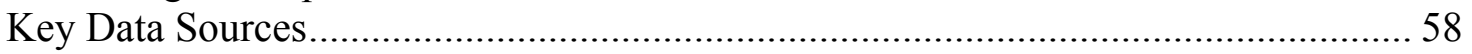

Approach for Identifying and Recommending Performance Metrics......................... 59

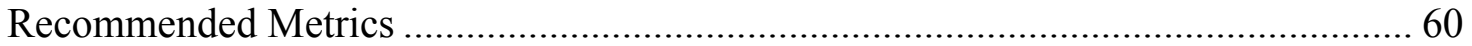

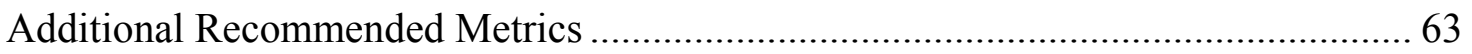

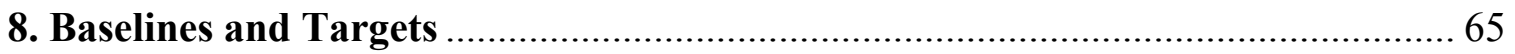

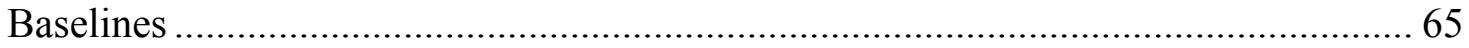

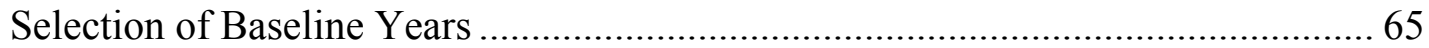

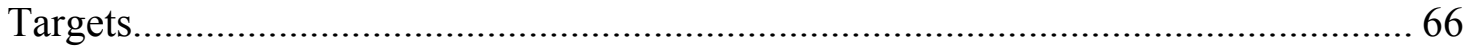

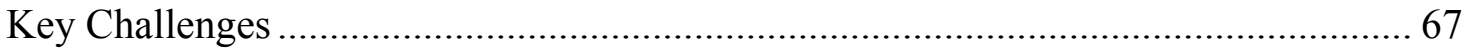

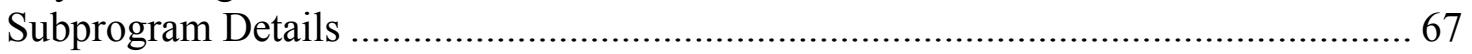

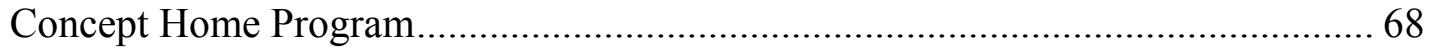

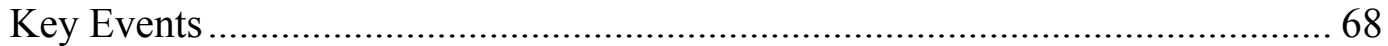

Concept Home Baseline and Target Values ........................................................ 68

ToolBase Program ...................................................................................... 71

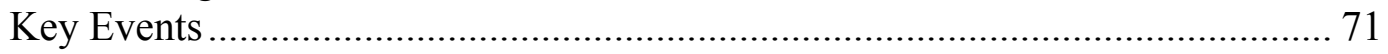

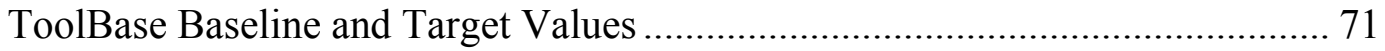

Structural Insulated Panels Program .................................................................... 75

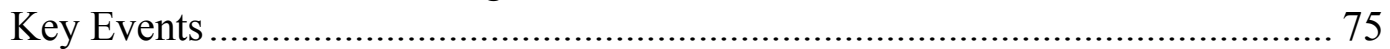

SIPs Baseline and Target Values ............................................................... 75

Advanced Steel Framing Program ................................................................. 78

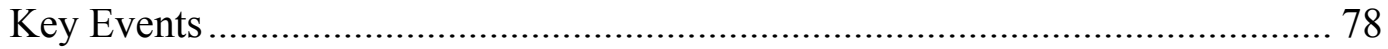

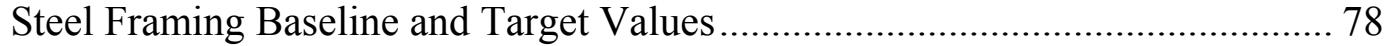

Insulating Concrete Forms Program ................................................................. 81

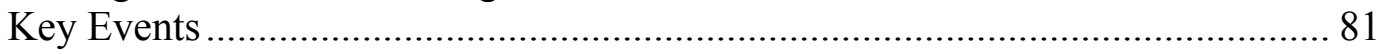

Baseline and Target Values ...................................................................... 81

9. Guidelines for Developing Metrics, Data Collection, Analysis and Reporting for

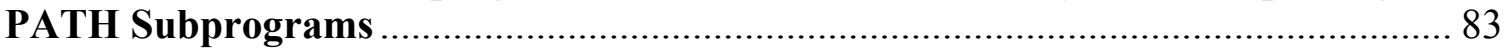

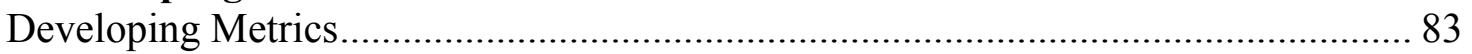

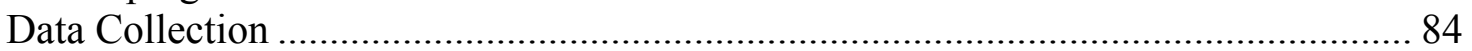

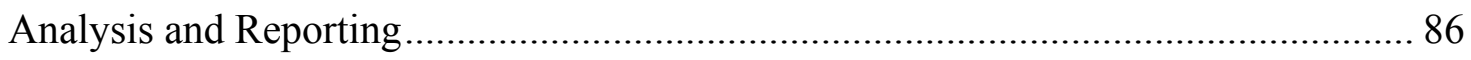

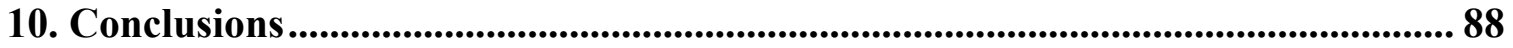

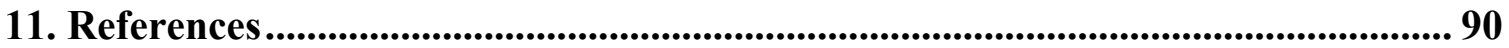

Appendix A. Metrics for Goals ........................................................................93

Appendix B. Metrics for Scoring ................................................................................... 98 


\section{Background and Objectives}

The U.S. Department of Housing and Urban Development (HUD) Office of Policy Development and Research has been extensively involved in supporting research and development (R\&D) of U.S. building technologies. This R\&D includes innovations, construction systems, products, standards, regulations, and code issues that affect the affordability, safety, and livability of the nation's housing. As the interrelationships of these topics become more complex, the continued need to conduct research and demonstrations becomes even more critical.

In addition to the research and demonstration efforts administered directly by the Office of Policy Development and Research, HUD administers the Partnership for Advancing Technology in Housing (PATH) program. PATH provides an unprecedented opportunity to the private and public sectors of the U.S. housing industry to advance state-of-the-art practices in the design and construction of housing. Many scholars argue that the meager investment in residential technology research necessitates a program like PATH. Despite the importance of the housing industry to the American economy, this innovative chasm is especially true for detached, single-family housing - a market that makes up most of America's housing stock. It can purportedly take 10 to 25 years for a new housing technology to achieve full market penetration. Often, it takes that much time to simply introduce an innovation to the market. As such, PATH spurs new R\&D initiatives, enhances the access to and quality of information resources about them, and decreases the institutional barriers to their development, adoption, and diffusion in housing.

Because accomplishing this mission is broad and the partnering approach is complex, the program has experimented with numerous strategies and activities since its inception. In 1994, the White House convened representatives from all segments of the U.S.

construction industry to consider a broad set of National Construction Goals, which were subsequently published and disseminated as potential goals for the industry and strategies for reconsidering governmental investments in research and diffusion efforts. During the next three years, the residential segment of the construction industry - represented by home builders, code officials, product manufacturers, federal researchers across the cabinet, and other interested parties - developed a research plan for implementing the goals for the housing sector. PATH was the outgrowth of those proposals, and was officially launched on May 4, 1998. HUD was selected as the appropriate agency to house PATH because of the compatibility of both entities' missions; with a focus on the housing market and industrial context rather than on individual home performance issues like energy, HUD was well-suited for PATH's innovation goals. Likewise, PATH's emphasis on affordability and quality supported HUD's overall mission and its specific goals for increased homeownership and expanded, decent housing options.

PATH is a public/private partnership program of HUD and is aimed at accelerating the development and use of advanced housing technology. To that end, PATH's original goals are as follows:

1) Reduce the monthly cost of new housing by $20 \%$ or more. 
2) Cut the environmental impact and energy use of new homes by $50 \%$ or more, and reduce energy use in at least 15 million existing homes by $30 \%$ or more.

3) Improve durability and reduce maintenance costs by $50 \%$.

4) Reduce by at least $10 \%$ the risk of life, injury, and property destruction from natural hazards, and decrease by at least $20 \%$ illnesses and injuries to residential construction workers.

The National Research Council's (NRC's) PATH evaluation found no evidence or baseline data to indicate that the housing performance goals were measurable and achievable (NRC 2003). These and other challenges associated with the original numeric goals are well-documented and can be summarized in five main points (Martin 2005, RAND unreleased documents, Cohn (ed.) 2006):

- The program was broadly focused, but the goals involved measuring the end-user market.

- The metrics were not appropriate to measuring the impact of an innovationfocused program.

- Due to the public/private partnership structure of the program, metrics should measure the impact of the sector interaction through information sharing as well as research and development.

- The rate of impact of the program varies over time and should be reflected in the performance metrics. Variable impacts are due to the length of time from building conception to completion resulting in a slow rate of uptake for new technology.

- The housing market is large and complex with multiple participating stakeholders and national geographic scope. Separating the PATH programmatic impact from other impacts for the former metrics of overall housing costs and efficiency gains is impossible given the complexity of the market.

All of these factors - the broad program focus, the research and development and public/private partnership program aspects, the slow rate of change, and complex industry structure - create challenges for directly attributing savings to the PATH program as the original goals require.

Recognizing these challenges through an evaluation by the NRC (Cohn 2006) and realizing the need for program impact measurement changes to meet national government program reporting requirements (e.g., the Government Performance and Results Act or GPRA), PATH refocused and refined its goals in 2002. Prior to 2002, the goals were overambitious, yet specific enough to enable development of precise quantifiable metrics tied to unambiguous goals that measure programmatic success. The revised goals focus on addressing barriers to technology innovation, which consists of a broader emphasis on the application of creative new ideas and the processes by which new products and services enter the market. The goals refocused PATH and its associated objectives with the overall aim of increasing the impact of technology innovation in the home-building sector. The revised goals are listed in Table 1. 
Table 1. Revised Goals of PATH Program

\begin{tabular}{|l|l|}
\hline 1) Remove barriers and facilitate technology development and adoption \\
a. Identify current and potential barriers and measure their impacts \\
b. Develop practical methods to overcome current barriers \\
c. Develop alternative future industrial processes that eliminate barriers
\end{tabular}

The objective of this study is to evaluate the conceptual soundness of the PATH program's revised goals and establish and apply a framework to identify and recommend metrics that are the most useful for measuring PATH's progress. This report provides an evaluative review of PATH's revised goals, outlines a structured method for identifying and selecting metrics, proposes metrics and benchmarks for a sampling of individual PATH programs, and discusses other metrics that potentially could be developed that may add value to the evaluation process. The framework and individual program metrics can be used for ongoing management improvement efforts and to inform broader program-level metrics for government reporting requirements.

Chapter 2 addresses the conceptual soundness of the revised goals and the methodology for developing metrics, while the subsequent chapters describe the recommended metrics for five PATH subprograms: Concept Home $(\mathrm{CH})$, ToolBase ${ }^{\circledR}$, Structural Insulated Panels (SIPs), Advanced Steel Framing, and Insulated Concrete Forms (ICFs). These programs were selected for evaluation based partly on prominence in the PATH suite of program, longevity, and data availability. Baseline and target values for five of the subprograms are provided in Chapter 8 . Chapter 9 suggests guidelines for developing metrics, data collection, analysis, and reporting; and conclusions are presented in Chapter 10. 


\section{Conceptual Soundness}

This section evaluates the conceptual soundness of the PATH program's revised goals and develops a framework for identifying the most useful metrics for measuring PATH's progress. The revised PATH goals seem to be more in line with the program purpose of improving innovation in the residential sector and are in accordance with the program's structure as a public/private partnership.

This section presents the list of candidate metrics developed by the PATH program for measuring progress toward its goals. It also highlights the proposed framework to rank the candidate metrics on the basis of clarity of the metric (to be understood by stakeholders), the ability to be attributed to the program, the feasibility of the data, and the comparability of the metric over time. This methodology provides an initial step toward refining the proposed metrics,

\section{Working Definitions for this Report}

Framework: Methodology for identifying recommended metrics.

Candidate (or proposed or potential) metrics: Metrics that could potentially be used for measuring program performance but have not yet been scrutinized by applying the framework.

Recommended metrics: Metrics that are considered useful for measuring program performance based on application of the framework.

Additional recommended metrics: Metrics that would be considered useful for measuring program performance but lack a key attribute (e.g., data availability). Often additional recommended metrics are meant to fill in any gaps in the set of recommended metrics in order to provide a comprehensive evaluation.

which, over the course of further evaluation and testing for usability, are refined to form a proposed set of metrics and recommendations for numeric goals for the PATH program. These recommended metrics will measure the progress and impact of the PATH program in the coming years, and help inform a long-term program assessment.

\section{Goals}

Based on NREL programmatic review experience, the new goals are evaluated for applicability and appropriateness by answering the following program management criteria:

- Are the goals clear and unambiguous? We find these goals to be reflective of the general program vision and useful for an innovation-driven program with a public/private partnership structure. For a program of this structure, challenges arise from integrating the public and private sector and understanding and evaluating the needs of multiple market actors. These goals, even in their general nonquantified state, reflect an increased understanding and knowledge of both.

- Do the goals align with PATH's capabilities and actions? The goals do align PATH's capabilities and actions because the goals were developed after the start of the program and after its programmatic capabilities were already defined. A potential drawback to defining the goals after the activities were already in place is that the goals are designed to fit the program actions rather than vice-versa. This possible disadvantage can be minimized with the careful selection of metrics that are directed toward measuring overall program market impact. 
- Are the goals focused on key market drivers? By way of PATH's public/private partnership structure, the goals do focus on market drivers. Because private industry is involved in the program, PATH administrators have unique access and opportunity to impact the market and the market drivers. These goals account for this partnership approach to understanding the needs of the market actors and how to engage them to influence key market drivers.

- Do the goals incorporate leveraging with other market actors? Leveraging is directly considered through the second goal. Goal 2 acknowledges the need for understanding and increasing information dissemination to other market players. Despite the program's limited resources to create market change, this will leverage indirect program impacts by influencing external actors.

- Are the goals measurable? Measuring the program goals are a critical component of an overall assessment of PATH. Program metrics that are clear, attributable, feasible, and comparable over time are still in development.

From a program planning and evaluation standpoint, these revised goals are reasonable and sound for a public/private partnership innovation program such as PATH. The new goals reflect the NRC recommendations to narrow the program's focus, and they align with PATH's decision to focus on technology innovation. These goals focus specifically on barriers to innovation such as regulatory barriers and lack of information dissemination in the residential-housing sector. The goals approach the home-building market from an innovation perspective. That is, the goals address market behavior of stakeholders in the innovation process and attempt to understand these behaviors in order to improve innovation in the market. They incorporate changes resulting from the public/private partnership by striving to impact the information regarding innovative technologies within and outside of PATH. All three goals strive to improve the environment for innovative thinking and focus on the process of innovation rather than end results of innovation (e.g., a 50\% decrease in home energy use or energy costs).

\section{Activities}

The PATH program has proposed a variety of associated inputs, activities, and outcomes to meet the above outlined goals and objectives (Table 2). This section presents a summary of the activities suggested to meet each of these. It also briefly reviews these activities for soundness based on the connection of the activities to the goals, the uniqueness of the activities related to other government programs, and the appropriateness of these activities within the program structure. The remainder of this section presents an overview of activities arranged according to the goals, which are restated below.

\section{Goal 1 - Remove barriers and facilitate technology development and adoption with the following objectives:}

a. Identify current and potential barriers and measure their impacts

b. Develop practical methods to overcome current barriers

c. Develop alternative future industrial processes that eliminate barriers 
The first goal aims to remove barriers to technology development and deployment. The first two objectives for Goal 1, $a$ and $b$, address identifying barriers and developing methods to overcome these barriers. The activities associated with the two initial objectives address identification and points of origination of barriers and effective ways to overcome them.

The first objective, objective $a$, of Goal 1 addresses the need for identifying and studying the barriers and their impacts. The second objective, $b$, of Goal 1 considers the results of objective $a$ and addresses developing options for overcoming these barriers. Activities may include pilot programs and training sessions based on the specific barrier being addressed. This objective is difficult to apply directly to Goal 1 . The recommendation for these barrier-reduction activities is to temporally space them behind barrier identification and public/private collaboration to determine methods to address the identified barriers.

The activities associated with the third objective, objective $c$, of Goal 1, however, approach the goals from the perspective of a paradigm shift toward new views of innovation. Therefore, they are able to be carried out simultaneously to the activities associated with the first objective. The impacts of these activities may be difficult to measure because, if successful, new industrial processes and methods will completely avoid existing barriers instead of having to identify the barriers in order to reduce their effects, as in the first two objectives. These activities do provide an opportunity for largescale change in the innovation patterns of the building industry, and therefore fit with the overarching aim of Goal 1 to remove barriers.

\section{Goal 2 - Improve technology transfer, development, and adoption through information dissemination with the following objectives:}

a. Establish and maintain noncommercial information sources on innovation

b. Understand behaviors, attitudes, and needs regarding innovation information

c. Have relevant information materials on innovation and innovators for different parties

Goal 2, improving technology transfer and adoption, includes activities ranging from updating noncommercial information on products and services to outreach involving information distribution to relevant builders, owners, and remodelers. Like many government programs, the role of providing unbiased information on the innovation process as well as existing products and services is a critical part of the public side of the program. An Internet review indicates that the government-funded data repository for home-building information, ToolBase, is the only free, comprehensive, noncommercial source for a wide variety of information for the home-building industry. The ToolBase database maximizes the public/private partnership structure of the PATH program because it leverages relationships with private industry to gather a wealth of information, which is then presented in a noncommercial way as a service to the greater homebuilding audience. It should be noted that the ToolBase database can be run simultaneously to and support the research and intent of Goal 1, the reduction/removal of barriers. 


\section{Goal 3 - Advance housing technologies' research and foster development of new technology with the following objectives:}
a. Establish sustained public and private R\&D investment resources
b. Clarify and assist innovators with processes from technology transfer to market penetration
c. Have comparative standards for innovation performance, cost, benefits, and agendas.

The activities associated with Goal 3 involve the final stages of innovation: increasing market penetration of innovative products and processes. These activities include understanding the market and, in order to turn technology awareness into technology transfer that results in market penetration, making that information more readily available to innovators through outreach. In addition, actions should be taken to leverage intergovernmental agency and private company partnerships to encourage R\&D funding - a critical piece of the innovation pipeline. All of the activities listed could accomplish the third goal in some aspect, but further refinement will be based on how the activity can have measured success against the goal.

In summary, the activities suggested in the PATH strategic plan match the revised goals and objectives stated for the program. Given the large number and broad range of potential activities, a more refined list of selected activities will need to be made based on effectiveness of the activity on meeting a specific goal. To understand the potential impacts of each activity, implementers must select a set of effective metrics. The following section outlines a multiyear process to identify the most promising metrics for measuring PATH program impact on the established goals. This process will result in a refined list of activities to carry out the PATH program charter most effectively. 
Table 2. PATH Goals, Objectives, and Activities

\begin{tabular}{|c|c|c|}
\hline Goal & Objective & Proposed Activities \\
\hline \multirow{3}{*}{$\begin{array}{l}\text { Goal 1: Remove } \\
\text { barriers and facilitate } \\
\text { technology } \\
\text { development and } \\
\text { adoption }\end{array}$} & $\begin{array}{l}\text { Identify current and potential } \\
\text { barriers and measure their } \\
\text { impacts }\end{array}$ & $\begin{array}{l}\text { - Barrier-impact studies } \\
\text { - Barrier-identification forums } \\
\text { - Barrier-reduction collaboration forums }\end{array}$ \\
\hline & $\begin{array}{l}\text { Develop practical methods to } \\
\text { overcome current barriers }\end{array}$ & $\begin{array}{l}\text { - Study Evaluation Service (ES) process, outreach to International Code } \\
\text { Council (ICC) jurisdictions to enforce ES reports } \\
\text { - } \text { Prototype insurance initiative (same Insurer for manufacturer and builder } \\
\text { - } \text { Consumer utility and insurance programs, analysis of R\&D tax incentives } \\
\text { - Innovators' training assistance on-site, professional curriculum review } \\
\text { - } \text { Prototype innovation marketing with retailers } \\
\text { - } \text { Additional valuation studies, development of comparable and installation } \\
\text { - } \quad \text { listings' architect spec sheets } \\
\text { - Macroeconomic analysis of building activity and innovation rates }\end{array}$ \\
\hline & $\begin{array}{l}\text { Develop alternative future } \\
\text { industrial processes that } \\
\text { eliminate barriers }\end{array}$ & $\begin{array}{l}\text { - Performance-based codes prototypes and advocacy } \\
\text { - Prototype innovation insurance initiative } \\
\text { - Consumer programs advocacy, innovation adoption tax-credit studies } \\
\text { - Full labor-training programs and certifications, curriculum standards advocacy } \\
\text { - Prototype innovation marketing with suppliers } \\
\text { - Professional training requirements on innovation }\end{array}$ \\
\hline \multirow{3}{*}{$\begin{array}{l}\text { Goal 2: Improve } \\
\text { technology transfer, } \\
\text { development, and } \\
\text { adoption through } \\
\text { information } \\
\text { dissemination }\end{array}$} & $\begin{array}{l}\text { Establish and maintain } \\
\text { noncommercial information } \\
\text { sources on innovation }\end{array}$ & $\begin{array}{l}\text { - Tool Base and PATH generated info } \\
\text { - Manufacturer information and market training } \\
\text { - ToolBase and PATH collected info }\end{array}$ \\
\hline & $\begin{array}{l}\text { Understand behaviors, } \\
\text { attitudes, and needs } \\
\text { regarding innovation } \\
\text { information }\end{array}$ & $\begin{array}{l}\text { - Market research agenda forum, research project scoping and funding } \\
\text { - Advanced research project scoping and funding, preliminary data } \\
\text { - Market research dissemination and monitoring }\end{array}$ \\
\hline & $\begin{array}{l}\text { Have relevant information } \\
\text { materials on innovation and } \\
\text { innovators for different parties }\end{array}$ & $\begin{array}{l}\text { - Home-buyer outreach } \\
\text { - Home-builder technical outreach } \\
\text { - Home-builder marketing and sales outreach } \\
\text { - Remodeler technical outreach } \\
\text { - Remodeler marketing and sales outreach } \\
\text { - Manufacturer outreach }\end{array}$ \\
\hline
\end{tabular}


Table 2. PATH Goals, Objectives, and Activities

\begin{tabular}{|c|c|c|}
\hline & \\
\hline Goal & Objective & $\begin{array}{c}\text { Proposed Activities } \\
\end{array}$ \\
\hline \multirow{3}{*}{$\begin{array}{l}\text { Goal 3: Advance } \\
\text { housing technologies' } \\
\text { research and foster } \\
\text { development of new } \\
\text { technology }\end{array}$} & $\begin{array}{l}\text { Establish sustained public } \\
\text { and private R\&D investment } \\
\text { resources }\end{array}$ & $\begin{array}{l}\text { - National Science Foundation (NSF)-PATH program } \\
\text { - Joint research agendas, federal applied research funds } \\
\text { - Current research findings shared event, joint research agendas } \\
\text { - Collaborative federal/state research funds } \\
\text { - Identify foundations, convene events for agendas, develop preliminary } \\
\text { projects } \\
\text { - Identify trade associations with research, model research programs; } \\
\text { preliminary collaboration } \\
\text { - Identify and access venture capital (VC) funds for industrial collaborations for } \\
\text { - Preliminary research projects with individual firms or collaborations } \\
\text { - Roadmap research projects with individual firms or collaborations }\end{array}$ \\
\hline & $\begin{array}{l}\text { Clarify and assist innovators } \\
\text { with processes from } \\
\text { technology transfer to market } \\
\text { penetration }\end{array}$ & $\begin{array}{l}\text { - PATH-related technology transfer efforts (basic to applied) } \\
\text { - State/local technology transfer outreach } \\
\text { - Network building of independent tech transfer efforts (basic to applied) } \\
\text { - PATH technology scanning } \\
\text { - PATH commercialization tools } \\
\text { - Commercialization center } \\
\text { - R\&D capacity evaluation and assistance } \\
\text { - Testing facility clearinghouse and outreach to innovators, PATH field } \\
\text { evaluations }\end{array}$ \\
\hline & $\begin{array}{l}\text { Have comparative standards } \\
\text { for innovation performance, } \\
\text { cost, and benefits and } \\
\text { agendas }\end{array}$ & $\begin{array}{l}\text { - PATH beyond-code performance testing protocols (e.g., durability) } \\
\text { - Testing protocol outreach } \\
\text { - Testing protocol expansion } \\
\text { - PATH roadmaps }\end{array}$ \\
\hline
\end{tabular}




\section{Metrics}

After the revision of its goals, PATH identified about 50 potential metrics for measuring progress and quantifying the impacts of the program. These metrics were developed by the PATH program in 2005. This section maps the metrics in terms of measurability and applicability to the three goals of the program, and presents a framework for identifying the most useful, applicable, and feasible metrics for measuring progress toward those goals. Future research will result in further refinement and specific recommended numeric goals to gauge the progress of the PATH program.

Due to the slow-change nature of the housing market leading to a long-range nature of the goals, the metrics are divided into near term and long term. For summary purposes, only the long-term outcome potential metrics are listed in Table 3. The possible metrics listed here are preliminary; the following framework will help refine the list, and further research and understanding will provide a final list of proposed metrics. These metrics will be described in this paper for particular PATH programs - Concept Home, ToolBase, Structural Insulated Panels, Advanced Steel Framing, and Insulated Concrete Forms - and will include benchmark levels for future evaluation. 
Table 3. Summary of Complete List of Potential Metrics for Measuring PATH Progress Toward Goals

\begin{tabular}{|c|c|c|}
\hline Goal & Objective & $\begin{array}{ll} & \text { Potential Metrics }\end{array}$ \\
\hline \multirow{3}{*}{$\begin{array}{l}\text { Goal 1: Remove } \\
\text { barriers and facilitate } \\
\text { technology } \\
\text { development and } \\
\text { adoption }\end{array}$} & $\begin{array}{l}\text { Identify current and potential } \\
\text { barriers and measure their } \\
\text { impacts }\end{array}$ & $\begin{array}{ll}\text { - } & \text { Number of measures for determining policy effects on barriers } \\
\text { - } & \text { Reduced or eliminated number of barriers identified } \\
\text { - } & \text { Percent of event commitments completed annually }\end{array}$ \\
\hline & $\begin{array}{l}\text { Develop practical methods to } \\
\text { overcome current barriers }\end{array}$ & 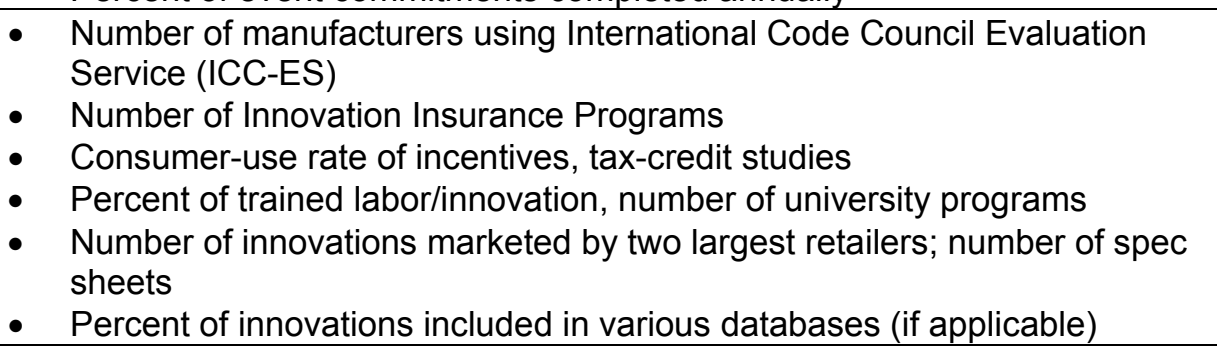 \\
\hline & $\begin{array}{l}\text { Develop alternative future } \\
\text { industrial processes that } \\
\text { eliminate barriers }\end{array}$ & $\begin{array}{l}\text { - } \quad \text { Percent of code provisions drafted in performance basis } \\
\text { - } \quad \text { Number of innovations insured under program } \\
\text { - Number of consumer programs, number of tax-credit programs } \\
\text { - Number of trained labor, number of accredited university programs } \\
\text { - Number of innovations marketed by } 50 \text { largest suppliers } \\
\text { - } \quad \text { Percent of certified professionals in three fields (architecture, appraisal, } \\
\text { inspection) }\end{array}$ \\
\hline \multirow{3}{*}{$\begin{array}{l}\text { Goal 2: Improve } \\
\text { technology transfer, } \\
\text { development, and } \\
\text { adoption through } \\
\text { information } \\
\text { dissemination }\end{array}$} & $\begin{array}{l}\text { Establish and maintain } \\
\text { noncommercial information } \\
\text { sources on innovation }\end{array}$ & $\begin{array}{ll}\text { - } & \text { ToolBase } \AA \text { use rates } \\
\text { - } & \text { Number of noncommercial information sources } \\
\text { - } & \text { Use rates of noncommercial information sources (non-PATH) }\end{array}$ \\
\hline & $\begin{array}{l}\text { Understand behaviors, } \\
\text { attitudes, and needs } \\
\text { regarding innovation } \\
\text { information }\end{array}$ & $\begin{array}{l}\text { - } \quad \text { Percentage completed of market research agenda } \\
\text { - } \quad \text { Total research funding proportion to sales consistency } \\
\text { - } \quad \text { Use of market research data }\end{array}$ \\
\hline & $\begin{array}{l}\text { Have relevant information } \\
\text { materials on innovation and } \\
\text { innovators for different parties }\end{array}$ & $\begin{array}{l}\text { - } \text { Proportion of home buyers purchasing homes with 5+ PATH technologies } \\
\text { - } \quad \text { Proportion of homeowners remodeling with 5+ path technologies } \\
\text { - } \quad \text { Proportion of home builders building homes with 5+ PATH technologies } \\
\text { - } \quad \text { Proportion of remodelers remodeling homes w/ 5+ PATH technologies } \\
\text { - } \quad \text { Proportion of remodelers marketing services with } 5+\text { PATH technologies } \\
\text { - } \quad \text { Market shares for all PATH-identified technologies of average share of firm } \\
\text { sales by innovative products launched in the past } 10 \text { years }\end{array}$ \\
\hline
\end{tabular}




\begin{tabular}{|c|c|c|}
\hline Goal & Objective & Potential Metrics \\
\hline \multirow{3}{*}{$\begin{array}{l}\text { Goal 3: Advance } \\
\text { housing technologies' } \\
\text { research and foster } \\
\text { development of new } \\
\text { technology }\end{array}$} & $\begin{array}{l}\text { Establish sustained public } \\
\text { and private R\&D investment } \\
\text { resources }\end{array}$ & $\begin{array}{l}\text { - Total federal funding to academic research } \\
\text { - Total federal funding to applied research } \\
\text { - } \quad \text { Annual international exchange events } \\
\text { - Total state/local applied research funding (proportional to sales) } \\
\text { - Total foundation applied research dollars (proportional to sales) } \\
\text { - Total association research projects and funding } \\
\text { - } \quad \text { sales) } \\
\text { - Total roadmap research matching funding }\end{array}$ \\
\hline & $\begin{array}{l}\text { Clarify and assist innovators } \\
\text { with processes from } \\
\text { technology transfer to market } \\
\text { penetration }\end{array}$ & $\begin{array}{l}\text { - } \quad \text { Federal technology transfer funding and programs } \\
\text { - Number of state technology transfer housing programs } \\
\text { - } \quad \text { Total independent technology transfer programs } \\
\text { - Number of housing product sales efforts by non-housing firms } \\
\text { - } \quad \text { Percent of manufacturers using tools } \\
\text { - Percentage of firms ranked as mid- to high innovators } \\
\text { - } \quad \text { Percent of fully tested innovations and market introduction } \\
\end{array}$ \\
\hline & $\begin{array}{l}\text { Have comparative standards } \\
\text { for innovation performance, } \\
\text { cost, and benefits and } \\
\text { agendas }\end{array}$ & $\begin{array}{l}\text { - Number of performance testing protocols } \\
\text { - } \quad \text { Percentage of maintained commitments versus commitments made } \\
\text { - } \quad \text { Number of non-PATH testing protocols } \\
\text { Percentage of executed research projects; number of roadmaps }\end{array}$ \\
\hline
\end{tabular}




\section{Framework for Metric Selection}

This section describes a basic framework for narrowing a list of potential metrics (and any other suggested metrics) into a set of recommended metrics that measure PATH's progress toward its revised goals. The set of recommended metrics should be considered for informing a broader assessment of PATH. As noted in the NRC report, there are no ideal assessment processes that can be applied to evaluating programs for advancing technologies. Programs need to be considered individually to determine the metrics that best respond to the specific program and technologies (NRC 2003). As such, the basic framework outlines a process for determining metrics that best represent the progress of the program and its specific activities in advancing housing technology and achieving its overall goals. The framework follows a four-step process as described below:

\section{Develop a simple logic model of the program activities, outputs, and outcomes. The logic model translates the program activities and revised goals into a diagram that illustrates how these function collectively while being measured individually. A vital attribute for any metric is that it show a clear relationship to the desired goals and objectives, and a logic model provides the conceptual foundation for understanding this relationship. For the overall PATH program, potential metrics already have been identified and therefore this step may not be necessary. Developing metrics for individual programs within PATH, however, would significantly benefit from following this step.}

2. Identify candidate metrics based on the logic model. The logic model conceptualizes the activity-goal relationships. By identifying potential metrics based on a logic model, the analysis ensures that the metrics are appropriately matched with the goals and structure of each program. PATH goals focus on technology development, transfer, and adoption; and as a result, its metrics should measure these activities throughout the innovation cycle. Mapping potential metrics that are aligned with PATH goals and objectives means that the set of metrics are more likely to cover both the means (program activities) and the ends (program outcomes) and track the movement of technologies through the innovation cycle.

\section{Apply a scoring system to the candidate metrics based on key} characteristics. Several key characteristics for determining meaningful metrics apply to the PATH evaluation. These characteristics are used as criteria for scoring candidate metrics to refine the set into recommended metrics. The metrics or performance indicators should be as clear and precise as possible to remove ambiguities and ensure that the metric is understood by a wide audience. The metrics should, as possible, discern PATH's influence versus influence from external factors. The metrics should be based on quantifiable, reliable data that is available at minimal collection cost or effort. The metrics should be trendable (comparable over time) and enable fair comparisons to previous and/or future measurements. These characteristics and the scoring system are explained in greater detail later. 
4. Rebalance and recommend set of metrics. This final step adds expert judgment to the recommendation process, which ensures that the objective scoring technique in the previous step generates a set of metrics that are representative of the breadth of PATH activities and includes measures of activities, outputs, and outcomes. If necessary, the set of recommended metrics are adjusted or rebalanced so that the various criteria required for such a multifaceted program evaluation as PATH are met.

The remainder of this section outlines the methodology and scoring system for refining the list of potential metrics based on four key characteristics:

1. Understandable. Extent to which the metric is able to be understood by external stakeholders.

2. Attributable. Ability to accurately determine PATH contribution.

3. Feasible. Available and reliable data.

4. Comparable over time. Ability to make fair comparisons to previous and/or future measurements.

Characteristic 1: Understandable. The recommended metrics must clearly articulate the progress of PATH internally to decision makers and communicate externally to interested stakeholders. This characteristic of understandability to a wide range of stakeholders is particularly important for PATH metrics due to its public/private partnership structure involving both an internal and external audience. This is a challenging criterion because external stakeholders are generally of broad backgrounds and difficult to classify into an easily identifiable audience.

Each candidate metric is given a score between " 0 " and " 2 " based on the metric's level of understandability as shown in Table 4.

Table 4. Scoring System for "Understandable"

\begin{tabular}{|c|l|}
\hline Score & \multicolumn{1}{c|}{ Meaning } \\
\hline 0 & Too complex for internal or external stakeholders to understand. \\
\hline 1 & $\begin{array}{l}\text { Possibly understandable by stakeholders. Measure may have complicated } \\
\text { units (e.g., Web hits per application per promotional period). }\end{array}$ \\
\hline 2 & Straightforward metric. Simple units. \\
\hline
\end{tabular}

Characteristic 2: Attributable. As mentioned earlier, attribution of impact is a challenge associated with government programs. The structure of PATH as a public/private partnership makes it particularly difficult to distinguish the impact of the program from impacts due to external factors (e.g., partners' activities, natural market forces, etc.). The ability to attribute PATH's influence on the progress toward its goals is therefore a key criterion for determining the best set of recommended metrics for PATH. PATH has limited direct influence on ultimate outcomes or market penetration of a given technology; this will be determined primarily by the technology's cost and performance advantages compared to its competition. Nonetheless, metrics that are able to attribute credit to PATH are beneficial in helping inform a long-term program assessment. 
These criteria for rating the proposed metrics require assessing whether the PATH impact can be separated from the market/private-sector impact. The scoring system is described in Table 5.

Table 5. Scoring System for "Attributable"

\begin{tabular}{|c|l|}
\hline Score & \multicolumn{1}{|c|}{ Meaning } \\
\hline 0 & $\begin{array}{l}\text { Largely unable to decipher whether progress/impacts can be attributed to } \\
\text { PATH. }\end{array}$ \\
\hline 1 & Partially able to determine PATH's portion of the progress/impact. \\
\hline 2 & Able to clearly distinguish PATH's contribution. \\
\hline
\end{tabular}

Characteristic 3: Feasible. Feasibility consists of three characteristics of the data supporting the metric: available, reliable, and quantitative. A useful metric obtains reliable measurements and data. The availability of quantitative data from reliable sources presents a major hurdle for the selection of PATH metrics. While the industry acknowledges the clear need to use quantitative measures, few sources of such data exist. Trade association data, census surveys, and Web site statistics offer the most promising leads. The importance of metrics data feasibility imparts a significant challenge and substantially reduces the number of metrics that can be used in a PATH assessment.

Table 6 defines the simple scoring system for estimating metric feasibility. The metrics with the highest score will be those with easily accessible, reliable, and quantitative data.

Table 6. Scoring System for "Feasible"

\begin{tabular}{|c|l|}
\hline Score & \multicolumn{1}{|c|}{ Meaning } \\
\hline 0 & Quantitative data unavailable. \\
\hline 1 & $\begin{array}{l}\text { Quantitative data partially available. May need to contact multiple sources } \\
\text { or extrapolate/interpolate gaps in data. Reliability may be questionable } \\
\text { (e.g., bias risk). }\end{array}$ \\
\hline 2 & Reliable quantitative data publicly available (e.g., U.S. census). \\
\hline
\end{tabular}

Characteristic 4: Comparable over time. PATH metrics are intended to communicate the progress and impacts of the program. To measure accomplishments, there must be consistent basis from which to measure. A metric that is comparable over time means that the methodology for reporting or manipulating the data does not change. It also requires that the metric is relevant from one year to the next. For instance, a one-time milestone of publishing a specific technical report is not comparable over time; however, the number of technical documents published per year may be comparable. Technologyspecific metrics also risk becoming outdated as new technologies evolve. This characteristic is critical for the metrics to be a useful contribution to the long-term assessment of PATH. 
Table 7 outlines the scoring system for the ability of metrics to be compared over time.

Table 7. Scoring System for "Comparable Over Time"

\begin{tabular}{|c|l|}
\hline Score & \multicolumn{1}{|c|}{ Meaning } \\
\hline 0 & One-time metric (e.g., meeting a milestone) \\
\hline 1 & $\begin{array}{l}\text { Comparable for a limited period of time, but environment may change that } \\
\text { would make the metric obsolete (e.g., measuring specific component of } \\
\text { technology) }\end{array}$ \\
\hline 2 & Comparable year after year, indefinitely (e.g., measuring technology area) \\
\hline
\end{tabular}

This system of scoring metrics is developed through market and programmatic evaluation knowledge in the home-building and innovation sectors. It is designed to narrow down the list of candidate metrics to only those with a high potential for accurately measuring the impacts of the PATH program. Based on the combined scores for all four key characteristics, the metrics are ranked and considered for recommendation. The final step involves using expert judgment to ensure that the set of metrics adequately represents the program activities, outputs, and outcomes.

\section{Chapter Summary}

The PATH program goal is to advance innovation of technology development in the residential-housing sector. PATH's initial goals, established at the program's outset in 1998, focused on achieving percentage reductions in housing costs and energy. In 2002, an extensive evaluation found these goals to be poorly matched to the program's role in expediting and facilitating the innovation process to impact the market. Consequently, the PATH program revised its goals to focus on the innovation process through technology development, transfer, and adoption. This report finds that the revised goals are more appropriately aligned with the original PATH charter because they more closely match the public/private partnership program structure and better target the innovation market, rather than the end-user market. These goals attempt to make real market impacts through continued focus on market adoption of innovative technologies.

The following chapters apply the framework described above and introduce recommended metrics for five individual PATH programs, which were selected partly based on their prominence in PATH, their longevity, and data availability for these programs. 


\section{Recommended Metrics for PATH's Concept Home}

\section{Program Background}

The U.S. Department of Housing and Urban Development's Partnership for Advancing Technology in Housing (PATH) administers the Concept Home program. This program demonstrates a vision for the future of American residential home building by showcasing advanced technologies and innovative building practices, through the design, construction, and marketing of Concept Homes. The technologies and building practices offer opportunities for home builders to improve the durability, affordability, safety, and energy efficiency of residential housing in the United States.

The Concept Home program was conceived from PATH's "Technology Roadmap: Whole House and Building Process Redesign, and Technology Scanning." The roadmap concluded that modern homes are "currently built to be inflexible, with systems tangled behind interior walls and embedded in structural elements. But the home of the future will combine functions that make better use of labor, material, time, and money, consequently reducing cost and installation time" (PATH 2004).

The Concept Home program has two overarching goals:

- Demonstrate advanced technologies and building practices by creating the first whole-house prototype that can be easily altered with options, upgrades, and improvements.

- Showcase Concept Home and promote its specific innovative technologies.

The whole-house prototype represents an entirely new approach to home design that has the potential to reshape the U.S. residential-housing market. In the end, program implementers will construct several demonstration Concept Homes, which will each highlight a variety of technologies.

\section{Which PATH Goal(s) Does This Program Address?}

PATH goals focus on reducing the multiple constraints throughout the innovation pipeline in the residential-housing sector, and developing the infrastructure for increasing innovation in that pipeline. PATH's three overall goals are:

- Identify and reduce barriers that impede innovation, including regulatory barriers (PATH Goal 1)

- Disseminate information to speed the development and adoption of advanced building technologies (PATH Goal 2)

- Advance housing technology research and foster development of new technology (PATH Goal 3)

The Concept Home program primarily addresses PATH Goal 2 (see Appendix A for a listing of metrics by program and the specific objectives addressed by the metrics.) Information on new technologies is disseminated to the housing market using a variety of methods, such as open house demonstrations, marketing events and conferences, Web pages, news releases, and case studies. 


\section{Major Activities}

Concept Home aligns its major activities with its overarching goals of technology demonstration and information sharing through the following:

\section{Conceiving the Concept Home}

PATH identifies core concepts and principles that will be the foundation for deciding which innovative technologies to incorporate into the Concept Home. For the first Concept Home - Omaha - the vision was to create a home that would be flexible (easy to update and expand for different life stages), efficient (easy to build and easy to live in), and sustainable (featuring green, energy-efficient products).

\section{Designing the Concept Home}

PATH elicits a builder to contribute to the design of the home, select a site for the home, and construct the home. An advisory committee of industry professionals - including the selected builder and PATH - selects advanced technologies and building practices to include in the demonstration Concept Home. PATH identifies and coordinates with product manufacturers to provide the technologies and building materials.

\section{Constructing the Concept Home}

PATH provides technical support during the planning and construction phases through codes, standards, and certification development for the new technologies and practices. PATH does not provide direct financial support for constructing the home.

\section{Demonstrating and Promoting the Concept Home}

A primary focus of the program centers on information dissemination of the home's technologies. PATH produces marketing articles and Web pages about the Concept Home and the various technologies it showcases. It also stages promotional events such as open houses and walk-throughs of the demonstration home, and works with the media to publicize the program and its technologies. The target audience includes builders, manufacturers, home buyers, and the general public.

\section{Continually Improving the Concept Home}

Following the construction and demonstration of a Concept Home, a performance evaluation is conducted to identify lessons learned that can be applied to the next home. For instance, PATH identifies ways to improve cost-effectiveness, durability, safety, and/or identifies any technologies that should be added or subtracted from the next Concept Home.

\section{Web Tools for Information Dissemination}

PATHnet (http://PATHnet.org/) is PATH's information Web portal that provides detailed information about the program's ongoing and completed projects. The portal offers information on designs, technologies, and product manufacturers, and includes news releases and other publications related to Concept Home. 
ToolBase (http://www.toolbase.org/) is a PATH-sponsored technical information resource for the home-building industry that contains free, comprehensive, noncommercial, and un-biased "product descriptions, design \& construction guides, best practices, performance reports, case studies, and other resources...that builders and remodelers will find useful." "Within the ToolBase site, a section called Technology Inventory (i.e., TechInventory), includes many or all of the technologies used by the Concept Home program. For example, the downloadable TechSpecs document, included in the TechInventory section of many of the technologies, provides in-depth information on costs, results from field evaluations, and tips for determining whether a specific technology is right for a certain kind of project.

\section{Measuring the Impact}

Metrics provide quantitative evidence of the progress and impacts of specific programs. Measuring impacts is often more difficult than measuring the progress of a program, but both are vital for gauging overall performance. Both types of metrics are discussed in the Recommended Performance Metrics section. Two approaches are considered for measuring the impacts:

- Direct measurement of increased market penetration of the specific technologies that are included in each of the Concept Homes constructed

- Direct measurement of Concept Home information dissemination, including the extent and results of marketing campaigns and measured overall awareness of the Concept Home

Although the first type of metric more directly measures the impacts on the market of the specific technologies of PATH Concept Homes, it would require extensive research on each of the included technologies. It may not be practical or feasible to collect this type of data and conduct the relevant analyses. Market-penetration metrics for each technology would be required to assess each technology in each demonstration Concept Home. Many of these technologies are in the development stages and the sales data are proprietary, which complicates measuring the program impacts. Even if market penetration data are available, the data are likely influenced by external factors that make attribution to PATH uncertain.

The second measurement type - evaluating the impact of Concept Home marketing campaigns to the broad community of builders, designers, manufacturers, home buyers, etc. - allows for practical measurement and a useful understanding of program effects with respect to PATH's overall Goal 2: information dissemination. While this measure does not reveal direct market impacts of the program, it effectively shows the exposure of information to the marketplace as a result of PATH efforts.

\section{Key Data Sources}

Data for Concept Home metrics are available primarily from two key sources:

\footnotetext{
1 "About ToolBase." <http://www.toolbase.org/about.aspx>.
} 


\section{D\&R International}

D\&R International, PATH's marketing consultant, provides quantitative data on the attendance and frequency of promotional events as well as data on information distribution. D\&R also supplies information on the number of publications and other articles created, and they track the estimated audience reached by such materials.

\section{NAHB Research Center}

The National Association of Home Builders (NAHB) Research Center compiles statistics on Web site use of ToolBase, including page views and downloads.

Potential additional data sources are presented in the Recommended Metrics section.

\section{Approach for Identifying and Recommending Performance Metrics}

The following approach, which is explained further in Chapter 2, is used for recommending performance metrics:

1. Develop a logic model of the Concept Home activities, outputs, and outcomes. The logic model translates the program activities and goals described earlier into a diagram that illustrates how these function collectively while being measured individually (see Figure 1 for logic model).

2. Identify candidate metrics based on the logic model that measure the progress of these activities, outputs, and outcomes toward achieving project and program goals.

3. Apply the scoring system described in the Conceptual Soundness report to the candidate metrics. The scoring system is based on general characteristics of useful metrics for the PATH program. Scores are based on four key criteria:

a. Understandable. Extent to which the metric is understood by external stakeholders

b. Attributable. Ability to determine PATH contribution

c. Feasible. Availability and reliability of data

d. Comparable over time. Ability to make fair comparisons to previous and/or future measurements

4. Tally scores and rebalance. Metrics are selected based on the scores and a rebalancing using expert judgment to ensure that the set of recommended metrics are representative of the breadth of PATH Concept Home activities and include measures of activities, outputs, and outcomes. 


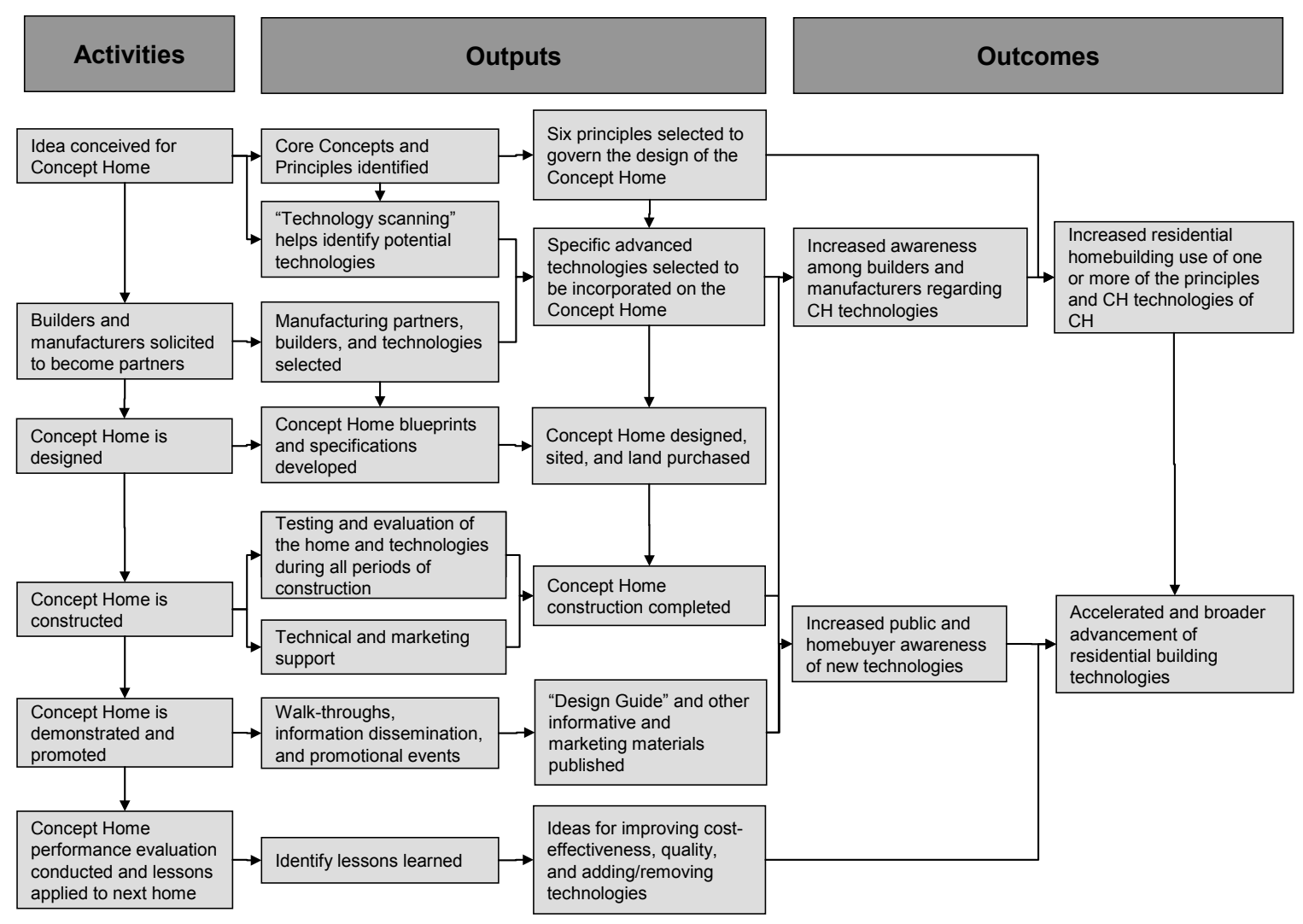

Figure 1. Concept Home Logic Model

\section{Recommended Metrics}

Recommended metrics and potential data sources for Concept Home are presented in this section. Note that additional recommended metrics are proposed in the next section. That section represents measure(s) that would complement the current metrics set, but the data are not likely to be easily available. Together, these two sections represent a full set of recommended metrics that measure both the means and the ends of the program, and inform a process for long-term assessment and program improvement. See Appendix B for a listing of metrics and their respective scoring considering the attributes discussed in the Conceptual Soundness section - understandable, attributable, feasible, and comparable over time.

Note that Concept Home is unique from other PATH programs because of the multiyear cyclical nature of its activities. That is, one home is built every few years with activities purposefully intended to correspond with the timing of the home-building phase.

Therefore, the metrics should account for the cyclical characteristics of this program. Typically, metrics are measured on an annual basis (e.g., average number of Web hits per month in a given year). Because the Concept Home cycle operates on a multiyear basis, several of the recommended metrics include "cumulative" statistics that cover the 
lifetime of the program. This technique helps avoid potentially misleading statistics if the period is limited to one year.

Number of partners and technologies

1) Cumulative number of industry partners (such as designers, builders, technology manufacturers) who have participated in Concept Home since the inception of the program

This metric measures the program's ability to engage the home-building community and seek out relevant partners to contribute to the development and construction of Concept Homes. It measures a key Concept Home activity necessary to reach a wide audience about innovative technologies and practices in the industry. A possible addition to this metric would incorporate the percentage of the market that the industry partners represent, indicating the size of participants relative to the industry as a whole. Obtaining market data may be an obstacle for this addition and simply measuring the cumulative number of partners will be an adequate first-order measure.

Data Source: PATH personnel and pathnet.org. For example, a list of technology sponsors for Concept Home Omaha is available at: http://www.pathnet.org/sp.asp?id=22428\&pbg=3

2) Cumulative number of technologies that are promoted by Concept Home and included in completed homes since the inception of the Concept Home program

This metric shows the program's ability to incorporate advanced technologies into Concept Home design and construction. It provides an indicator of the extent that the program is generating opportunities to demonstrate and share information about advanced technologies to the housing market.

Data Source: pathnet.org. For example, the list of technologies for Concept Home Omaha is available at: http://www.pathnet.org/sp.asp?id=21935\&pbg=3

$\underline{\text { Information dissemination activities and outputs }}$

3) Cumulative potential audience reached through mass marketing and news releases (e.g., television promotions, circulation of newspapers containing articles about Concept Home)

This metric measures the extent that the program and its technologies and practices are exposed to a wide audience. Note that the potential audience for this metric is less likely to fully absorb the information about Concept Home than the audience for user-initiated information sources, such as PATHnet. For example, only a fraction of the recipients of a newspaper or magazine that covers a wide range of topics read a given article. Audience reached for user-initiated sources measured in Metrics 4 and 5 - are more likely to retain the information.

Data Source: D\&R International 
4) Cumulative audience reached via in-person information events, such as Concept Home promotional events and open houses

This metric represents the captive in-person audience reached by the Concept Home program. While Metric 3 indicates the breadth of marketing coverage, this metric indicates the depth of coverage - the audience pursuing specific information about the technologies.

Data Source: D\&R International

5) Average monthly number of Web page hits that contain information about Concept Home and its technologies on PATH-sponsored Web sites (i.e., PATHnet, ToolBase, HUDUser)

Publishing information on PATHnet and ToolBase are key activities for disseminating information. Interested parties will frequently use these sites as long as these sites are updated with relevant, unbiased, accurate, clear, and concise information (NRC 2003). Complementing Metric 4, this metric represents the captive audience reached by the Concept Home program by measuring the audience pursuing specific information about the technologies. Metrics 3, 4, and 5 collectively indicate the total audience reached by Concept Home marketing efforts. These metrics measure the extent that PATH's information-dissemination activities are reaching various audiences: a wide audience (Metric 3) or a targeted audience (Metrics 4 and 5). These metrics also measure the trend over time of audience reached.

Data Source: D\&R International for pathnet.org and NAHB Research Center for ToolBase.org

6) Annual percentage growth in number of Google hits when searching the following exact phrase: "Partnership for Advancing Technology in Housing" and "Concept Home"

This metric gauges overall public interest in Concept Home by measuring the availability of information and reference materials pertaining to the program on the Internet. This exact search phrase was considered meaningful because, when tested, each search result was relevant to the PATH Concept Home program. Google hits are a useful metric because they measure the number of pages referencing PATH and Concept Home not only from pathnet.org or toolbase.org, but also from external sites either in industry, academia, or government.

Data Source: Google.com 


\section{Additional Recommended Metrics}

Program administration efficiency

7) Annual administrative costs as a percentage of total program expenses

This metric measures how efficiently PATH is operating the Concept Home program.

Data Source: PATH may be able to provide the data for this metric.

\section{$\underline{\text { Market penetration outcomes }}$}

8) Cumulative revenues of products/technologies that were incorporated into Concept Home (real dollars)

Product revenues indicate the extent of an advanced technology being incorporated into the home-building market. Dollar values should be adjusted to real dollars to account for variances in the producer price index (i.e., inflation). Data Source: Product revenues potentially can be collected from trade associations, or provided directly by the manufacturers.

9) Percentage of new homes in the United States using at least one of the technologies showcased in the Concept Home program

This metric gauges how deeply Concept Home technologies are penetrating the new residential home market, an ultimate outcome of the program.

Data Source: Measuring the number of new homes using one or more of the technologies requires estimating the U.S. new-housing market each year, and the technologies included in them. A survey of builders may provide a sufficient sample of the percentage of Concept Home technologies in new homes to extrapolate estimates for overall market share. 


\section{Recommended Metrics for PATH's ToolBase Program}

\section{Program Background}

The U.S. Department of Housing and Urban Development's Partnership for Advancing Technology in Housing (PATH) Program administers the ToolBase ${ }^{\circledR}$ program, and uses ToolBase.org as a portal to provide information to the building community. The objective of the ToolBase program is to give builders and remodelers access to the latest information on innovative building materials, processes, and systems (PATH 2003a). ${ }^{2}$ The program offers a means for disseminating objective residential building technology information.

PATH's involvement in ToolBase began in 1999 when it partnered with the National Association of Home Builders (NAHB) Research Center - a separately incorporated, notfor-profit subsidiary of the NAHB. The ToolBase.org Web site was launched in 2001, and relaunched with major updates in subsequent years (NAHB 2008). ToolBase.org is a Web-based portal that provides technical information to the home-building industry. It contains free, noncommercial, and unbiased product descriptions, design and construction guides, best practices, performance reports, case studies, and other resources useful for builders and remodelers. ToolBase provides stakeholders with quick and easy access to objective information, links to suppliers and products, and neutral reviews of specific housing techniques (Martin 2003).

The ToolBase program currently focuses on maintaining and updating its comprehensive resource listing of emerging housing technologies on its Web site. Previously, the program has provided additional services and enhancements. In July 2007, these additional services were indefinitely discontinued due to the funding vehicle for these tasks expiring. Prior to July 2007, ToolBase services had included, for example, a tollfree telephone hotline staffed by technical experts to answer questions from builders and remodelers; a news service to report the latest building research information directly to trade, real estate, and local home-builder association editors; an expansion of its Web site; and active involvement with program promotions (PATH 1999).

The ToolBase site continues to offer and maintain technical details primarily in two sections: Technology Inventory (i.e., TechInventory) and Field Evaluations. TechInventory includes thorough technical information for many or all of the new technologies promoted by PATH. These technologies demonstrate great potential for improving housing performance, but are not yet widely accepted in the market. Field Evaluations provide detailed real-world results from builders who have tested advanced building technologies listed in the TechInventory.

2 "PATH Technology Inventory." <http://www.pathnet.org/sp.asp?id=1395>. 


\section{Which PATH Goal(s) Does This Program Address?}

PATH's goals focus on reducing the multiple constraints throughout the innovation pipeline in the residential-housing sector, and developing the infrastructure for increasing innovation in that pipeline. PATH's three overall goals are:

- Identify and reduce barriers that impede innovation, including regulatory barriers (Goal 1)

- Disseminate information to speed the development and adoption of advanced building technologies (Goal 2)

- Advance housing technology research and foster development of new technology (Goal 3)

The ToolBase program primarily addresses PATH Goal 2 (see Appendix A for a listing of metrics by program and the specific objectives addressed by the metrics). The program also addresses Goal 3 through its demonstration activities. The TechInventory provides detailed technical information for a variety of emerging housing technologies and is available for any interested party to view (Goal 2). PATH also supports Field Evaluations, which are described by ToolBase.org as cooperative efforts between builders, remodelers, manufacturers, PATH, and the NAHB Research Center that place new technologies into homes so they can be evaluated in real-world conditions. ${ }^{3}$ These evaluations contribute to Goal 3, while publication of the findings of the nearly 40 Field Evaluations that have been completed applies to Goal 2.

\section{Major Activities}

When PATH first partnered with the NAHB Research Center, the program integrated the ToolBase Web pages with the Web site for the NAHB Research Center (www.nahbrc.org). In July 2001, after a major redesign effort, the toolbase.org site was launched as a separate Web site. The site again was revamped and relaunched in July 2006, completely independent from the nahbrc.org Web site, with the ToolBase portal design the same that is seen today (McGee 2008). The scope of the program was altered in July 2007, although the Web site itself did not significantly change at that time. During these different phases, PATH's involvement varied.

The program's major activities can be separated into two parts: pre-July 2007 activities and current activities. Prior to July 2007, PATH was able to provide funding to expand the Technology Inventory, develop and execute Field Evaluations, promote the ToolBase site and its technologies, and make other enhancements to the Web site. When one of the funding vehicles expired in July 2007, PATH and its partner NAHB Research Center were limited to maintaining the existing content in ToolBase, focusing on the Technology Inventory and Field Evaluation sections.

Major activities in PATH's ToolBase program can be summarized as follows:

\footnotetext{
3 "Field Evaluations." <http://www.toolbase.org/FieldEvaluations/SearchHome.aspx>.
} 


\section{Technology Inventory}

The TechInventory section of toolbase.org provides builders with a reliable source of information on new products or processes in the home-building industry. It lists details on each technology and contact information for the manufacturers. The TechInventory focuses on new housing industry technologies that are in use by $5 \%$ or less of the market. Adding information about technologies to the TechInventory aims to accelerate the awareness and acceptance process. ${ }^{4,5}$ Following the July 2007 change in scope, new technologies are no longer added to the inventory, but the TechInventory section remains an important section of the ToolBase site.

\section{Field Evaluations}

Field evaluations are real-world demonstrations to field test PATH technologies, provide the foundation for evaluating the new technologies, and convey their values to a variety of audiences including builders, remodelers, and manufacturers. ${ }^{4}$ PATH uses the TechInventory list to select technologies for use in the field evaluations and demonstrations. Similar to the TechInventory, no significant new content has been added since July 2007. Despite this, the Field Evaluations section remains an important section for Web site visitors.

\section{Promotions}

Prior to July 2007, site managers used numerous news service promotions to increase traffic on the ToolBase site and increase awareness of its technologies. They also created a biweekly electronic news service called ToolBase E-News, which focused on residential construction industry news dealing with information technology and homebuilding. ${ }^{6}$ Site managers established a ToolBase E-News RSS Feed to provide residential construction industry news directly to subscriber's computers. They also produced a bimonthly technical print newsletter (ToolBase News) to provide practical information that building professionals could use immediately in their businesses. It was available free through local and state home-builder associations. $^{4}$

ToolBase also promoted its site through television and magazines. For example, PATH advertised on cable television stations HGTV and HGTV Pro. The program also reached builders and consumers by advertising in the magazine Fine Homebuilding.

\section{Other Enhancements}

Other ToolBase enhancements pre-July 2007 included increased accessibility of the Web site, extending hours and adding Spanish language capability for its telephone hotline, creating a complementary Catalog of Building Products

\footnotetext{
4 "Technology Inventory." <http://www.toolbase.org/Techlnventory/About.aspx>.

5 "About ToolBase." <http://www.toolbase.org/about.aspx>.

6 "Newsletters." <http://www.toolbase.org/Newsletters/EnewsHome.aspx>.
} 
and Services, and optimizing its ability to be found through Web searches (i.e., Web search optimization).

After July 2007, PATH-supported ToolBase activities included maintaining the TechInventory and Field Evaluations sections of the Web site. Maintenance activities include ensuring that the Web site is "live" and functioning on the Internet, that the links are active and not broken, and that technical material and contact information is updated and added to the site as it is received (no new materials for the TechInventory and Field Evaluations are being developed) (PATH and NAHB 2008).

\section{Measuring the Impact}

Metrics provide quantitative evidence of the progress and impacts of specific programs. ToolBase is unique compared to other PATH programs in that its impacts can be approximated by home builders' awareness and understanding of the technologies contained on the Web site, rather than by focusing on impact measures such as market penetration, which are common in other PATH programs. Direct measures for market penetration of the program's technologies are not as applicable for ToolBase. By measuring ToolBase impacts based on awareness and understanding, the decision model borrows from technology market diffusion theory to assume the various stages that decision makers will go through to adopt a technology (Rogers 2003). The theory states that they will go through the following stages: becoming aware of the technology, understanding the technology, purchasing the technology, and confirming the decision to purchase the technology. Because ToolBase aims only to disseminate information and does not focus on attracting builders or consumers to purchase the technologies, the impacts can be measured by the first two stages of technology adoption: awareness and understanding. For this program, these stages can be approximated by the following methods:

1. Direct measurement of awareness of the technologies. Example metrics include how often TechInventory or Field Evaluations pages are accessed by unique visitors.

2. Indirect measurement of technology understanding. This can be approximated by measuring the number and frequency of visitors returning to the site. Visitors that return to the site can indicate that they find the Web site useful and understandable.

These methods are intended to establish metrics that approximate the impact of the program's information-dissemination activities.

\section{Key Data Sources}

Data for ToolBase metrics are available primarily from the NAHB Research Center. The center contributes content, hosts and maintains toolbase.org, and compiles statistics on use of the ToolBase Web site. Statistics include the number of unique visitors, page views, documents downloads, and several others. Potential additional data sources are presented in the Recommended Metrics section. 
Prior to July 2001, ToolBase Web pages were integrated with the Web site for the NAHB Research Center, so there are no reliable statistics available for this period. Toolbase.org was launched as a separate Web site in July 2001; in 2002, the research center began to collect statistics separately for the ToolBase site. The current ToolBase site, launched in July 2006, is independent from the NAHBRC.org Web site and has its own set of more accurate statistics.

It should be noted that the research center reports that there are still some difficulties in gathering exact numbers. Due to the way the site is built, depending on how the user found a particular page, the Web statistics software (Urchin) has some difficulties counting page hits.

\section{Approach for Identifying and Recommending Performance Metrics}

The following approach, which is explained further in Chapter 2, is used for recommending performance metrics:

1. Develop a logic model of the ToolBase activities, outputs, and outcomes. The logic model translates the program activities and goals described earlier into a diagram that illustrates how these function collectively while being measured individually (see Figure 2 for logic model).

2. Identify candidate metrics based on the logic model that measure the progress of these activities, outputs, and outcomes toward achieving project and program goals.

3. Apply the scoring system described in the Conceptual Soundness report to the candidate metrics. The scoring system is based on general characteristics of useful metrics for the PATH program. Scores are based on four key criteria:

a. Understandable. Extent to which the metric is understood by external stakeholders

b. Attributable. Ability to determine PATH contribution

c. Feasible. Availability and reliability of data

d. Comparable over time. Ability to make fair comparisons to previous and/or future measurements

4. Tally scores and rebalance. Metrics are selected based on the scores and a rebalancing using expert judgment to ensure that the set of recommended metrics are representative of the breadth of ToolBase activities and include measures of activities, outputs, and outcomes. 


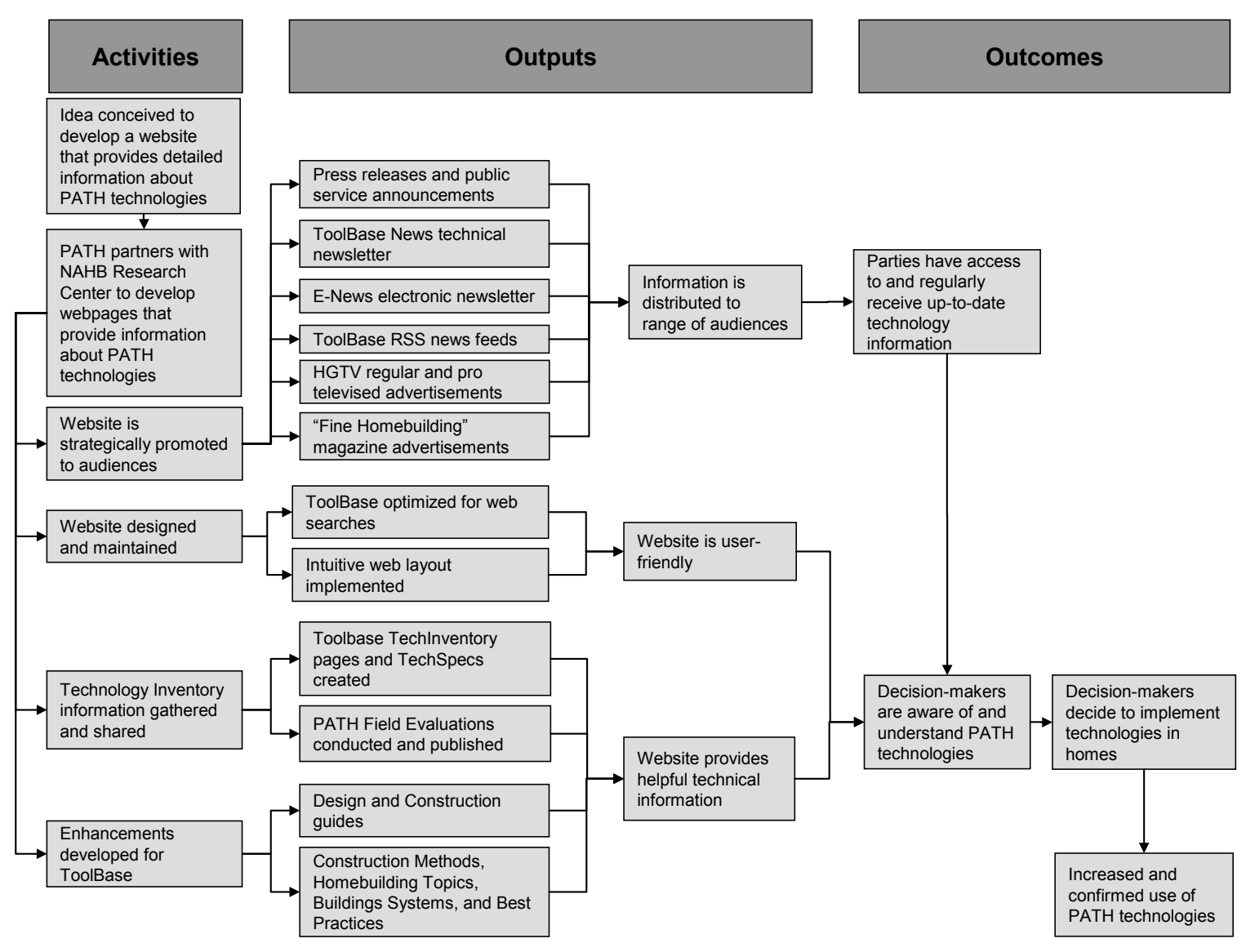

Figure 2. ToolBase Logic Model

\section{Recommended Metrics}

Recommended metrics and potential data sources for ToolBase are presented in this section. Note that additional recommended metrics are proposed in the next section. That section includes measure(s) that would complement the current metrics set, but the data are not likely to be easily available. Together, these two sections represent a full set of recommended metrics that measure both the means (activities) and the ends (impacts) of the program, and inform a process for long-term assessment and program improvement. See Appendix B for a listing of metrics and their respective scoring considering the attributes - understandable, attributable, feasible, and comparable over time - discussed in Chapter 2.

As noted earlier, the scope of the ToolBase program changed significantly in July 2007 when one of the two funding vehicles expired. The program previously had been involved with developing new content, promotions, and other enhancements. Following the expiration of one of the funding vehicles, the program switched to a maintenance mode that focuses on ensuring the current site is functioning properly but is not actively promoting the site or adding significant new content. As a result of this change, the set of recommended metrics presented below cover both the historical period (pre-July 2007) 
and the current maintenance period. Analysis of the metrics data should consider the changing scope of the program.

Recommended metrics for the ToolBase program are organized into three groups:

- Activities metrics measure the progress of key activities enabling the program to meet its mission of information dissemination of objective information on housing technologies. A subset of the Activities metrics measure the Design and Maintenance of the ToolBase site.

- Awareness metrics are output/outcome measurements of the impact that the program is having on the first stage of technology diffusion (see Measuring the Impact of ToolBase section).

- Understanding metrics provide indicators for the impact of ToolBase on the second stage of technology diffusion (see Measuring the Impact of ToolBase). These metrics generally use proxies to estimate users' understanding of the ToolBase content.

\section{$\underline{\text { Activities }}$}

\section{1) Cumulative number of technologies featured in the TechInventory}

This metric provides a historical and ongoing count of technologies featured in the TechInventory section of the ToolBase site. The metric measures the program's aptness in adding technologies to the ToolBase Web site and enabling the broader mission of information dissemination about innovative technologies and practices in the housing industry. The TechInventory is a major focus of the ToolBase site, and the number of technologies in the inventory measures a key activity necessary to reach a wide audience.

Data Source: NAHB Research Center

\section{2) Cumulative number of Field Evaluations completed with results published} on ToolBase

This metric provides a historical and ongoing count of the number of field evaluations whose results are featured on ToolBase. Field Evaluations and TechInventory are the top two areas where users can find technical information on the site, and the two areas the program would like to direct site visitors.

This metric provides an indicator for the program's ability to include content on the site that is necessary for information dissemination about innovative building technologies and practices.

Data Source: NAHB Research Center

$\underline{\text { Web site design and maintenance }}$

3) Total number of TechInventory and Field Evaluations page views per total number of user visits/sessions in each month 
The metric indicates the ability of toolbase.org to direct users to the two areas of the site that provide the most information: the TechInventory and Field Evaluations sections. A large ratio for this metric would indicate that the design of the Web site is successfully bringing visitors to the TechInventory and Field Evaluations pages. Note that data are collected for only the top few (2 to 10, depending on the month of data collection) pages within each section, and these top pages can be used as a proxy for the total number of views of the sections. The total number of user visits includes the number of times the ToolBase site is accessed in a given month. If a visitor leaves the site and returns in the same month, it is counted as a separate visit. This metric measures output from the sitedesign activities.

Data Source: NAHB Research Center

\section{4) Number of broken links in toolbase.org}

This metric provides an indicator for the maintenance of the ToolBase site. In general, URLs of Web sites anywhere on the Internet can frequently change, and this affects the sites that link to those pages. If a URL for a Web page changes, then any Web site linking to the former URL will have a "broken link." To fix the broken link, the new URL must be programmed into the Web site. Web sites that are actively maintained have few broken links. Broken links for any public Web site can be counted and monitored with free Web software, such as Xenu. Data Source: Xenu or other similar software

\section{Awareness of ToolBase technologies}

\section{5) Total number of unique visitors to ToolBase.org per month}

This metric indicates the number of unique visitors to the toolbase.org site in a given month. A unique visitor means that if a person visits ToolBase more than once in a single month, then it is counted as only one unique visitor. Web statistics software from the NAHB Research Center is able to distinguish between a "unique" visitor and a repeat visitor by recording the IP address of the user and determining whether the same IP address had already logged into the site during that month. The total number of unique visitors should reflect any promotional and marketing efforts to attract new users to the site.

Data Source: NAHB Research Center

\section{6) Total number of toolbase.org page views per month}

This metric indicates the number of times visitors access a page on the toolbase.org site in a given month. A user often will access multiple pages during a single visit, and "page views" counts each page that the user sees. The total number of page views reflects the ability to attract and retain visitors to the site. Note that the number of page views is only comparable over time when the site 
format and structure is constant. For instance, if the Web site is reconfigured to include more material on fewer Web pages, then comparing the number of page views before and after the reconfiguration would not be meaningful.

Data Source: NAHB Research Center

7) Total number of TechInventory page views per month

This metric provides an estimate of how many times a key section of the ToolBase Web site has been viewed. TechInventory and Field Evaluations (Metric 8) are the two sections of the site that provide important housing technology information. Compare Metrics 7 and 8 to Metric 3. Metric 3 indicates how well the site is directing users to the technical information sections, while Metrics 7 and 8 indicate the total number of page views of their respective sections. Metrics 7 and 8 also should be considered in conjunction with Metric 9, which normalizes the number of Web hits based on the housing market - a key factor that is external to program influence. Note that data for TechInventory is available for only the top few (2 to 10, depending on the month of data collection) pages within in each section, and these top few pages will be used as a proxy for the total number in that section. The metric provides input into the target audience's level of awareness of the technical information offered in ToolBase. Data Source: NAHB Research Center

\section{8) Total number of Field Evaluations page views per month}

Similar to Metric 7, this metric estimates the number of times a key section of ToolBase has been viewed. A Field Evaluation section that is relevant, up-todate, and provides useful information for builders should receive a sustained high number of page views. Data for Field Evaluations may be available only for the top (based on page views) few pages. If this is the case, these will be used as a proxy for the total number of Field Evaluation page views per month. In combination with Metrics 6,7, and 9, this metric offers insight into the level of awareness of the ToolBase technologies.

Data Source: NAHB Research Center

9) Total number of visitors ("visitor sessions") accessing toolbase.org per square feet of all new residential-housing units in the United States per month

This metric provides a count of the total number of user visits (or "visitor sessions") to the ToolBase.org site per month - i.e., the number of times any person visits the ToolBase site - as a fraction of total square footage of new houses being built. This metric is useful in two ways: It represents the total number of times the site is accessed, including repeat visitors, and 2) it normalizes the traffic on the ToolBase site by accounting for the fluctuating housing market. It is important to account for key external factors, such as new housing units, so that attribution from program efforts can be correctly measured - rather than 
measuring factors outside the program's control. Note that "user visits" are different than "page views," which provide a count of every page within the site that is accessed. User visits count how many visits occur in a given month, i.e., how many visitors (not necessarily unique visitors) access the site. The metric offers insight into how well the site is attracting new and repeat visitors, accounting for changes in the residential-housing market - and provides input for evaluating overall awareness of ToolBase technologies.

Data Source: NAHB Research Center

\section{$\underline{\text { Understanding ToolBase technologies }}$}

\section{0) Average number of page views per session}

This metric shows the number of page views per total number of visitor sessions. It is calculated as "total number of page views" (Metric 6) divided by "total number of visitor sessions." The metric provides an indicator for the level of engagement that the user has with the site during any given visit to ToolBase. A larger number of page views per session can indicate that the user is finding multiple sources of useful information. Because ToolBase is a source for technical information and the Web site is structured such that multiple page views would typically be required to gather substantial details about a technology, it is expected that a user viewing many pages is likely to attain greater understanding of the content. Conversely, a user that views very few pages may not understand the material he/she is viewing or is not interested in further detail. Note that a reconfiguration of the Web site would require recalibrating the comparison of page views over time (see explanation for Metric 6).

Data Source: NAHB Research Center

11) Average number of repeat visits per month ("average sessions per visitor in a given month")

This metric shows the number of times, on average, a visitor returns to the toolbase.org site in the same month. The metric is calculated as "total number of visitor sessions" divided by "total number of unique visitors" (Metric 5). For example, if the average sessions per visitor equals " 2 ," this indicates that the average ToolBase user visits twice per month; if average sessions per visitor equals " 1 ," this indicates that the average user visits just once (i.e., on average, unique visitors do not return to the site during that month). Repeat visits provide an indicator that users understand the information, find the Web site useful, and are therefore returning back to the site. Together with Metric 10, this metric offers insight into understanding the stage of technology diffusion.

Data Source: NAHB Research Center 


\section{Additional Recommended Metrics}

\section{Enhanced services activities}

12) Total number of promotional events per year

This metric measures the number of PATH-sponsored promotional events related to ToolBase. The program currently is not able to conduct promotional events, but has done so historically. Measuring the total number of promotional events per year provides demonstrable evidence of efforts to increase awareness of the site and encourage interested parties to use the resources available on it. This metric could be used in conjunction with the Activities metrics (Metrics 1-4) to provide additional input for a program assessment. Promotional event data are not currently available.

Possible Data Source: NAHB Research Center

13) Total number of news subscribers - including subscribers to E-news, RSS feeds, and print newsletter mailings

Similar to Metric 12, this metric provides insight into the program's promotional activities, which are no longer part of the ToolBase program. The metric offers an output indicator for the promotional activities that encourage builders to visit ToolBase.

Possible Data Source: NAHB Research Center

14) Percentage of home builders who are aware of the technologies in ToolBase, understand the technologies, decide use the technologies, and confirm their use of the technologies

With ample resources, a survey of home builders could be conducted to provide data regarding the effectiveness of ToolBase information accelerating technology adoption. Program impacts could be measured from the survey data regarding the stages of the technology diffusion, as described earlier. Survey responses for "awareness," "understanding," "deciding to use the technology," and "confirming its use" can be evaluated for builders who have accessed ToolBase and compared with those who do not visit the site. The difference between these data sets would offer useful input for measuring the impact of the program on the market.

Possible Data Source: Survey of home builders 


\section{Recommended Metrics for PATH's Structural Insulated Panels Program}

\section{Program Background}

The U.S. Department of Housing and Urban Development's Partnership for Advancing Technology in Housing (PATH) administers the Structural Insulated Panels (SIPs) program. This program seeks to accelerate the adoption of SIPs in the residentialhousing market. Compared to conventional wood framing materials, SIPs are thermally more efficient; they offer competitive cost, higher strength, improved fire resistance, and are made of more environmentally friendly materials. Despite these benefits, homes constructed using SIPs account for only a small fraction of the U.S. residential-housing market.

Since PATH's inception, the program has sought to accelerate adoption of technologies that provide an alternative to conventional wood framing. SIPs, Insulated Concrete Forms (ICFs), and steel framing were three technologies selected as the most likely alternatives to wood that would be able to penetrate the market. For all three of these technologies, PATH sought to identify the critical barriers impeding greater adoption into the marketplace. PATH identified regulatory barriers and lack of available information about the products as key obstacles to widespread deployment. The programs focused on removing the regulatory barriers and increasing dissemination of information regarding how the technologies work, their cost, and the value in their use.

\section{Which PATH Goal(s) Does This Program Address?}

PATH goals focus on reducing the multiple constraints throughout the innovation pipeline in the residential-housing sector, and developing the infrastructure for increasing innovation in that pipeline. PATH's three overall goals are:

- Identify and reduce barriers that impede innovation, including regulatory barriers (PATH Goal 1)

- Disseminate information to speed the development and adoption of advanced building technologies (PATH Goal 2)

- Advance housing technology research and foster development of new technology (PATH Goal 3)

The SIPs program addresses PATH Goals 1 and 2 (see Appendix A for a listing of metrics by program and the specific objectives addressed by the metrics). Program activities aligning with Goal 1 include identifying barriers during the development of the SIPs Prescriptive Methods document and working with organizations to address the regulatory hurdle of having SIPs adopted into building codes.

PATH posts specific technical information about SIPs on its toolbase.org Web site. Pathnet.org and huduser.org also offer information about SIPs to interested parties, helping the program accomplish PATH's Goal 2. 


\section{Major Activities}

At the outset of the SIPs program, PATH collaborated with the Structural Insulated Panel Association (SIPA), APA - The Engineered Wood Association, and SIP manufacturers across the United States to identify critical barriers impeding wider market uptake of structural insulated panels. Regulatory barriers and lack of available information about SIPs were determined to be the key barriers that PATH could address. Examples of regulatory barriers include the lack of prescriptive construction guidelines and the absence of SIPs in residential building codes. As guidance to help overcome these barriers, the program developed a "Prescriptive Method for Structural Panels" that establishes performance standards for SIPs and shares technical information about the technology, offering specific guidelines to facilitate the use of SIPs in wall systems for the construction of one- and two-family dwellings (PATH 2006a).

The Prescriptive Method and specifications were submitted to the International Code Council (ICC) for adoption into the International Residential Code (IRC) - a set of building codes commonly implemented by states and counties. The ICC develops codes used to construct residential and commercial buildings, including homes and schools. Most U.S. cities, counties, and states that adopt codes choose the International Codes developed by the ICC. In May 2007, the ICC voted to adopt SIPs into the IRC, and shortly thereafter they were included as a supplement to the 2006 IRC (SIPA 2007). The adoption of SIPs into the IRC addresses a major regulatory barrier to the widespread use of SIPs in residential housing (Goal 1). SIPs are a code-recognized option and "home builders using SIPs will no longer be required to conduct additional engineering to show equivalency to the IRC" (NAHB 2007).

Marketing and information-dissemination activities of the SIPs program support efforts to increase development and adoption of the technology (Goal 2). The program broadly follows three points to achieve this goal.

- Communicate the technology's technical soundness, establishing that performance of SIPs is equivalent, if not superior, to competing wood alternatives. PATH's testing and evaluation activities support the dissemination of technical figures (PATH 2006b).

- Convey costs of the technology in specific housing installations. The program encourages builders to select building materials and technologies based on value rather than defaulting to industry status quo.

- Articulate benefits of using SIPs. PATH offers numerous resources that have been published or offered on its Web sites that seek to clearly express the value of using SIPs to the builder and customer.

\section{Web Tools for Information Dissemination}

PATHNET (http://PATHnet.org/) is PATH's information Web portal that provides information on numerous housing technologies, including SIPs. The portal offers information on designs, technologies, and product manufacturers, and includes other publications related to SIPs. 
ToolBase (http://www.toolbase.org/) is a PATH-sponsored technical information resource for the home-building industry that contains free, comprehensive, noncommercial, and unbiased "product descriptions, design \& construction guides, best practices, performance reports, case studies, and other resources...that builders and remodelers will find useful." 7 Within the ToolBase site, a section called Technology Inventory includes sections devoted to SIPs. This section of the site provides in-depth information on costs, results from field evaluations, and tips for determining whether SIPs are appropriate for certain kinds of projects.

\section{Measuring the Impact}

Metrics provide quantitative evidence of the progress and impacts of specific programs. Measuring impacts is often more difficult than measuring the progress of a program, but both are vital for gauging overall performance. Both types of metrics are discussed in the Recommended Performance Metrics section. Two approaches are considered for measuring the impacts:

1. Measurement of increased market penetration of SIPs using a proxy, such as SIPs production data from manufacturers

2. Direct measurement of information dissemination, such as number of page views of the ToolBase Technology Inventory on SIPs

The first type of metric provides insight into the extent that SIPs have penetrated the market. Although it is difficult to measure exactly how many residential units are constructed using SIPs each year, production figures may provide a reasonable estimate. A complete profile of the technology's market penetration would include the percentage of homes incorporating SIPs and details into the distribution of the technology, such as among large and small homes and geographic location. Production figures may be difficult to obtain if SIPs are produced by manufacturers who are not members of the Structural Insulated Panel Association (SIPA) (See Data Sources section). As SIPs become mainstream, it also would be expected that more companies will offer SIPs, thus making production estimates more challenging.

Before SIPs can attain significant market penetration, builders must be confident that the technology will perform adequately, be cost-effective, and be safe. Energy efficiency improvements provide an additional benefit. This program has taken on the role of disseminating this information to the residential-housing sector. The second type of metric allows for practical measurement and a useful understanding of program effects from information-dissemination efforts (PATH Goal 2). While this measure does not reveal direct market impacts of the program, it effectively shows the exposure of information to the marketplace as a result of PATH efforts.

\section{Key Data Sources}

Data for SIPs metrics are available primarily from two key sources:

\footnotetext{
7 "About ToolBase" <http://www.toolbase.org/about.aspx>.
} 
Structural Insulated Panel Association (SIPA)

SIPA provides SIPs production data and data about the number of housing units supplied with SIPs from member companies.

\section{NAHB Research Center}

The National Association of Home Builders (NAHB) Research Center compiles statistics on Web site use of ToolBase, including page views and downloads.

Note that PATHnet pages for SIPs were developed as a resource for users interested in the SIPs Prescriptive Method rather than as a resource for increasing broad public knowledge or awareness of the technology. The Prescriptive Method and the relevant studies that contributed to the creation of this method were developed and conducted explicitly to be submitted to the International Code Council. Therefore, it is not expected that PATHnet page views or downloads would necessarily be an appropriate indicator of the program's overall information-dissemination activities. On the other hand, ToolBase is specifically geared toward sharing technical information with the home-building community. Page views and downloads from ToolBase will more accurately reflect interest and awareness on the topic.

\section{Approach for Identifying and Recommending Performance Metrics}

The following approach, which is explained further in Chapter 2, is used for recommending performance metrics:

1. Develop a logic model of the SIPs program activities, outputs, and outcomes. The logic model translates the program activities and goals described earlier into a diagram that illustrates how these function collectively while being measured individually (see Figure 3 for logic model).

2. Identify candidate metrics based on the logic model that measure the progress of these activities, outputs, and outcomes toward achieving project and program goals.

3. Apply the scoring system described in the Conceptual Soundness report to the candidate metrics. The scoring system is based on general characteristics of useful metrics for the PATH program. Scores are based on four key criteria:

a. Understandable. Extent to which the metric is understood by external stakeholders

b. Attributable. Ability to determine PATH contribution

c. Feasible. Availability and reliability of data

d. Comparable over time. Ability to make fair comparisons to previous and/or future measurements

4. Tally scores and rebalance. Metrics are selected based on the scores and a rebalancing using expert judgment to ensure that the set of recommended metrics are representative of the breadth of PATH SIPs-related activities and include measures of process (i.e., activities and outputs) and end results (i.e., outcomes). 


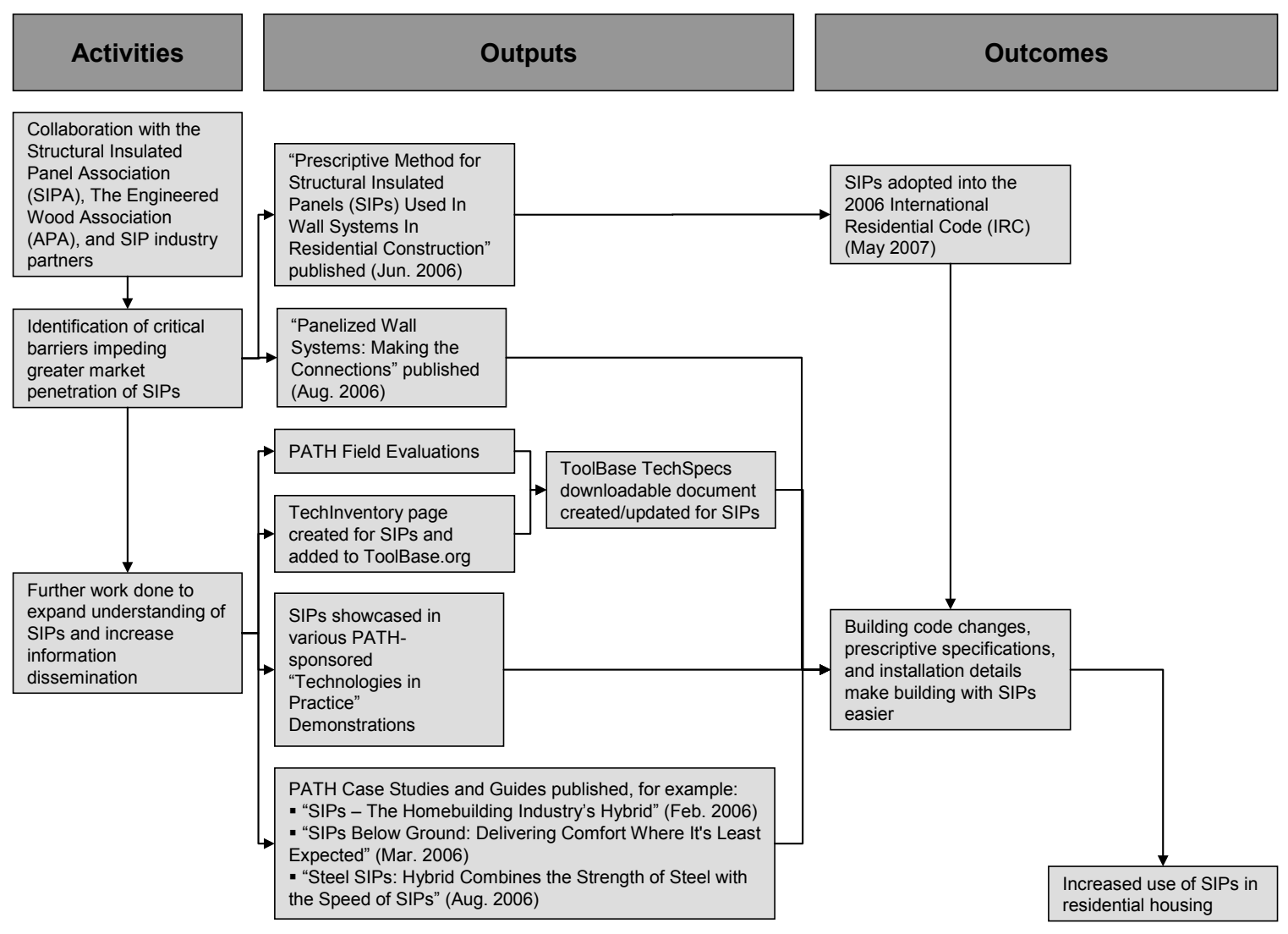

Figure 3. SIPs Logic Model

\section{Recommended Metrics}

Recommended metrics and potential data sources for the SIPs program are presented in this section. Note that additional recommended metrics are proposed in the next section. That section includes measure(s) that would complement the current metrics set but where the data are not likely to be easily available. Together, these two sections represent a full set of recommended metrics that measure both the means and the ends of the program, and inform a process for long-term assessment and program improvement. See Appendix B for a listing of metrics and their respective scoring considering the attributes discussed in the Conceptual Soundness section - understandable, attributable, feasible, and comparable over time.

One of the challenges in evaluating this PATH program involves differentiating between increases in SIP adoption due to PATH activities and increases in SIP adoption due to external factors. It is also important that data be considered in the context of the U.S. home-building industry at the time of the measurement. Measured values may fluctuate with changes in demand in the housing market. These complicating factors have been considered when selecting the recommended metrics described in this section, and the metrics are tailored where possible to account for these factors. 
Note that SIPs, Insulating Concrete Forms (ICFs), and Advanced Steel Framing are all similar PATH programs. All three technologies represent alternatives to conventional wood options, and the PATH activities for these programs all focus on removing regulatory barriers through building-code changes and disseminating information about the value of the technology. Because of these similarities, the recommended metrics are intended to be consistent and comparable across all three similar programs.

\section{$\underline{\text { Building code-related outputs }}$}

1) Percentage of new homes in the United States that are built in a location that has adopted the International Residential Code (IRC) or other building codes that include SIPs

This metric measures the ability of the SIPs program and its partners to gain approval of SIPs in widely adopted residential building codes. Because the metric measures "percent of new homes," it emphasizes building codes adopted in regions that are constructing a large number of new homes. This metric aligns with the program goal of removing regulatory barriers that inhibit greater market penetration of SIPs.

Data Source: U.S. Census publishes the total number of new residential units built per year. International Code Council (http://www.iccsafe.org/) lists states and jurisdictions adopting certain building codes.

Information dissemination activities and outputs

2) Number of unique visitors to the ToolBase SIPs Technology Inventory home page

Metric 2 indicates the number of interested parties referencing PATH's ToolBase Web site for information specifically pertaining to SIPs. The information provided on this site is technical and tailored for an audience of home builders, designers, manufacturers, and others in the housing industry rather than the general public. The site offers industry professionals reliable information about performance, cost, and value of the technology. Measuring the "unique visitors" estimates the number of different people accessing the information (as opposed to "page views," which counts the number of times a site is visited, even if it is accessed multiple times by the same person). This measure provides a better indication of the breadth of audience that PATH is reaching. The URL for the ToolBase SIPs Technology Inventory home page is http://www.toolbase.org/Technology-Inventory/Whole-House-Systems/structuralinsulated-panels.

Data Source: NAHB Research Center 
3) Average monthly downloads of the SIPs TechSpec (from ToolBase.org site)

This metric, which complements Metric 2, approximates the circulation of a key SIPs program document. The document articulates detailed information about the performance, cost, and value in PDF format that can be saved as a separate file. The number of downloads indicate the level of interest in the technology from building industry professionals, and indicate the ability of PATH to attract interested parties to download a key document. Data Source: NAHB Research Center

4) Annual percentage growth in the number of Google hits when searching the following exact phrase: "Partnership for Advancing Technology in Housing" and "Structural Insulated Panels" or "SIPS"

This metric gauges overall public interest in the SIPs program by measuring the availability of information and reference materials pertaining to the program on the Internet. This exact search phrase was considered meaningful because, when tested, each search result was relevant to the PATH SIPs program. Google hits are a useful metric because they measure the number of pages referencing PATH and SIPs not only from pathnet.org or toolbase.org, but also from external sites either in industry, academia, or government.

Data Source: Google.com

\section{Market penetration outputs and outcomes}

\section{5) Number of home builders offering SIPs}

This metric estimates the market penetration of SIPs in the building industry, and should be evaluated in conjunction with Metric 6 and Metric 7. It measures the ability of an interested home buyer to select the SIPs technology for use in their new house. An increased number of builders offering SIPs can be a leading indicator of increased adoption of the technology. A possible addition to this metric would incorporate the percentage of the market that these home builders represent, indicative of the market share of these builders. Obtaining this market data may be an obstacle; simply measuring the number of builders will be an adequate first-order measure.

Data Source: Structural Insulated Panel Association (SIPA). Although there may be other builders who offer SIPs, the number of SIPA home-builder members will be used as a proxy.

\section{6) Percentage of new homes in the United States using SIPs}

This metric provides another estimate of market penetration and approximates the range of coverage of SIPs in new homes. This metric should be evaluated in combination with Metric 5 and Metric 7 to obtain a better profile of the market progress of the technology. While Metric 5 measures whether SIPs are an option 
offered by builders, Metric 6 measures whether builders are actually implementing SIPs in their homes. Compare this to Metric 7, which indicates the total production of SIPs but not the extent of broad market penetration.

Data Source: SIPA can provide the annual number of housing units supplied with SIPs. U.S. Census publishes the total number of new residential units built per year.

7) SIPs annual production for residential use (in square feet) per square feet of all new residential-housing units in the United States per year

Metric 7 estimates the total production of SIPs as a fraction of total square footage of new houses being built. Because the housing market fluctuates significantly from year to year, it is important to measure SIPs production compared to overall new home construction. This metric, together with Metric 5 and Metric 6, offer insights into the market penetration of the technology. Particularly useful will be comparisons of these three metrics over time - assessing the rate of improvement or acceleration of the technology into the marketplace.

Data Source: SIPA collects this data in an annual production survey submitted by all SIP manufacturers. U.S. Census publishes data necessary to compute the total square footage of new residential units built per year.

Metrics 5, 6, and 7 are also useful for evaluating the program retrospectively. Specifically, the impact of including SIPs in residential building codes can be quantified. The use of SIPs in residential-housing units before and after the incorporation of SIPs into the International Residential Code will gauge the extent that this regulatory barrier has been removed.

The market penetration attributable to PATH is difficult to separate from the market penetration from external factors. Metrics 1 through 4 are more directly correlated with specific PATH activities. Regardless, the ultimate objectives of the SIPs program align with the market-penetration metrics recommended here and are meaningful for evaluating the success of the program.

\section{Additional Recommended Metrics}

\section{8) Number of states that have greater than $0.5 \%$ of new residential-housing units built using SIPs}

This metric captures the geographic distribution of the technology. Some states may have significant market penetration, while others are lagging. For example, SIPs use may be clustered in one or two states. This metric could highlight states with significant opportunity for SIPs market growth. A half percent was chosen as the cutoff because, according to an analysis of SIPA and U.S. Census data, the national average of SIPs in new homes for 2004, 2005, and 2006 was roughly $0.5 \%$.

Data Source: SIPA and U.S. Census data. State-level data for housing units with SIPs may be difficult to obtain. 


\section{Recommended Metrics for PATH's Steel Framing Program}

\section{Program Background}

The U.S. Department of Housing and Urban Development's Partnership for Advancing Technology in Housing (PATH) administers the Steel Framing program. This project seeks to accelerate the adoption of steel framing in the residential-housing market. Compared to conventional framing materials, steel offers the highest strength-to-weight ratio of any building material. Steel frames are noncombustible, and they do not rot, warp, split, or change shape with moisture content. They offer price stability and consistent material quality (no regional variations). ${ }^{8}$ Despite the advantages that steel framing offers to both home builders and consumers, homes constructed using steel framing account for only a small fraction of the U.S. residential framing market.

PATH seeks to accelerate adoption of technologies that provide an alternative to conventional wood framing. Steel Framing, Insulating Concrete Forms, and Structural Insulated Panels were three technologies identified at PATH's inception as the most likely alternatives to wood that would be able to penetrate the residential-housing market. PATH identified critical barriers impeding greater adoption of these technologies into the marketplace. The three programs focus on addressing these critical barriers, including working with codes organizations to address regulatory barriers and increasing dissemination of information regarding how the technology works, its cost, and the value in its use.

\section{Which PATH Goal(s) Does This Program Address?}

PATH goals focus on reducing the multiple constraints throughout the innovation pipeline in the residential-housing sector, and developing the infrastructure for increasing innovation in that pipeline. PATH's three overall goals are:

- Identify and reduce barriers that impede innovation, including regulatory barriers (Goal 1)

- Disseminate information to speed the development and adoption of advanced building technologies (Goal 2)

- Advance housing technology research and foster development of new technology (Goal 3)

The Steel Framing program primarily addresses PATH Goals 1 and 2 (see Appendix A for a listing of metrics by program and the specific objectives addressed by the metrics.) Program activities aligning with Goal 1 include identifying barriers during the development of steel framing prescriptive methods and other technical support documents, and working with organizations to address the regulatory hurdle of having steel framing adopted into building codes.

8 "About Steel Framing." < http://www.steelframing.org/sfa_aboutsteelframing.shtml>. 
Helping the program accomplish Goal 2, PATH posts specific technical information about steel framing on its toolbase.org Web site. Pathnet.org and huduser.org also offer information about steel framing to interested parties.

Prior to 2003, the Steel Framing program conducted research to demonstrate that steel is an acceptable alternative to wood in residential housing. This research early in the program aligns with PATH's current Goal 3.

\section{Major Activities}

The Steel Framing program can be separated into two phases. Phase 1 involved research and demonstration on the acceptability of steel framing material as an alternative to wood. Phase 2 of the program works to develop a broader market for steel framing through published documents and information dissemination.

During Phase 1, PATH entered a cooperative agreement with the National Association of Home Builders (NAHB) and the American Iron and Steel Institute (AISI) to identify critical barriers impeding wider market uptake of steel framing. Regulatory barriers and lack of available information about steel framing were determined to be the key barriers that PATH could address. Examples of regulatory barriers include the lack of prescriptive construction guidelines and applications, and the absence of steel framing in residential building codes. As guidance to help overcome these barriers, the program developed prescriptive methods that established performance standards for steel framing and shared technical information about the technology.

The "Prescriptive Method for Residential Cold-Formed Steel Framing" was published in 1997, and was based on three years of HUD-sponsored research that incorporated input from experts in the fields of construction, research, engineering, and building-code enforcement (HUD 1997a). This document and companion publications offered practical recommendations to builders and code officials on the application and performance of steel framing (HUD 1997b). In 2002, PATH partnered with the Steel Framing Alliance (SFA) (formerly, the North American Steel Framing Alliance) and funded the Manufactured Housing Research Alliance (MHRA) to produce the technical support document, "Design for a Cold-Formed Steel Framed Manufactured Home." (PATH 2002). The document was developed in conjunction with trade associations, builders, testing laboratories, and manufacturers and assessed the viability of substituting steel for wood as the structural skeleton of homes built under the HUD manufactured-home standards.

These early documents represent an earlier phase of steel framing research (completed in 2002) that demonstrated steel as an acceptable framing material under the performancebased HUD standards (HUD 2003). These methods were adopted by the International Code Council (ICC) into the International Residential Code (IRC 2000 and 2003), which is commonly incorporated into local and state building codes. ${ }^{9}$ The adoption of steel

\footnotetext{
9 "ToolBase Technology Inventory Steel Framing." <http://www.toolbase.org/TechnologyInventory/Whole-House-Systems/steel-framing>.
} 
framing into the IRC addresses a major regulatory barrier to the widespread use of steel framing in residential housing, allowing construction of site-built framed steel homes without the certification of a professional engineer (NAHB 2003).

The second phase of the program involved developing steel framing to the point of viability in a wider market. In 2003, PATH partnered with the SFA to examine and report on corrosion of galvanized fasteners used in cold-formed steel, and to produce "Hybrid Wood and Steel Details - Builders Guide," a report that provides information for builders to construct hybrid cold-formed steel and wood homes (PATH 2006c and 2003b). Also in 2003, the "Prescriptive Method for Connecting Cold-Formed Steel Framing to Insulating Concrete Form Walls in Residential Construction" was published to facilitate the construction of houses from insulating concrete forms and cold-formed steel, both of which are important PATH technologies (PATH 2003c). PATH also partnered with MHRA to explore the potential of steel framing for the construction of factory-built homes. This research into developing a wider market for steel frames critically assessed and refined the use of light-gauge steel design in the factory environment.

The Steel Framing program marketing and information-dissemination activities support efforts to increase development and adoption of the technology. The program broadly follows three key messages for these activities:

- Technical soundness. Establish that performance of steel framing is equivalent, if not superior, to competing alternatives.

- Costs. Provide objective estimates of the installation, operation, and maintenance costs in specific housing applications.

- Benefits. Encourages builders and customers to consider the numerous benefits of using steel framing in their homes.

\section{Web Tools for Information Dissemination}

PATHNET (http://pathnet.org/) is PATH's information Web portal that provides information on numerous housing technologies, including steel framing. The portal offers information on designs, technologies, and product manufacturers, and includes other publications related to steel framing.

ToolBase (http://www.toolbase.org/) is a PATH-sponsored technical information resource for the home-building industry that contains free and unbiased product descriptions, design and construction guides, best practices, performance reports, case studies, and other resources for builders and remodelers. ${ }^{10}$ Within the ToolBase site, the section called Technology Inventory includes sections devoted to steel framing. This section of the site provides in-depth information on costs, results from field evaluations, and tips for determining whether steel framing is appropriate for certain kinds of projects.

10 "About ToolBase" <http://www.toolbase.org/about.aspx>. 


\section{Measuring the Impact}

Metrics provide quantitative evidence of the progress and impacts of specific programs. Measuring impacts is often more difficult than measuring the progress of a program, but both are vital for gauging overall performance. Recall that the metrics themselves do not determine how well a program is performing. Metrics provide insight into program performance and help inform a long-term program evaluation; comprehensive program evaluation should be accompanied with setting ambitious targets and time frames that are measured by the metrics. Both types of metrics - progress (activities, outputs) and impact (outcome) metrics - are discussed in the Recommended Performance Metrics section. Two approaches are considered for measurement:

- Measurement of increased market penetration of steel framing technology using proxies, such as steel framing production data, steel frames supplied to housing units, market share of steel frames in residential building, and others.

- Direct measurement of information dissemination, such as number of page views of the ToolBase Technology Inventory on steel framing.

The first type of metric provides insight into the extent that steel frames have penetrated the market. Although it is difficult to measure exactly how many residential units are constructed using steel framing each year, production figures may provide a reasonable estimate. A complete profile of the technology's market penetration would include the percentage of homes incorporating steel and details into the distribution of the technology, such as among large and small homes as well as geographic location. It would be expected that residential steel frames production correlate with use, such that the number of housing units supplied with steel frames would approximate the number of housing units constructed with steel. Production figures, however, may themselves be difficult to obtain if steel frames are produced by manufacturers who are not members of the Steel Framing Alliance (SFA) (see Data Sources section). In addition, as steel frames become mainstream, it would be expected that more manufacturers will produce steel frames, thus making production estimates more challenging.

The second type of metric allows for practical measurement and a useful understanding of program effects from information-dissemination efforts. Before steel framing can attain significant market penetration, builders must be confident that the technology will perform adequately, be cost-effective, and be safe. Energy efficiency improvements provide an additional benefit. This program has taken on the role of disseminating such information on steel framing to builders, consumers, and other interested parties in the residential-housing sector. While this measure does not reveal direct market impacts of the program, it effectively shows the exposure of information to the marketplace as a result of PATH efforts. 


\section{Key Data Sources}

Data for Steel framing metrics are available primarily from two key sources:

\section{Steel Framing Alliance (SFA)}

The Steel Framing Alliance is a trade association that encourages the widespread use of cold-formed steel framing in residential construction. SFA may be able to provide relevant industry data, including data on steel framing manufacturing shipments to the residential industry. SFA may also provide market trends data for both single-family site-built and multifamily site-built homes including tons of light-gauge steel framing used and units built. SFA membership lists may provide useful data about the number of steel framing residential builders, suppliers/distributors, architects, and related manufacturers such as stud, truss, and component fabricators (SFA 2007 and SFA 2003). ${ }^{11}$

\section{NAHB Research Center}

The National Association of Home Builders (NAHB) Research Center compiles statistics on use of the ToolBase Web site, including page views and downloads.

Note that PATHnet pages for steel framing were developed as a resource for users interested in the Steel Framing Prescriptive Methods and other reports rather than as a resource for increasing broad public knowledge or awareness of the technology. The Prescriptive Methods and the relevant studies that contributed to the creation of these methods were developed and conducted explicitly to be submitted to the International Code Council. Therefore, it is not expected that PATHnet page views or downloads would necessarily be an appropriate indicator of the program's overall informationdissemination activities. On the other hand, ToolBase is specifically geared toward sharing technical information with the home-building community. Page views and downloads from ToolBase will more accurately reflect interest and awareness on the topic.

\section{Approach for Identifying and Recommending Performance Metrics}

The following approach, which is explained further in Chapter 2, is used for recommending performance metrics:

1. Develop a logic model of the steel framing program activities, outputs, and outcomes. The logic model translates the program activities and goals described earlier into a diagram that illustrates how these function collectively while being measured individually (see Figure 4 for logic model).

2. Identify candidate metrics based on the logic model that measure the progress of these activities, outputs, and outcomes toward achieving project and program goals.

\footnotetext{
11 "About Steel Framing Alliance." <http://www.steelframing.org/sfa_aboutus.shtml>.
} 
3. Apply the scoring system described in the Conceptual Soundness report to the candidate metrics. The scoring system is based on general characteristics of useful metrics for the PATH program. Scores are based on four key criteria: a. Understandable. Extent to which the metric is understood by external stakeholders

b. Attributable. Ability to determine PATH contribution

c. Feasible. Availability and reliability of data

d. Comparable over time. Ability to make fair comparisons to previous and/or future measurements

4. Tally scores and rebalance. Metrics are selected based on the scores and a rebalancing using expert judgment to ensure that the set of recommended metrics are representative of the breadth of PATH steel framing-related activities and include measures of process (i.e., activities and outputs) and end results (i.e., outcomes). 


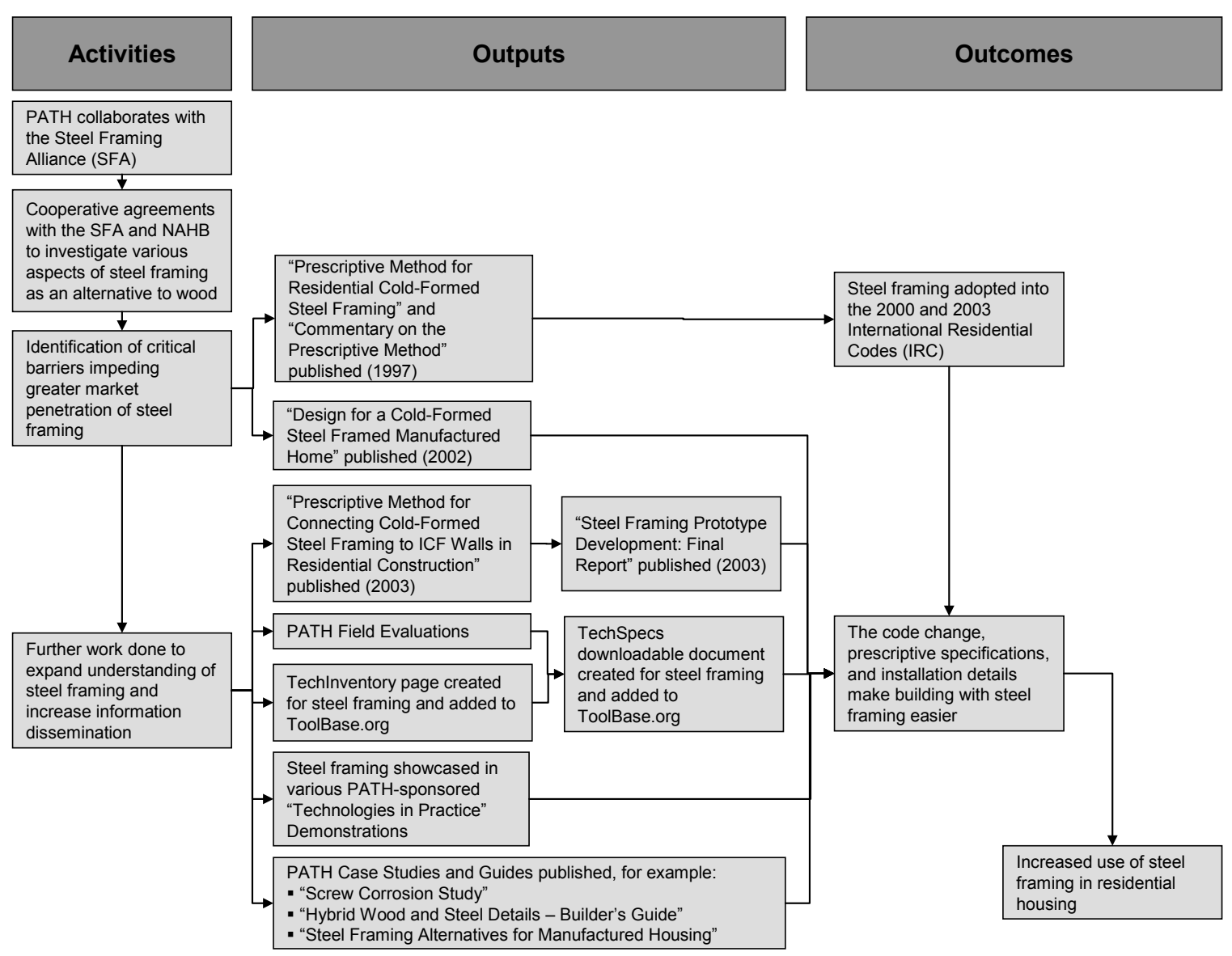

Figure 4. Steel Framing Logic Model

\section{Recommended Metrics}

Recommended metrics and potential data sources for the steel framing program are presented in this section. Note that additional recommended metrics are proposed in the next section. That section includes an additional measure that complements the current metrics set, but the data are not likely to be easily available. Together, these two sections represent a full set of recommended metrics that measure both the means and the ends of the program, and inform a process for long-term assessment and program improvement. See Appendix B for a listing of metrics and their respective scoring considering the attributes discussed in the Conceptual Soundness section - understandable, attributable, feasible, and comparable over time.

One of the challenges in evaluating this program involves differentiating between increases in steel framing adoption due to PATH activities and increases in steel framing use due to external factors. This is particularly challenging for public/private partnerships such as PATH where cooperative activities include both HUD-sponsored elements and private-sector elements. The partnership structure creates challenges but does not preclude the use of meaningful outcome metrics that incorporate components of PATH and components of external activities from providing useful input toward a 
comprehensive program evaluation. It is also important that data be considered in the context of the U.S. home-building industry at the time of the measurement. Measured values may fluctuate with changes in demand in the housing market. These complicating factors have been considered when selecting the recommended metrics described in this section, and the metrics are tailored where possible to account for these factors.

Note that Steel Framing, Structural Insulated Panels, and Insulating Concrete Forms are all similar PATH programs. All three technologies represent alternatives to conventional wood options, and the PATH activities for these programs all focus on removing regulatory barriers through building-code changes and disseminating information about the value of the technology. Because of these similarities, the recommended metrics are intended to be consistent and comparable across all three similar programs.

\section{Building code-related outputs}

1) Percentage of new homes in the United States that are built in a location that has adopted the International Residential Code (IRC) or other building codes that include steel framing

This metric measures the ability of the Steel Framing program and its partners to gain approval of the technology in widely adopted residential building codes. Because the metric measures "percent of new homes," it emphasizes building codes adopted in regions that are constructing a large number of new homes. This metric aligns with the program goal of removing regulatory barriers that inhibit greater market penetration of steel framing.

Data Sources: U.S. Census publishes the total number of new residential units built per year. International Code Council (http://www.iccsafe.org/) lists states and jurisdictions adopting certain building codes.

$\underline{\text { Information-dissemination activities and outputs }}$

\section{2) Number of unique visitors to the ToolBase Steel Framing Technology Inventory homepage}

Metric 2 indicates the number of interested parties referencing PATH's ToolBase Web site for information specifically pertaining to steel framing. The information provided on this site is technical and tailored for an audience of home builders, designers, manufacturers, and others in the housing industry rather than the general public. The site offers industry professionals reliable information about performance, cost, and value of the technology. Measuring the "unique visitors" estimates the number of different people accessing the information (as opposed to "page views," which counts the number of times a site is visited, even if it is accessed multiple times by the same person). This measure provides a better indication of the breadth of audience that PATH is reaching. The URL for the ToolBase steel framing Technology Inventory homepage is 
http://www.toolbase.org/Technology-Inventory/Whole-House-Systems/steelframing.

Data Source: NAHB Research Center

3) Average monthly downloads of the Cold-Formed Steel Framing TechSpec (from toolbase.org site)

This metric, which complements Metric 2, approximates the circulation of a key steel framing program document. This document is an important resource for builders who are considering making the switch to cold-formed steel. Document downloads estimate the level of interest among the building community and provide a leading indicator of market penetration. The metric also gauges the ability of PATH to attract interested parties to download a key document. The URL for the TechSpecs document for steel framing is: http://www.toolbase.org/pdf/techinv/steel_framing_techspec.pdf Data Source: NAHB Research Center

4) Annual percentage growth in the number of Google hits when searching the following exact phrase: "Partnership for Advancing Technology in Housing" and "Steel Framing"

This metric gauges overall public interest in the Steel Framing program by measuring the availability of information and reference materials pertaining to the program on the Internet. This exact search phrase was considered meaningful because, when tested, each search result was relevant to the PATH Steel Framing program. Measuring the absolute number of hits for this metric is not as important as measuring how the number of hits changes over time (i.e., the annual percentage growth). Google hits are a useful metric because they measure the number of pages referencing PATH and Steel Framing not only from pathnet.org or toolbase.org, but also from external sites either in industry, news media, academia, or government. Together with Metrics 2 and 3, they provide an objective method to measure this program's information-dissemination activities. Data Source: Google.com

Market penetration outputs and outcomes

5) Steel framing annual production for residential use (in square feet) per square feet of all new residential-housing units in the United States per year

Metric 5 estimates the total production of steel framing as a fraction of total square footage of new houses being built. Because the housing market fluctuates significantly from year to year, it is important to measure steel framing production compared to overall new-home construction. This metric, together with Metric 6 and Metric 7, offer insights into the market penetration of the technology. Particularly useful will be comparisons of these three metrics over time - 
assessing the rate of improvement or acceleration of the technology into the marketplace.

Data Sources: Steel Framing Alliance (SFA) collects data on annual shipments to the residential industry and can be used as a proxy for annual production. U.S. Census publishes data necessary to compute the total square footage of new residential units built per year.

\section{6) Number of home builders offering steel framing}

This metric estimates the market penetration of steel framing in the building industry, and should be evaluated in conjunction with Metric 5 and Metric 7 . It measures the ability of an interested home buyer to select steel framing for their new home. An increased number of builders offering steel framing can be a leading indicator of increased adoption of the technology. A possible addition to this metric would incorporate the percentage of the market that these home builders represent, indicative of the market share of these builders. Obtaining this market data may be an obstacle; simply measuring the number of builders will be an adequate first-order measure.

Data Source: Steel Framing Alliance (SFA). Although there may be builders who offer steel framing that are not members of SFA, the number of SFA homebuilder members can be used as a proxy for the total number of builders offering the technology.

\section{7) Percentage of new homes in the United States using steel framing}

This metric provides another estimate of market penetration and approximates the range of coverage of steel framing in new homes. This metric should be evaluated in combination with Metric 5 and Metric 6 to obtain a better profile of the market progress of the technology. While Metric 6 measures whether steel framing is an option offered by builders, Metric 7 measures whether builders are actually implementing steel framing in their homes. Compare this to Metric 5, which indicates the total production of steel framing but not the extent of broad market penetration. Recent data do not appear to be available online for a number of new homes with steel framing. If these data are not available, overall market share of steel frames in terms of mass (tons) compared to the entire framing market in tons could be considered as an alternate metric. ${ }^{12}$

Data Sources: SFA may be able to provide data on the number of new homes built using steel frames. U.S. Census provides data on the number of new residential-housing units built each year.

Metrics 5, 6, and 7 are also useful for evaluating the program retrospectively. Specifically, the impact of including steel framing in residential building codes can be quantified. The use of steel framing in residential-housing units before and after the incorporation of steel framing into the International Residential Code will gauge the impact of addressing this regulatory barrier.

12 "Data and Statistics." <http://www.steelframing.org/sfa_datastatistics.shtml>. 
The market penetration attributable to PATH is difficult to separate from the market penetration from external factors. Metrics 1 through 3 are more directly correlated with specific PATH activities. Regardless, the ultimate objectives of the Steel Framing program align with the market-penetration metrics recommended here and are meaningful for evaluating the successes of the program.

\section{Additional Recommended Metrics}

\section{8) Number of states that have greater than $1.5 \%$ of new residential-housing units built using steel framing}

This metric captures the geographic distribution of the technology. Some states may have significant market penetration, while others are lagging. Steel framing use may be clustered in a few states, for example. Implementers chose $1.5 \%$ as the baseline because the technology had a $1.5 \%$ market share of the residentialhousing sector in 2002. ${ }^{13}$ A greater number of states exceeding the 2002 average market penetration for new homes indicates greater geographic distribution. This metric should be used in conjunction with Metrics 5, 6, and 7, which indicate overall market penetration. As overall market penetration increases, Metric 8 should be expected to also increase. Discrepancies among the trends in Metrics 5, 6 , and 7 and Metric 8 can inform an analysis of geographic distribution as part of a broader evaluation of market penetration.

Data Source: SFA may be able to provide a breakdown by state of new homes built with steel framing. The total number of new homes is available from U.S. Census.

${ }^{13}$ Steel Framing Alliance. "Data and Statistics."

<http://www.steelframing.org/sfa_datastatistics.shtml>. 


\section{Recommended Metrics for PATH's Insulating Concrete Forms Program}

\section{Program Background}

The U.S. Department of Housing and Urban Development's Partnership for Advancing Technology in Housing (PATH) administers the Insulating Concrete Forms program. This program seeks to accelerate the adoption of Insulating Concrete Forms (ICFs) in the residential-housing market. Compared to conventional framing materials, ICFs have high R-values, low air infiltration, and high thermal mass; these attributes can reduce home energy use by $25 \%$ to $50 \%$ compared to wood- or steel-framed homes. In addition, ICFs reduce sound transmission and are structurally durable and cost-competitive. ${ }^{14}$ Despite these benefits, homes constructed using ICFs account for only a small fraction of the U.S. residential-housing market.

PATH seeks to accelerate adoption of technologies that provide an alternative to conventional wood framing. At PATH's inception, three technologies were selected as the most likely alternatives to wood that would be able to penetrate the market: ICFs, Structural Insulated Panels (SIPs), and Steel Framing. PATH identified critical barriers impeding greater adoption of the technology into the marketplace. The ICFs program focused on addressing these critical barriers, including working with building-code organizations to address regulatory barriers and increasing dissemination of information regarding how the technology works, its cost, and the value in its use.

\section{Which PATH Goal(s) Does This Program Address?}

PATH goals focus on reducing multiple constraints throughout the innovation pipeline in the residential-housing sector, and developing the infrastructure for increasing innovation in that pipeline. PATH's three overall goals are:

- Identify and reduce barriers that impede innovation, including regulatory barriers (Goal 1)

- Disseminate information to speed the development and adoption of advanced building technologies (Goal 2)

- Advance housing technology research and foster development of new technology (Goal 3)

The ICFs program primarily addresses PATH Goals 1 and 2 (see Appendix A for a listing of metrics by program and the specific objectives addressed by the metrics.) Activities aligning with Goal 1 include developing an ICFs Prescriptive Methods document that identifies key barriers impeding innovation, and working with organizations to address the regulatory hurdle of incorporating ICFs into building codes.

\footnotetext{
14 "Benefits - Easy To Build With and Easy To Love: Advantages of ICFs." $<$ http://www.forms.org/?act=benefits>.
} 
Supporting Goal 2, PATH posts specific technical information about ICFs on its toolbase.org Web site. Pathnet.org and huduser.org also offer links and information about ICFs to interested parties.

\section{Major Activities}

At the outset of the ICFs program, PATH collaborated with the NAHB Research Center and the Portland Cement Association (PCA) to identify critical barriers impeding greater market penetration of insulating concrete forms (ICFs). Regulatory barriers and lack of available information about ICFs were determined to be the key barriers that PATH could address. Examples of regulatory barriers include the lack of a consistent and comprehensive set of prescriptive requirements, such as prescriptive construction guidelines, and the absence of ICFs in residential building codes (PATH 1998). Lack of information includes technical guidance for home builders and general marketing of the technology for a wider audience.

To help overcome regulatory barriers, the program developed a prescriptive method titled "Prescriptive Method for Insulating Concrete Forms in Residential Construction," which established performance standards for ICFs and shared technical information about the technology. This first report was published in May 1998 and was accepted in 2000 by the International Code Council (ICC) for adoption into the International Residential Code (IRC) - a set of building codes commonly adopted by states and counties. The ICC develops codes used to construct residential and commercial buildings, including homes and schools. Most U.S. cities, counties, and states that adopt codes choose the International Codes developed by the ICC. In January 2002, the Prescriptive Method was revised based on user feedback and expanded to include provisions for seismic design, wall construction requirements using Grade 60 reinforcing steel, and concrete mixes with selected compressive strengths (HUD 2002).

ICFs program marketing and information-dissemination activities support efforts to increase adoption of the technology. The program broadly follows three key messages for its information-dissemination activities:

- Technical soundness. Establish that performance of ICFs is equivalent, if not superior, to competing alternatives.

- Costs. Provide objective estimates of the installation, operation, and maintenance costs in specific housing applications.

- Benefits. Encourage builders and customers to consider the numerous benefits of using ICFs in their homes.

HUD PATH has published several documents to convey these messages, including:

- "Prescriptive Method for Insulating Concrete Forms in Residential Construction"

- "Insulating Concrete Forms for Residential Construction"

- "In-Plane Shear Resistance of Insulating Concrete Form Walls"

- "Insulating Concrete Forms Lintel Tests"

- "Prescriptive Method for Connecting Cold-Formed Steel Framing to Insulating Concrete Form Walls in Residential Construction" 


\section{Web Tools for Information Dissemination}

PATHnet (http://PATHnet.org/) is PATH's information Web portal that provides information on numerous housing technologies, including ICFs. The portal offers information on designs, technologies, and product manufacturers, and includes other publications related to ICFs.

ToolBase (http://www.ToolBase.org/) is a PATH-sponsored technical information resource for the home-building industry that contains free and unbiased product descriptions, design and construction guides, best practices, performance reports, case studies, and other resources for builders and remodelers. ${ }^{15}$ Within the ToolBase site, the section called Technology Inventory includes sections devoted to ICFs. This section of the site provides in-depth information on costs, results from field evaluations, and tips for determining whether ICFs are appropriate for certain kinds of projects.

\section{Measuring the Impact}

Metrics provide quantitative evidence of the progress and impacts of specific programs. Measuring impacts is often more difficult than measuring the progress of a program, but both are vital for gauging overall performance. The metrics themselves do not determine how well a program is performing, but rather provide insight into program performance and help inform a long-term program evaluation; comprehensive program evaluation should be accompanied with setting ambitious targets and time frames that are measured by the metrics. Both types of metrics - progress (activities, outputs) and impact (outcome) metrics - are discussed in the Recommended Performance Metrics section. Two approaches are considered for measurement:

- Measurement of increased market penetration of ICFs using proxies, such as ICFs production data, ICFs supplied to housing units, market share of ICFs in residential building, and others.

- Direct measurement of information dissemination, such as number of page views of the ToolBase Technology Inventory on ICFs

The first type of metric provides insight into the extent that ICFs have penetrated the market. Although it is difficult to measure exactly how many residential units are constructed using ICFs each year, production figures may provide a reasonable estimate. A complete profile of the technology's market penetration would include the percentage of homes incorporating ICFs and details into the distribution of the technology, such as among large and small homes and geographic location. It would be expected that ICFs production correlate with use, such that the number of housing units supplied with ICFs would approximate the number of housing units constructed with ICFs. Production figures, however, may themselves be difficult to obtain if ICFs are produced by manufacturers who are not members of the Insulating Concrete Forms Association (ICFA) (see Data Sources section). In addition, as ICFs become mainstream, it would be

15 "About ToolBase" <http://www.toolbase.org/about.aspx>. 
expected that more manufacturers will produce ICFs, thus making production estimates more challenging.

The second type of metric allows for practical measurement and a useful understanding of program effects from information-dissemination efforts. Before ICFs can attain significant market penetration, builders must be confident that the technology will perform adequately, be cost-effective, and be safe. Energy efficiency improvements provide an additional benefit. This program has taken on the role of disseminating such information on ICFs to builders, consumers, and other interested parties in the residentialhousing sector. While this measure does not reveal direct market impacts of the program, it effectively shows the exposure of information to the marketplace as a result of PATH efforts.

\section{Key Data Sources}

Data for ICFs metrics are available primarily from three key sources:

\section{Insulating Concrete Form Association (ICFA)}

The Insulating Concrete Form Association (ICFA) (http://www.forms.org/) is an organization "dedicated to expanding the use of insulating concrete forms through research, education, promotion, and public affairs work" (PCA 2008). ICFA may be able to provide industry data, such as annual shipment reports showing production trends.

ICFA membership lists also may provide useful proxy data indicating number of system manufacturers, distributors, contractors, suppliers, etc.

\section{Portland Cement Association (PCA)}

The Portland Cement Association (http://www.cement.org/) is an organization that represents cement companies in the United States and Canada and conducts market development, engineering, research, education, and public affairs programs. PCA offers relevant articles about ICFs and a list of known producers (PCA 2008). ${ }^{16}$ PCA may have data related to ICFs production or market data.

\section{National Association of Home Builders (NAHB) Research Center}

The National Association of Home Builders (NAHB) Research Center compiles statistics on Web site use of ToolBase, including page views and downloads.

Note that PATHnet pages for ICFs were developed as a resource for users interested in the ICFs Prescriptive Methods (first and second editions) rather than as a resource for increasing broad public knowledge or awareness of the technology. The Prescriptive Methods and the relevant studies that contributed to the creation of these methods were developed and conducted explicitly to be submitted to the International Code Council. Therefore, it is not expected that PATHnet page views or downloads necessarily would be an appropriate indicator of the program's overall information-dissemination activities. On the other hand, ToolBase is specifically geared toward sharing technical information

16 "Portland Cement Association" <http://www.cement.org/pca/> 
with the home-building community. Page views and downloads from ToolBase will more accurately reflect interest and awareness on the topic.

\section{Approach for Identifying and Recommending Performance Metrics}

The following approach, which is explained further in Chapter 2, is used for recommending performance metrics:

1. Develop a logic model of the ICFs program activities, outputs, and outcomes. The logic model translates the program activities and goals described earlier into a diagram that illustrates how these function collectively while being measured individually (see Figure 5 for logic model).

2. Identify candidate metrics based on the logic model that measure the progress of these activities, outputs, and outcomes toward achieving project and program goals.

3. Apply the scoring system described in the Conceptual Soundness report to the candidate metrics. The scoring system is based on general characteristics of useful metrics for the PATH program. Scores are based on four key criteria:

a. Understandable. Extent to which the metric is understood by external stakeholders

b. Attributable. Ability to determine PATH contribution

c. Feasible. Availability and reliability of data

d. Comparable over time. Ability to make fair comparisons to previous and/or future measurements

4. Tally scores and rebalance. Metrics are selected based on the scores and rebalanced using expert judgment to ensure that the set of recommended metrics are representative of the breadth of PATH ICFs-related activities and include measures of process (i.e., activities and outputs) and end results (i.e., outcomes). 


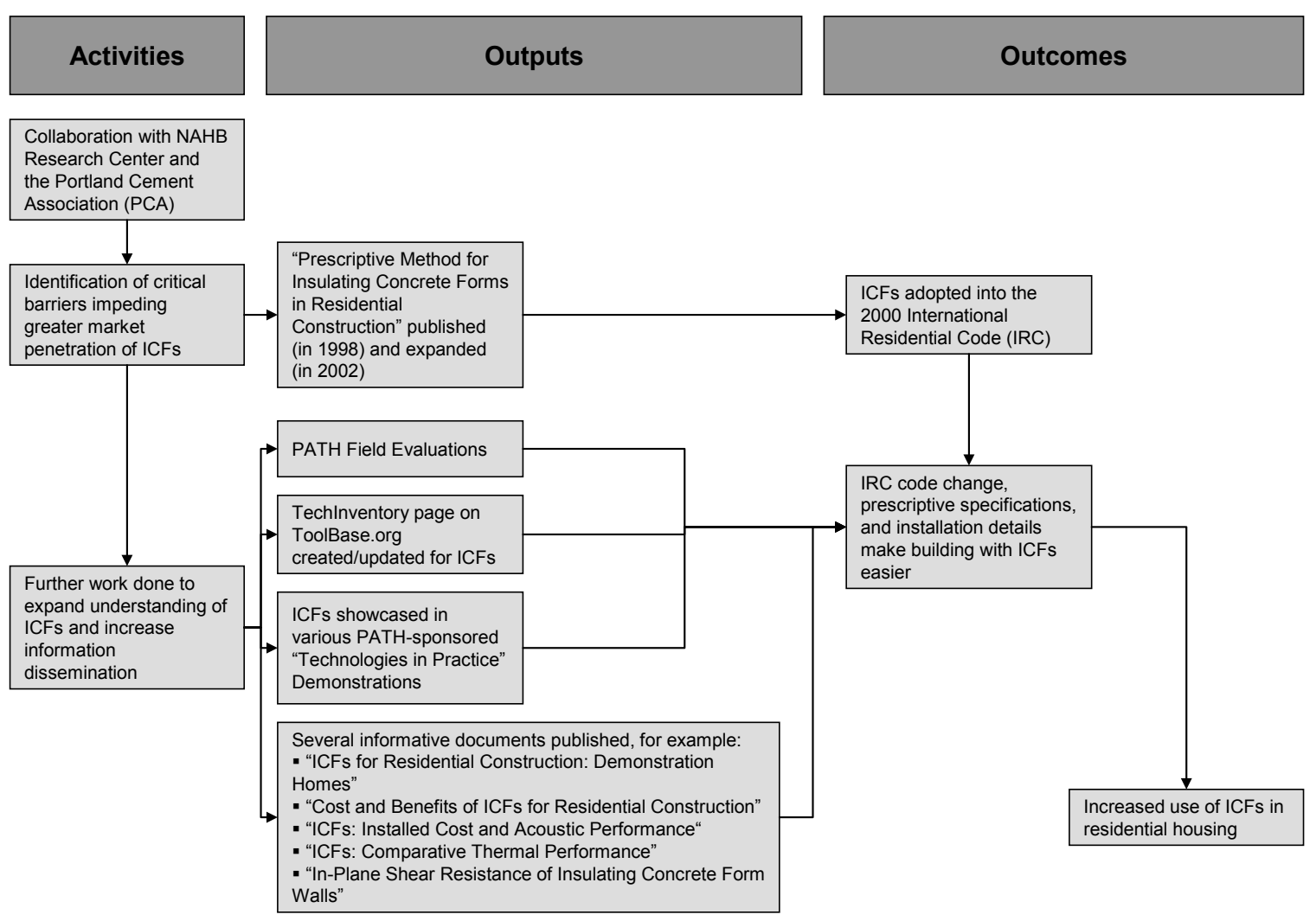

Figure 5. ICFs Logic Model

\section{Recommended Metrics}

Recommended metrics and potential data sources for the ICFs program are presented in this section. Note that additional recommended metrics are proposed in the next section. That section includes an additional measure that complements the current metrics set, but the data are not likely to be easily available. Together, these two sections represent a full set of recommended metrics that measure both the means and the ends of the program, and inform a process for long-term assessment and program improvement. See Appendix $\mathrm{B}$ for a listing of metrics and their respective scoring considering the attributes discussed in the Conceptual Soundness section - understandable, attributable, feasible, and comparable over time.

One of the challenges in evaluating this program involves differentiating between increases in ICF adoption due to PATH activities and increases in ICF adoption due to external factors. This is particularly challenging for public/private partnerships such as PATH where cooperative activities include both HUD-sponsored elements and privatesector elements. The partnership structure creates challenges but does not preclude the use of meaningful outcome metrics that incorporate components of PATH and components of external activities from providing useful input toward a comprehensive program evaluation. It is also important that data be considered in the context of the U.S. home-building industry at the time of the measurement. Measured values may fluctuate with changes in demand in the housing market. These complicating factors have been 
considered when selecting the recommended metrics described in this section, and the metrics are tailored where possible to account for these factors.

Note that ICFs, Structural Insulated Panels, and Steel Framing are all similar PATH programs. All three technologies represent alternatives to conventional wood options, and the PATH activities for these programs all focus on removing regulatory barriers through building code changes and disseminating information about the value of the technology. Because of these similarities, the recommended metrics are intended to be consistent and comparable across all three similar programs.

\section{$\underline{\text { Building code-related outputs }}$}

1) Percent of new homes in the United States that are built in a location that has adopted the International Residential Code (IRC) or other building codes that include ICFs

This metric measures the ability of the ICFs program and its partners to gain approval of ICFs in widely adopted residential building codes. Because the metric measures "percent of new homes," it emphasizes building codes adopted in regions that are constructing greater numbers of new homes. This metric aligns with the program goal of removing regulatory barriers inhibiting greater market penetration of ICFs.

Data Sources: U.S. Census publishes the total number of new residential units built per year. International Code Council (http://www.iccsafe.org/) lists states and jurisdictions adopting certain building codes.

\section{$\underline{\text { Information dissemination activities and outputs }}$}

\section{2) Number of unique visitors to the ToolBase ICFs Technology Inventory home page}

This metric indicates the number of interested parties referencing PATH's ToolBase Web site for information specifically pertaining to ICFs. The information provided on this site is technical and tailored for an audience of home builders, designers, manufacturers, and others in the housing industry rather than the general public. The site offers industry professionals reliable information about performance, cost, and value of the technology. Measuring the "unique visitors" estimates the number of different people accessing the information (as opposed to "page views," which counts the number of times a site is visited, even if it is accessed multiple times by the same person). This measure provides a better indication of the breadth of audience that PATH is reaching. The URL for the ToolBase ICFs Technology Inventory home page is http://www.toolbase.org/Technology-Inventory/walls/Insulating-Concrete-Forms. Data Source: NAHB Research Center 
3) Annual percentage growth in the number of Google hits when searching the following exact phrase: "Partnership for Advancing Technology in Housing" and "Insulating Concrete Forms" or "ICFs"

This metric gauges overall public interest in the ICFs program by measuring the availability of information and reference materials pertaining to the program on the Internet. This exact search phrase was considered meaningful because, when tested, each search result was relevant to the PATH ICFs program. Measuring the absolute number of hits for this metric is not as important as measuring how the number of hits changes over time (i.e., the annual percentage growth). Google hits are a useful metric because they measure the number of pages referencing PATH and ICFs not only frompathnet.org or toolbase.org, but also from external sites either in industry, news media, academia, or government. Together with Metric 2, these metrics provide an objective method to measure this program's information-dissemination activities.

Data Source: Google.com

Market penetration outputs and outcomes

4) ICFs annual production for residential use (in square feet) per square feet of all new residential-housing units in the United States per year

Metric 4 estimates the total production of ICFs as a fraction of total square footage of new houses being built. Because the housing market fluctuates significantly from year to year, it is important to measure ICFs production compared to overall new home construction. This metric, together with Metric 5 and Metric 6, offers insights into the market penetration of the technology. Particularly useful will be comparisons of these three metrics over time, which will help assess the rate of improvement or acceleration of the technology into the marketplace.

Data Source: ICFA publishes ICF shipments of its members, and can be used to approximate ICF annual production. U.S. Census publishes data necessary to compute the total square footage of new residential units built per year.

\section{5) Number of home builders offering ICFs}

This metric approximates the market penetration of ICFs in the building industry, and should be evaluated in conjunction with Metric 4 and Metric 6. It measures the ability of an interested home buyer to select the ICFs technology for use in his/her new house. An increased number of builders offering ICFs can be a leading indicator of increased adoption of the technology. A possible addition to this metric would incorporate the percentage of the market that these home builders represent, indicative of the market share of these builders. Obtaining this market data may be an obstacle; simply measuring the number of builders will be an adequate first-order measure. 
Data Source: Insulating Concrete Form Association (ICFA). Although there may be other builders who offer ICFs, the number of ICFA home-builder members will be used as a proxy.

\section{6) Percent of new homes in the United States using ICFs}

This metric provides another estimate of market penetration and approximates the range of coverage of ICFs in new homes. This metric should be evaluated in combination with Metric 4 and Metric 5 to obtain a better profile of the market progress of the technology. While Metric 5 measures whether ICFs are an option offered by builders, Metric 6 measures whether builders are actually implementing ICFs in their homes. Compare this to Metric 4, which indicates the total production of ICFs but not the extent of broad market penetration. Data Source: The Portland Cement Association (PCA) and/or the National Association of Home Builders Research Center (NAHBRC) may be able to provide data on the use of ICFs in the residential market. The number of houses built using ICFs can be compared to the U.S. Census total number of new residential units built in that year.

Metrics 4, 5, and 6 are also useful for evaluating the program retrospectively. Specifically, the impact of including ICFs in residential building codes can be quantified. The use of ICFs in residential-housing units before and after the incorporation of ICFs into the International Residential Code will help gauge the impact of addressing this regulatory barrier.

The market penetration attributable to PATH is difficult to separate from the market penetration due to external factors. Metrics 1 through 3 are more directly correlated with specific PATH activities. Regardless, the ultimate objectives of the ICFs program align with the market-penetration metrics recommended here and are meaningful for evaluating the successes of the program.

\section{Additional Recommended Metrics}

\section{7) Number of states that have greater than $2.7 \%$ of new residential-housing} units built using ICFs

This metric captures the geographic distribution of the ICFs technology. Some states may have significant market penetration, while others are lagging. ICFs use may be clustered in a few states, for example. Implementers chose $2.7 \%$ as the baseline because, in 2001, ICFs were installed in $2.7 \%$ of all U.S. above-grade homes, according to the National Association of Home Builders and the Portland Cement Association (NAHB 2002). A greater number of states exceeding the 2001 average market penetration for new homes indicates greater geographic distribution. This metric should be used in conjunction with Metrics 4, 5, and 6, which indicate overall market penetration. As overall market penetration increases, Metric 7 should be expected to also increase. Discrepancies among the 
trends in Metrics 4, 5, and 6, and Metric 7 can inform an analysis of geographic distribution as part of a broader evaluation of market penetration.

Data Source: ICFA collects annual shipment data by state. Number of housing units with ICFs may be more difficult to obtain. 


\section{Baselines and Targets}

Baselines establish and record levels of activity by which future comparisons can be made. Baselines allow reliable, defendable, and straightforward tracking of later progress, establishing a standard to compare, measure, and eventually evaluate program improvements. Over time, comparing program performance against a baseline can help validate or invalidate whether a program is focusing on the most important issues or problems and thereby optimizing its effects and benefits. Establishing baselines is an important step of a comprehensive program assessment and provides critical information for management to improve performance, efficiency, and effectiveness. ${ }^{17}$

Targets are used for tracking program progress toward predetermined goals, typically by comparing performance achieved against performance expected. Target setting is an important component in a comprehensive program assessment. Without targets, the usefulness of program assessment is significantly reduced.

\section{Baselines}

Baselines also are a necessary component of the President's Management Agenda Program Assessment Rating Tool (PART). PART was developed by the Office of Management and Budget (OMB) to assess and improve federal program performance. PART assists in identification of programs' strengths and weaknesses and can be used to inform funding and management decisions aimed at making programs more effective. Thorough assessment of government programs through PART, for example, requires analysis and tracking progress relative to a baseline.

\section{Selection of Baseline Years}

The U.S. Department of Housing and Urban Development's Partnership for Advancing Technology in Housing (PATH) Program was founded in 1998 as a public/private partnership to improve innovation in the residential-housing sector. The program aimed to accelerate the development and use of advanced housing technology and was guided by a list of quantitative housing performance goals.

The National Research Council's (NRC) evaluation of PATH found that no evidence or baseline data could be identified to indicate that the housing performance goals were measurable and achievable (NRC 2003). These and other challenges associated with PATH's original numeric goals were identified. Recognizing these issues, PATH refocused and refined its goals in 2002 to reflect the overall aim of increasing the impact of technology innovation in the home-building sector while aligning with PATH capabilities and actions.

The years of baseline recommendations for the PATH subprograms featured in this document reflect these two major periods in the PATH program. Baseline year 1998 reflects the start of PATH and its original goals, which are presented in Chapter 2. The second baseline year, 2003, is the earliest year that impacts from the 2002 PATH

17 "Assessing Program Performance." <http://www.whitehouse.gov/omb/part/>. 
strategic revision can be measured. Baseline values also were identified for 2007 - the most recent full year that data are available. Using these earlier years, target values for 2008 can be recommended (see Targets section). These recommendations are shown in this report following the baseline values.

It should be noted that, due to incomplete data sets (see Key Challenges), baseline years for some metrics varied from the default years of 1998, 2003, and 2007. For example, data provided by NAHBRC on ToolBase Web site activity (e.g., page views, downloads, and unique visitors), were only provided for 2005, 2006, and 2007. Additionally, for example, industry market research data from the Steel Framing Alliance (SFA) only reported percent of new housing starts using steel framing for a single year, 2002.

For metrics where very few data points were available, baseline data for alternate years were estimated by extrapolation and/or proxy data. For example, for the missing SFA market-penetration data, the percent changes were tied to trends in steel framing production (tons) data from 1997 to 2005. Details and key assumptions for each baseline value are provided in the sections below.

\section{Targets}

The methods used to choose target values can include expert judgment, objective statistical analysis, complex formula, or other methods. Using a structured process enables a target setting methodology that is easy to understand and adjust later, if needed. A target-setting process should ensure that the targets are relevant to program goals and objectives. The target values presented in this study correspond to individual metrics developed specifically to align with program goals, and the targets already should be relevant to meaningfully gauging program progress.

Even through the use of a structured process, as conducted in this study, target setting can be difficult. In its simplest form, target setting involves projecting future performance based strictly on historical performance. This can be done by using linear trends, or simply using the most recent data point as the target value for future years. In practice, programs are more complex and dynamic and multiple elements contribute, to varying degrees, to the program's performance throughout the program's active performance period. However, establishing targets based on multiple variants can complicate the process and lead to unnecessarily reducing the transparency of the targets.

For this study, a straightforward structured approach based primarily on historical data trends was used for setting recommended targets. Linear regression was applied to the baseline values, and other relevant historical data and target values for 2008, 2013, and 2018 were extrapolated. Where insufficient historical data were available, alternative data were used. For example, Insulating Concrete Form Association (ICFA) membership data were only available for 2008. Without the use of alternative data, both baseline and target membership values could not be easily determined. As such, ICF shipment data trends were used to extrapolate both the baseline and target values for ICFA membership. 
PATH may want to examine each of the recommendations in detail and adjust the targets, based on external factors likely to influence the target values. For instance, increased or deceased program funding may require adjustments to the aggressiveness of targets achieved in subsequent years.

\section{Key Challenges}

During the baselining and target-setting processes, many challenges arose, primarily due to gaps in historical data. Some data that were thought to be publicly available are collected infrequently and incompletely. Data gaps exist from several sources, including directly from the program and its partners, as well as industry market-research organizations.

Incomplete and infrequently collected data, in conjunction with limited information about historical subprogram activities, provided challenges in recommending appropriate baselines and targets. For example, comprehensive data sets often were not available from industry marketing groups such as SIPA, ICFA, and SFA. Historical membership data were either not collected, could not be obtained, or, due to various factors, turned out to be an inadequate measure of the metric. Alternative methods were used in such cases and are described below where applicable.

Incomplete data were particularly a challenge in analyzing the ToolBase use data. For example, one metric recommends measuring the "Total number of TechInventory page views per month"; however, only "Top 10" ToolBase individual Web pages (e.g., TechInventory page views for specific technologies), pages view were obtained. Further complicating the quantification of the metric for the baseline and target years is that these "Top 10" are not limited to only TechInventory page views - the Top 10 reported in any given month may include other ToolBase Web pages. Therefore, to report baselines and targets for this metric, only "Top 5" TechInventory technologies are considered (closer examination of the data set reveals that in each "Top 10" data set there are at least five TechInventory pages included).

In addition to the challenge of incomplete and infrequently collected data, methods of data collection varied over time. For example, toolbase.org Web site use statistics were collected with two different programs: WebTrends and Urchin. WebTrends and Urchin each used different formulas for data collection and, therefore, resulted in slightly different data categories, which introduced inconsistency and difficultly in interpretation.

\section{Subprogram Details}

Baseline and target recommendations have been developed for the five PATH subprograms that have been evaluated for this study. The following section contains two parts for each subprogram. The first part outlines key events in the programs' history, which is presented so the reader can compare the historical activities with the corresponding baseline values. The second part presents the recommended baseline and target values. 
Accompanying spreadsheets provide further detail for the recommended baselines and targets. The spreadsheets contain full data sets, analysis, and projections that were used for each metric. There is a separate worksheet summarizing the baselines and targets of all relevant metrics for each of the five subprograms, and a separate tab within each worksheet for each metric.

\section{Concept Home Program}

\section{Key Events}

2004: The conception of the first Concept Home is completed. ${ }^{18}$ The Concept Home architectural model is unveiled during a reception in Washington, D.C. (PATH 2004).

2005: Concept Home technology and manufacturer partners are selected. Blueprints and specifications are detailed

2006: Builder and site for Concept Home Demonstration Project are selected (PATH 2006d). HUD breaks ground in Omaha, Nebraska, on the first PATH Concept Home in the United States.

Summer 2007: Concept Home Omaha is completed and a ribbon-cutting event and open house is held. $^{19}$

Fall 2007: PATH convenes experts and innovators to design the initial design of Concept Home in Charleston, South Carolina (PATH 2007) ${ }^{20}$ HUD names Charleston builder for PATH Concept Home. Architects, builders, engineers, interior designers, and landscape architects participate in an integrated design review session.

Winter 2008: At the 2008 International Builders' Show, PATH reveals the design plans for the Charleston Concept Home. The home will serve as a model of sustainability, hurricane resistance, efficient building practices, and floor plan flexibility.

\section{Concept Home Baseline and Target Values}

\begin{tabular}{|c|c|c|}
\hline \multicolumn{3}{|c|}{$\begin{array}{l}\text { Metric 1: Cumulative number of industry partners (such as designers, builders, technology } \\
\text { manufacturers) who have participated in Concept Home since the inception of the program } \\
\text { Baseline Values: }\end{array}$} \\
\hline 1998 & 2003 & 2007 \\
\hline NA & NA & 51 \\
\hline \multicolumn{3}{|c|}{$\begin{array}{l}\text { The first Concept Home was unveiled in June 2004. The count of partners is updated each } \\
\text { time that the PATHnet site adds to its Concept Home Sponsors page. }\end{array}$} \\
\hline \multicolumn{3}{|c|}{ Target Values: } \\
\hline 2008 & 2013 & 2018 \\
\hline 51 & 102 & 153 \\
\hline
\end{tabular}

\footnotetext{
18 "History of the PATH Concept Home." <http://www.pathnet.org/sp.asp?id=21947\&pbg=1>.

19 "The Concept Home Experience!" <http://www.pathnet.org/sp.asp?id=24487\#June\%206>.

20 "Welcome to Concept Home Charleston!" <http://www.pathnet.org/sp.asp?id=11175>.
} 
the same. Because it took from December 2004 to June 2007 to complete the first Concept Home, it would be reasonable to expect that a new Concept Home be completed every five years. The number of sponsors (per Concept Home) should equal or exceed those of the first Concept Home.

\begin{tabular}{|c|c|c|}
\hline \multicolumn{3}{|c|}{$\begin{array}{l}\text { Metric 2: Cumulative number of technologies that are promoted by Concept Home and } \\
\text { included in completed homes since the inception of the Concept Home program }\end{array}$} \\
\hline \multicolumn{3}{|c|}{ Baseline Values: } \\
\hline 1998 & 2003 & 2007 \\
\hline NA & NA & 38 \\
\hline \multicolumn{3}{|c|}{$\begin{array}{l}\text { The first Concept Home was unveiled June 2004. The count of technologies showcased is } \\
\text { updated each time that the PATHnet site adds to its technologies page. }\end{array}$} \\
\hline \multicolumn{3}{|c|}{ Target Values: } \\
\hline 2008 & 2013 & 2018 \\
\hline 38 & 76 & 114 \\
\hline \multicolumn{3}{|c|}{$\begin{array}{l}\text { Because no new Concept Homes have been built since June } 2007 \text {, that year and } 2008 \text { are } \\
\text { the same. Because it took from December } 2004 \text { to June } 2007 \text { to complete the first Concept } \\
\text { Home, it would be reasonable to expect that a new Concept Home be completed every five } \\
\text { years. The number of technologies (per Concept Home) should equal or exceed those of the } \\
\text { first Concept Home. }\end{array}$} \\
\hline
\end{tabular}

\begin{tabular}{|c|c|c|}
\hline $\begin{array}{l}\text { Metric 3: Cumulative } \\
\text { (e.g., television prom } \\
\text { Home). For this metr }\end{array}$ & $\begin{array}{l}\text { eached thrc } \\
\text { newspapers } \\
\text { ation only is }\end{array}$ & $\begin{array}{l}\text { g and news releases } \\
\text { about Concept }\end{array}$ \\
\hline Baseline Values: & & \\
\hline 1998 & 2003 & 2007 \\
\hline NA & NA & $4,000,000$ \\
\hline $\begin{array}{l}\text { There were no Conce } \\
\text { audience (circulation }\end{array}$ & $\begin{array}{l}\text { ior to June } \\
\text { ne Concept }\end{array}$ & $\begin{array}{l}\text { seline reflects the } \\
\text { at year. }\end{array}$ \\
\hline Target Values: & & \\
\hline 2008 & 2013 & 2018 \\
\hline $4,000,000$ & $8,000,000$ & $12,000,000$ \\
\hline $\begin{array}{l}\text { Because no new Con } \\
\text { the same. Because it } \\
\text { Home, it would be re } \\
\text { years. The audience } \\
\text { Concept Home. }\end{array}$ & $\begin{array}{l}\text { en built sin } \\
2004 \text { to Ju } \\
\text { hat a new C } \\
\text { pt Home) sl }\end{array}$ & $\begin{array}{l}\text { year and } 2008 \text { are } \\
\text { e the first Concept } \\
\text { mpleted every five } \\
\text { ed that of the first }\end{array}$ \\
\hline
\end{tabular}

\begin{tabular}{|c|c|c|}
\hline \multicolumn{3}{|c|}{ Baseline Values: } \\
\hline 1998 & 2003 & 2007 \\
\hline NA & NA & 405 \\
\hline \multicolumn{3}{|c|}{$\begin{array}{l}\text { There were no Concept Home activities prior to June 2004. The } 2007 \text { baseline reflects } \\
\text { attendance at Concept Home events in that year. }\end{array}$} \\
\hline \multicolumn{3}{|c|}{ Target Values: } \\
\hline 2008 & 2013 & 2018 \\
\hline 405 & 810 & 1,215 \\
\hline \multicolumn{3}{|c|}{$\begin{array}{l}\text { Because no new Concept Homes have been built since June } 2007 \text {, that year and } 2008 \text { are } \\
\text { the same. Because it took from December } 2004 \text { to June } 2007 \text { to complete the first Concept } \\
\text { Home, it would be reasonable to expect that a new Concept Home be completed every five }\end{array}$} \\
\hline
\end{tabular}


years. The in-person attendance (per Concept Home) should equal or exceed those of the first Concept Home.

Metric 5: Average monthly number of Web page hits that contain information about Concept Home and its technologies on PATH-sponsored Web sites (i.e., PATHnet, ToolBase,

HUDUser). For this metric only, page views of "About the Concept Home" ${ }^{21}$ were reported due to lack of data for other pages on the Concept Home (and related) Web sites.

Baseline Values:

\begin{tabular}{|c|c|c|}
\hline Baseline Values: & $\mathbf{2 0 0 7}$ \\
\hline $\mathbf{2 0 0 4}$ & $\mathbf{2 0 0 6}$ & 2,625 \\
\hline 744 & 1,300 & \\
\hline \multicolumn{3}{|l}{ Target Values: } \\
\hline 2008 & $\mathbf{2 0 1 3}$ & $\mathbf{2 0 1 8}$ \\
\hline 2,900 & 5,900 & 8,900 \\
\hline
\end{tabular}

Projections of trends based on linear regression of historical data were used to estimate targets, rounded to the nearest 100 .

Metric 6: Annual percentage growth in the number Google hits when searching the following exact phrase: "Partnership for Advancing Technology in Housing" or "Concept Home"

Baseline Values:

\begin{tabular}{c|c|c}
1998 & 2003 & 2007 \\
NA & NA & NA
\end{tabular}

Insufficient data are available to establish a baseline value. Data are available from spring 2008 to present, but these are not yet enough to set a baseline.

Target Values:

2008

TBD

2013

2018

There are insufficient data to extrapolate a trend. Targets will be developed over time.

21 "About the Concept Home." < http://www.pathnet.org/sp.asp?id=11175>. 


\section{ToolBase Program}

\section{Key Events}

Prior to July 2001: PATH partners with the NAHB Research Center, and the program integrated the ToolBase Web pages with the Web site for the NAHB Research Center (www.nahbrc.org).

July 2001: After a major redesign effort, the toolbase.org site was launched as a separate Web site.

July 2006: The Web site was again revamped and relaunched, completely independent from the nahbrc.org Web site. The ToolBase portal design is the same that is seen today (McGee 2008).

Prior to July 2007: PATH provides funding to expand the Technology Inventory, develop Field Evaluations, promote the ToolBase site and its technologies, and make other enhancements to the Web site

July 2007: The scope of the program is altered, although the Web site itself does not significantly change at this time. When one of the funding vehicles expires, PATH and its partner NAHB Research Center are limited to maintaining the existing content in ToolBase, focusing mainly on the Technology Inventory and Field Evaluation sections and ensuring that the Web site is "live" and functioning on the Internet. Currently, no new materials for the TechInventory and Field Evaluations are being developed

Note that baseline values for ToolBase are largely provided for 2003, 2005, and 2007, while other programs' baseline years are typically 1998, 2001, and 2007. The years 2003 and 2005 were used because of the availability of data. Prior to 2003, very limited data was obtained from the NAHB Research Center, which was the organization tracking ToolBase Web site use.

\section{ToolBase Baseline and Target Values}

\begin{tabular}{|c|c|c|}
\hline \multicolumn{3}{|c|}{ es featured in the Techlnventory } \\
\hline 2003 & 2005 & 2007 \\
\hline 171 & 197 & 246 \\
\hline \multicolumn{3}{|c|}{$\begin{array}{l}\text { The Techlnventory is a major focus of the ToolBase site. Archive.org was used to view } \\
\text { historical ToolBase Techlnventory home pages and create a timeline of technologies and their } \\
\text { dates of addition to the ToolBase site. }\end{array}$} \\
\hline \multicolumn{3}{|c|}{ Target Values: } \\
\hline 2008 & 2013 & 2018 \\
\hline 263 & 355 & 446 \\
\hline
\end{tabular}




\begin{tabular}{|c|c|c|}
\hline \multicolumn{3}{|c|}{$\begin{array}{l}\text { Metric 2: Cumulative number of Field Evaluations completed with results published on } \\
\text { ToolBase }\end{array}$} \\
\hline \multicolumn{3}{|c|}{ Baseline Values: } \\
\hline 2003 & 2005 & 2007 \\
\hline 21 & 34 & 41 \\
\hline \multicolumn{3}{|c|}{$\begin{array}{l}\text { Field Evaluations featured on the ToolBase site show information that is necessary for } \\
\text { information dissemination about innovative building technologies and practices. Archive.org } \\
\text { was used to view a historical list of Field Evaluations detailed in ToolBase. }\end{array}$} \\
\hline \multicolumn{3}{|c|}{ Target Values: } \\
\hline 2008 & 2013 & 2018 \\
\hline 45 & 63 & 82 \\
\hline
\end{tabular}

\begin{tabular}{|c|c|c|}
\hline \multicolumn{3}{|c|}{$\begin{array}{l}\text { Metric 3: Total number of Techlnventory page views (of top five technologies) per thousand } \\
\text { user visits/sessions }\end{array}$} \\
\hline \multicolumn{3}{|c|}{ Baseline Values: } \\
\hline 2005 & 2006 & 2007 \\
\hline 83 & 153 & 137 \\
\hline \multicolumn{3}{|c|}{$\begin{array}{l}\text { The total number of page views for the top five technologies in a given month for years } 2004 \\
\text { to } 2008 \text { was computed using several years of monthly "Top 10" ToolBase pages, of which at } \\
\text { least five were Techlnventory technologies. It should be noted that some data were missing } \\
\text { and estimates are based on the limited data set. } \\
\text { NAHBRC provided the number of visits/visitor sessions monthly from } 2003 \text { to } 2008 \text { for } \\
\text { individual months and annual monthly averages. The annual monthly averages were used as } \\
\text { the denominator to compute this metric. }\end{array}$} \\
\hline \multicolumn{3}{|c|}{ Target Values: } \\
\hline 2008 & 2013 & 2018 \\
\hline 150 & 172 & 182 \\
\hline \multicolumn{3}{|c|}{$\begin{array}{l}\text { Linear regression was used individually on the total number of page views of the top five } \\
\text { technologies baseline data and on the visitor sessions baseline data. The projected target } \\
\text { values of these two were computed into these target metric values (total page views/sessions } \\
\text { for } 2008,2013 \text {, and } 2018 \text {. }\end{array}$} \\
\hline
\end{tabular}

\begin{tabular}{|c|c|c|}
\hline \multicolumn{3}{|l|}{ Baseline Values: } \\
\hline 2003 & 2005 & 2007 \\
\hline NA & NA & NA \\
\hline \multicolumn{3}{|c|}{$\begin{array}{l}\text { The number of broken links provides an indicator for the maintenance of the ToolBase site. } \\
\text { Current data can be collected through specialized software packages, but have not yet been } \\
\text { applied to ToolBase. }\end{array}$} \\
\hline \multicolumn{3}{|l|}{ Target Values: } \\
\hline 2008 & 2013 & 2018 \\
\hline TBD & TBD & TBD \\
\hline
\end{tabular}




\begin{tabular}{|c|c|c|}
\hline \multicolumn{3}{|c|}{$\begin{array}{l}\text { Metric 5: Total number of unique visitors to toolbase.org per month } \\
\text { Baseline Values: }\end{array}$} \\
\hline 2003 & 2005 & 2007 \\
\hline 61,569 & 156,929 & 223,331 \\
\hline \multicolumn{3}{|c|}{$\begin{array}{l}\text { NAHBRC provided the number of unique visitors monthly from } 2003 \text { to } 2008 \text {. Data were } \\
\text { provided both for individual months and annual monthly averages. }\end{array}$} \\
\hline \multicolumn{3}{|c|}{ Target Values: } \\
\hline 2008 & 2013 & 2018 \\
\hline 260,000 & 440,000 & 620,000 \\
\hline
\end{tabular}

\begin{tabular}{|c|c|c|}
\hline \multicolumn{3}{|c|}{$\begin{array}{l}\text { Metric 6: Total number of toolbase.org page views per month } \\
\text { Baseline Values: }\end{array}$} \\
\hline 2003 & 2005 & 2007 \\
\hline 365,166 & 473,738 & 659,014 \\
\hline \multicolumn{3}{|c|}{$\begin{array}{l}\text { NAHBRC provided the number of page views monthly from } 2003 \text { to } 2008 \text {. Data were } \\
\text { provided both for individual months and annual monthly averages. }\end{array}$} \\
\hline \multicolumn{3}{|c|}{ Target Values: } \\
\hline 2008 & 2013 & 2018 \\
\hline 700,000 & $1,000,000$ & $1,300,000$ \\
\hline $\begin{array}{l}\text { Linear regression wa } \\
\text { "total number of toolk } \\
\text { nearest } 100,000 \text {. }\end{array}$ & $\begin{array}{l}\text { et of the bas } \\
\text { per month" }\end{array}$ & $\begin{array}{l}\text { ditional years of } \\
\text { yets, rounded to the }\end{array}$ \\
\hline
\end{tabular}

\begin{tabular}{|c|c|c|}
\hline \multicolumn{3}{|c|}{$\begin{array}{l}\text { Metric 7: Total number of Techlnventory page views per month (calculated using only the to } \\
\text { five Techlnventory technologies in each month). } \\
\text { Baseline Values: }\end{array}$} \\
\hline 2005 & 2006 & 2007 \\
\hline 17,940 & 36,224 & 34,510 \\
\hline \multicolumn{3}{|c|}{$\begin{array}{l}\text { The total number of page views for the top five technologies in a given month for } 2004 \text { to } \\
2008 \text { was computed using several years of monthly "Top } 10 \text { " ToolBase pages, of which at } \\
\text { least five were Techlnventory technologies. }\end{array}$} \\
\hline \multicolumn{3}{|c|}{ Target Values: } \\
\hline 2008 & 2013 & 2018 \\
\hline 43,000 & 78,000 & 113,000 \\
\hline \multicolumn{3}{|c|}{$\begin{array}{l}\text { Linear regression was used on the data set of the baseline values and additional years } \\
\text { of"total number of top five Techlnventory page views per month" data to estimate targets, } \\
\text { rounded to the nearest } 1,000 \text {. }\end{array}$} \\
\hline
\end{tabular}

\begin{tabular}{|c|c|c|}
\hline \multicolumn{3}{|c|}{ Baseline Values: } \\
\hline 2003 & 2005 & 2007 \\
\hline Data requested & Data requested & Data requested \\
\hline \multicolumn{3}{|c|}{ Baseline values will be determined pending data to be received from NAHBRC. } \\
\hline \multicolumn{3}{|c|}{ Target Values: } \\
\hline 2008 & 2013 & 2018 \\
\hline TBD & TBD & TBD \\
\hline
\end{tabular}




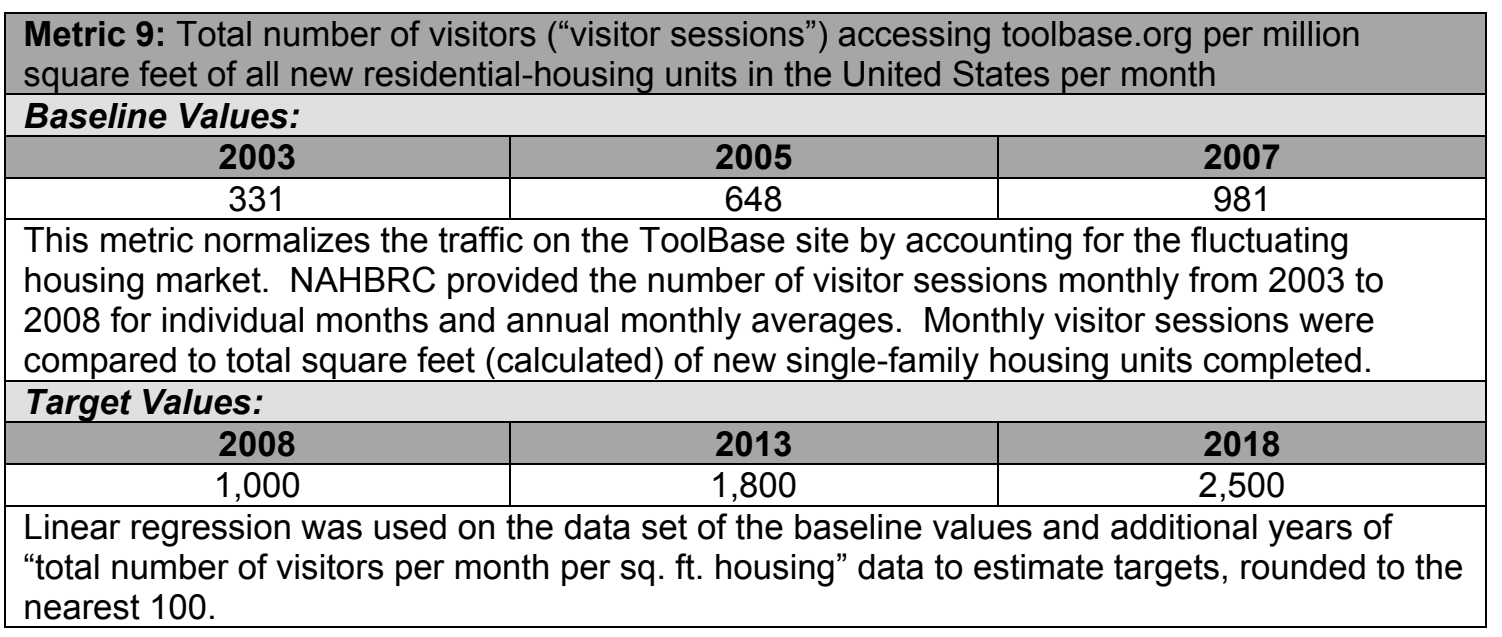

\begin{tabular}{|c|c|c|}
\hline \multicolumn{3}{|c|}{ Metric 10: Average number of page views per session } \\
\hline 2003 & 2005 & 2007 \\
\hline 4.1 & 2.2 & 2.6 \\
\hline \multicolumn{3}{|c|}{$\begin{array}{l}\text { NAHBRC provided number of page views monthly and number of visitor sessions monthly } \\
\text { from } 2003 \text { to } 2008 \text { for individual months and annual monthly averages. }\end{array}$} \\
\hline \multicolumn{3}{|c|}{ Target Values: } \\
\hline 2008 & 2013 & 2018 \\
\hline 2.6 & 4.1 & 4.1 \\
\hline \multicolumn{3}{|c|}{$\begin{array}{l}\text { A linear regression of the data for this metric results in downward trend for page views per } \\
\text { session. Instead of projecting fewer page views per session, the target values selected for } \\
2008 \text { are the same as the previous year (2007). In } 2013 \text { and 2018, page views per session } \\
\text { are targeted to match the peak of } 4.1 \text { in } 2003 \text {. }\end{array}$} \\
\hline
\end{tabular}

\begin{tabular}{|c|c|c|}
\hline \multicolumn{3}{|c|}{$\begin{array}{l}\text { Metric 11: Average sessions per visitor in a given month (total number of visitor sessions / } \\
\text { total number of unique visitors) }\end{array}$} \\
\hline \multicolumn{3}{|c|}{ Baseline Values: } \\
\hline 2003 & 2005 & 2007 \\
\hline 1.4 & 1.4 & 1.1 \\
\hline \multicolumn{3}{|c|}{$\begin{array}{l}\text { Number of monthly visitor sessions and number of unique visitors were obtained from } 2003 \text { to } \\
\text { 2008. Data were provided both for individual months and annual monthly averages. }\end{array}$} \\
\hline \multicolumn{3}{|c|}{ Target Values: } \\
\hline 2008 & 2013 & 2018 \\
\hline 1.1 & 1.4 & 1.4 \\
\hline \multicolumn{3}{|c|}{$\begin{array}{l}\text { Due to reduced funding for } 2008 \text {, the target values selected for this year are the same as the } \\
\text { previous year (2007). Additional funding is expected and the return rate of visitors should } \\
\text { improve and achieve that of previous years. }\end{array}$} \\
\hline
\end{tabular}




\section{Structural Insulated Panels Program}

\section{Key Events}

Early 2002: A TechInventory page on Structural Insulated Panels is added to the toolbase.org site.

Prior to June 2006: PATH collaborates with the Structural Insulated Panel Association (SIPA), APA-The Engineered Wood Association, and SIP manufacturers across the country to identify critical barriers impeding wider market uptake of structural insulated panels. Nearly a year of testing and evaluation goes into developing a prescriptive method for Structural Insulated Panels (PATH 2006b).

June 2006: Publication of the "Prescriptive Method for Structural Panels," which establishes performance standards for SIPs and shares technical information about the technology. It also offers specific guidelines to facilitate the use of SIPs in wall systems for the construction of one- and two-family dwellings (PATH 2006a).

After June 2006: The Prescriptive Method and specifications are submitted to the International Code Council (ICC) for adoption into the International Residential Code (IRC).

August 2006: A TechSpecs downloadable document (PDF format) on Structural Insulated Panels is added to the SIPs TechInventory page of toolbase.org site.

May 2007: The ICC votes to adopt SIPs into the IRC, and shortly thereafter they are included as a supplement to the 2006 International Residential Code (SIPA 2007).

\section{SIPs Baseline and Target Values}

\begin{tabular}{|c|c|c|}
\hline \multicolumn{3}{|c|}{ Baseline Values: } \\
\hline 1998 & 2003 & 2007 \\
\hline $0 \%$ & $0 \%$ & $25 \%$ \\
\hline \multicolumn{3}{|c|}{$\begin{array}{l}\text { SIPs were included in the } 2007 \text { supplement to the } 2006 \text { International Residential Code, } \\
\text { therefore baseline values prior to } 2006 \text { equal zero. }\end{array}$} \\
\hline \multicolumn{3}{|c|}{ Target Values: } \\
\hline 2008 & 2013 & 2018 \\
\hline $31 \%$ & $62 \%$ & $93 \%$ \\
\hline
\end{tabular}

\begin{tabular}{|c|c|c|}
\hline \multicolumn{3}{|c|}{$\begin{array}{l}\text { Metric 2: Average monthly page views of the ToolBase SIPs Technology Inventory home } \\
\text { page }\end{array}$} \\
\hline 2005 & 2006 & 2007 \\
\hline 3,704 & 4,370 & 5,731 \\
\hline
\end{tabular}




\begin{tabular}{|c|c|c|}
\hline \multicolumn{2}{|l|}{ Target Values: } \\
\hline $\mathbf{2 0 0 8}$ & $\mathbf{2 0 1 3}$ & $\mathbf{2 0 1 8}$ \\
\hline 6,600 & 11,700 & 16,800 \\
\hline $\begin{array}{l}\text { Projections of historical trends using linear regression were used to estimate targets and } \\
\text { rounded to the nearest } 100 .\end{array}$ \\
\hline
\end{tabular}

\begin{tabular}{|c|c|c|}
\hline \multicolumn{3}{|l|}{ Baseline Values: } \\
\hline 1998 & 2003 & 2007 \\
\hline NA & NA & Data requested \\
\hline \multicolumn{3}{|c|}{$\begin{array}{l}\text { The TechSpec for SIPs was added to ToolBase in } 2006 \text {. Baseline values prior to } 2006 \text { ar } \\
\text { not applicable. A baseline value for } 2007 \text { will be determined based on data from NAHBRC }\end{array}$} \\
\hline \multicolumn{3}{|c|}{ Target Values: } \\
\hline 2008 & 2013 & 2018 \\
\hline TBD & TBD & TBD \\
\hline
\end{tabular}

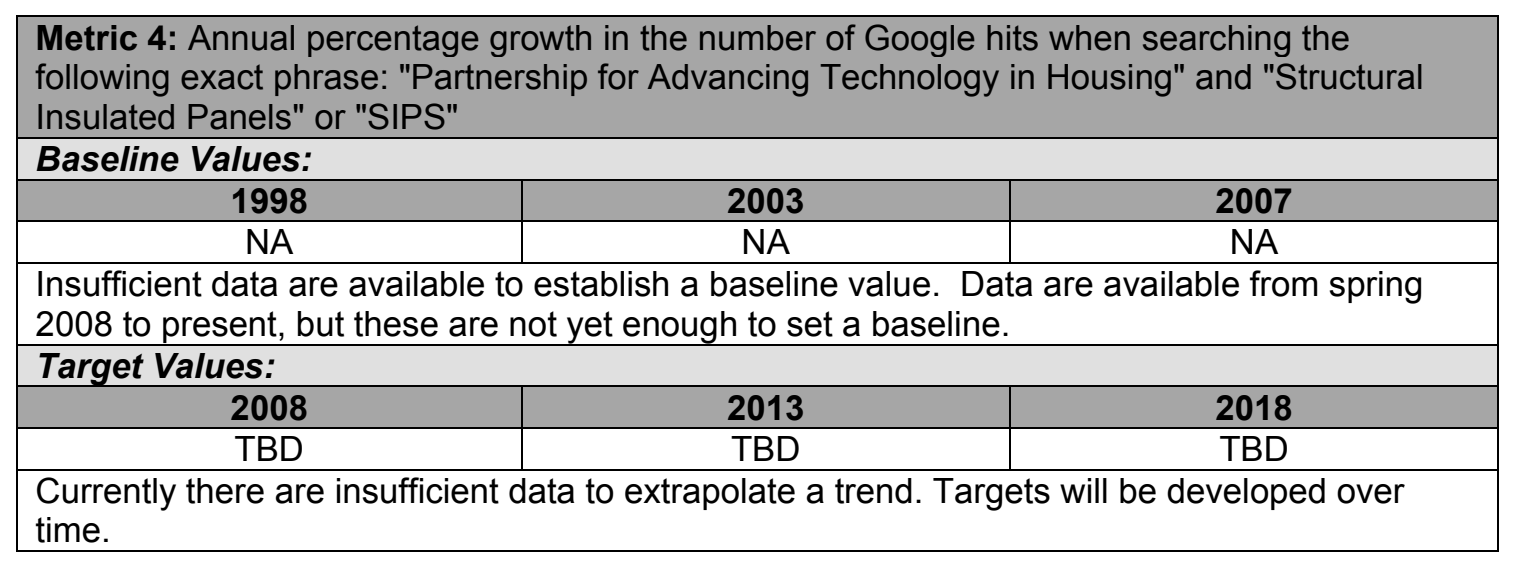

\begin{tabular}{|c|c|c|}
\hline \multicolumn{3}{|c|}{$\begin{array}{l}\text { Metric 5: Number of home builders offering SIPs (trend approximated by using SIPA home- } \\
\text { builder members) }\end{array}$} \\
\hline \multicolumn{3}{|c|}{ Baseline Values: } \\
\hline 1998 & 2003 & 2007 \\
\hline NA & TBD & TBD \\
\hline \multicolumn{3}{|c|}{$\begin{array}{l}\text { The number of home builders offering SIPs was to be approximated by using trade } \\
\text { association (SIPA) membership numbers. However, after personal correspondence with a } \\
\text { SIPA representative, baseline values should be determined using an alternative method or } \\
\text { determined later. SIPA did not have a builder program in 1998, and from 2003-2007, SIPA's } \\
\text { Board of Directors voted for a significant dues increase across all membership categories. } \\
\text { This drastically affected membership numbers. Considering these external factors influencing } \\
\text { SIPA membership numbers, the method for determining the approximate number of home } \\
\text { builders offering SIPs will be reevaluated. }\end{array}$} \\
\hline \multicolumn{3}{|c|}{ Target Values: } \\
\hline 2008 & 2013 & 2018 \\
\hline TBD & TBD & TBD \\
\hline
\end{tabular}




\begin{tabular}{|c|c|c|}
\hline \multicolumn{3}{|c|}{$\begin{array}{l}\text { Metric 6: Percent of new homes in the United States using SIPs } \\
\text { Baseline Values: }\end{array}$} \\
\hline 2002 & 2003 & 2007 \\
\hline $0.63 \%$ & $0.56 \%$ & $0.69 \%$ \\
\hline \multicolumn{3}{|c|}{$\begin{array}{l}\text { This metric provides an estimate of market penetration, and approximates the range of } \\
\text { coverage of SIPs in new single-family homes. SIP home construction was compared to nev } \\
\text { housing units completed ( } 1 \text { unit single-family). }\end{array}$} \\
\hline \multicolumn{3}{|c|}{ Target Values: } \\
\hline 2008 & 2013 & 2018 \\
\hline $0.63 \%$ & $0.67 \%$ & $0.72 \%$ \\
\hline
\end{tabular}

\begin{tabular}{|c|c|c|}
\hline \multicolumn{3}{|c|}{$\begin{array}{l}\text { Metric 7: SIPs annual production for residential use (in square feet) per million square feet of } \\
\text { all new residential (single-family) housing units in the United States per year }\end{array}$} \\
\hline \multicolumn{3}{|c|}{ Baseline Values: } \\
\hline 2001 & 2003 & 2007 \\
\hline 6,585 & 7,095 & 9,188 \\
\hline \multicolumn{3}{|c|}{$\begin{array}{l}\text { This metric gauges SIPs production compared to overall new home construction. SIP } \\
\text { production was compared to total square feet (calculated) of new single-family housing units } \\
\text { completed. }\end{array}$} \\
\hline \multicolumn{3}{|c|}{ Target Values: } \\
\hline 2008 & 2013 & 2018 \\
\hline 8,000 & 10,000 & 11,000 \\
\hline \multicolumn{3}{|c|}{$\begin{array}{l}\text { Projections of historical trends using linear regression were used to set the baseline values, } \\
\text { and additional years of "SIPs production (sq. ft.) per sq. ft. housing" data were used to } \\
\text { estimate targets. Targets were rounded to the nearest } 1,000 \text {. }\end{array}$} \\
\hline
\end{tabular}




\section{Advanced Steel Framing Program}

Phase 1 involves research and demonstration on the acceptability of steel framing material as an alternative to wood.

Phase 2 of the program works to develop a broader market for steel framing through published documents and information dissemination.

\section{Phase 1 Key Events}

Prior to 1997: PATH enters a cooperative agreement with the National Association of Home Builders (NAHB) and the American Iron and Steel Institute (AISI) to identify critical barriers impeding wider market uptake of steel framing.

1997: The "Prescriptive Method for Residential Cold-Formed Steel Framing" is published, and is based on three years of HUD-sponsored research that incorporates input from experts in the fields of construction, research, engineering, and building-code enforcement (HUD 1997a).

2002: PATH partners with the Steel Framing Alliance (SFA) (formerly, the North American Steel Framing Alliance) and funds the Manufactured Housing Research Alliance (MHRA) to produce the technical support document, "Design for a ColdFormed Steel Framed Manufactured Home" (PATH 2002). The document - developed in conjunction with trade associations, builders, testing laboratories, and manufacturers assesses the viability of substituting steel for wood as the structural skeleton of homes built under the HUD manufactured-home standards.

2002: Steel framing manufacturing methods are adopted by the International Code Council (ICC) into the International Residential Code of 2000 and 2003.

\section{Phase 2 Key Events}

2003: PATH partners with the SFA to examine and report on corrosion of galvanized fasteners used in cold-formed steel, and to produce "Hybrid Wood and Steel Details Builders Guide," a report that provides information for builders to construct hybrid coldformed steel and wood homes (PATH 2006c and PATH 2003b).

2003: The "Prescriptive Method for Connecting Cold-Formed Steel Framing to Insulating Concrete Form Walls in Residential Construction" is published to facilitate the construction of houses from insulating concrete forms and cold-formed steel, both of which are important PATH technologies (PATH 2003c).

\section{Steel Framing Baseline and Target Values}

\begin{tabular}{|c|c|c|}
\hline \multicolumn{3}{|c|}{$\begin{array}{l}\text { Metric 1: Percent of new homes in the United States that are built in a location that has } \\
\text { adopted the International Residential Code (IRC) or other building codes that include Steel } \\
\text { Framing }\end{array}$} \\
\hline \multicolumn{3}{|c|}{ Baseline Values: } \\
\hline 1998 & 2003 & 2007 \\
\hline $0 \%$ & $50 \%$ & $77 \%$ \\
\hline
\end{tabular}


Steel Framing was adopted into IRC 2000 and IRC 2003 codes in 2002. The baseline value for 1998 is assumed to be zero.

Target Values:

\begin{tabular}{|c|c|c|}
\hline 2008 & 2013 & $\mathbf{2 0 1 8}$ \\
\hline $83 \%$ & $100 \%$ & $100 \%$ \\
\hline \multicolumn{2}{|l|}{ Projections of historical data were used to estimate targets. } \\
\hline
\end{tabular}

\begin{tabular}{|c|c|c|}
\hline \multicolumn{3}{|l|}{ Baseline Values: } \\
\hline 1998 & 2005 & 2006 \\
\hline NA & 3,879 & 5,223 \\
\hline \multicolumn{3}{|c|}{$\begin{array}{l}\text { NAHB provided data for Steel Framing Techlnventory dating back to } 2005 \text {. In } 1998 \text {, it is } \\
\text { assumed that a Steel Framing page did not exist on ToolBase. }\end{array}$} \\
\hline \multicolumn{3}{|l|}{ Target Values: } \\
\hline 2008 & 2013 & 2018 \\
\hline 7,900 & 14,600 & 21,400 \\
\hline
\end{tabular}

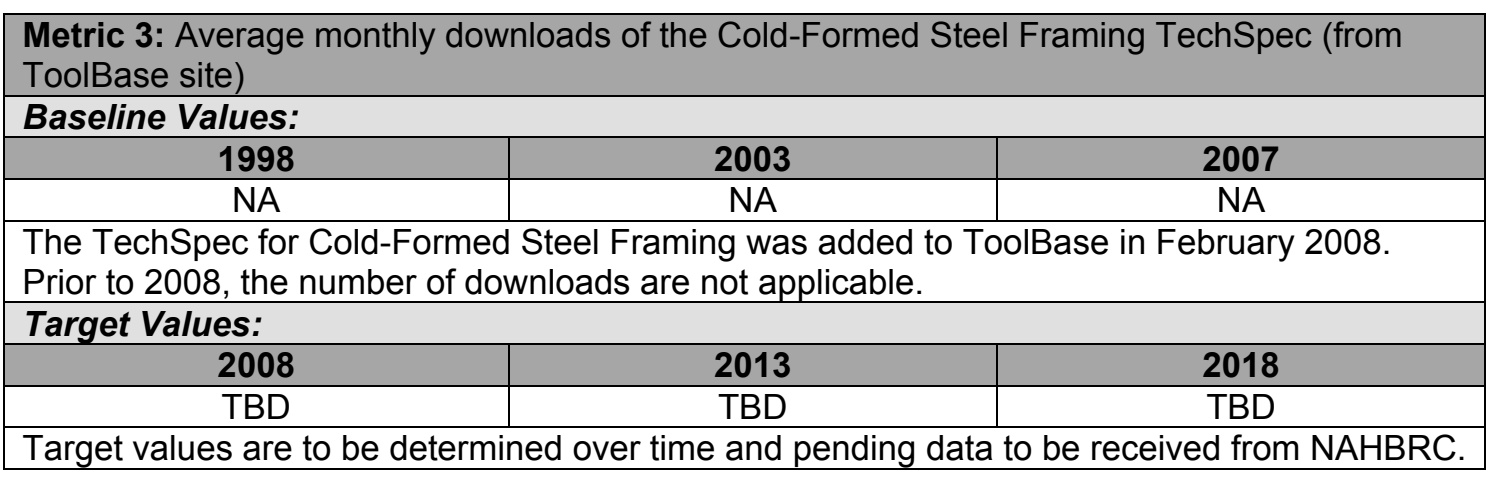

\begin{tabular}{|c|c|c|}
\hline $\begin{array}{l}\text { Metric 4: Annual p } \\
\text { following exact phr } \\
\text { Framing" }\end{array}$ & umber & $\begin{array}{l}\text { rching the } \\
\text { and "Steel }\end{array}$ \\
\hline Baseline Values: & & \\
\hline 1998 & 2003 & 2007 \\
\hline NA & NA & NA \\
\hline $\begin{array}{l}\text { Insufficient data ar } \\
2008 \text { to present, b }\end{array}$ & $\begin{array}{l}\text { baselir } \\
\text { hh to se }\end{array}$ & ole from sp \\
\hline Target Values: & & \\
\hline 2008 & 2013 & 2018 \\
\hline TBD & TBD & TBD \\
\hline
\end{tabular}

\begin{tabular}{|c|c|c|}
\hline \multicolumn{3}{|l|}{ Baseline Values: } \\
\hline 1998 & 2001 & 2005 \\
\hline 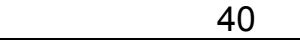 & 62 & 54 \\
\hline
\end{tabular}


Steel Framing production was compared to total square feet (calculated) of new single-family housing units completed.

Target Values:

\begin{tabular}{|c|c|c|}
\hline 2008 & 2013 & 2018 \\
\hline 71 & 85 & 99 \\
\hline \multicolumn{2}{|l|}{ Projections of historical data were used to estimate targets. } \\
\hline
\end{tabular}

\begin{tabular}{|c|c|c|}
\hline \multicolumn{3}{|l|}{ Baseline Values: } \\
\hline 1998 & 2003 & 2007 \\
\hline 37 & 62 & 81 \\
\hline \multicolumn{3}{|c|}{$\begin{array}{l}\text { Estimates of SFA membership values in conjunction with trends in historical steel framing } \\
\text { production were used as a proxy for the total number of home builders offering steel framing }\end{array}$} \\
\hline \multicolumn{3}{|c|}{ Target Values: } \\
\hline 2008 & 2013 & 2018 \\
\hline 86 & 110 & 135 \\
\hline
\end{tabular}

\begin{tabular}{|c|c|c|}
\hline \multicolumn{3}{|c|}{ Baseline Values: } \\
\hline 1998 & 2001 & 2007 \\
\hline $1.0 \%$ & $1.5 \%$ & $2.1 \%$ \\
\hline \multicolumn{3}{|c|}{$\begin{array}{l}\text { This metric provides an estimate of market penetration of steel framing in new homes. Steel } \\
\text { framing home construction was compared to total new housing units completed ( } 1 \text { unit single- } \\
\text { family). Limited data were obtained to extrapolate a trend in "percent of new homes in the } \\
\text { United States using steel framing." These data were augmented with trends in historical steel } \\
\text { framing production. }\end{array}$} \\
\hline \multicolumn{3}{|c|}{ Target Values: } \\
\hline 2008 & 2013 & 2018 \\
\hline $2.3 \%$ & $2.9 \%$ & $3.5 \%$ \\
\hline
\end{tabular}




\section{Insulating Concrete Forms Program}

\section{Key Events}

1998: PATH collaborates with the NAHB Research Center and the Portland Cement Association (PCA) to identify critical barriers impeding greater market penetration of insulating concrete forms.

May 1998: The "Prescriptive Method for Insulating Concrete Forms in Residential Construction" is first published. It establishes performance standards for ICFs and shares technical information about the technology (PATH 1998).

2000: The Prescriptive Method is accepted in 2000 by the International Code Council (ICC) for adoption into the International Residential Code (IRC).

Early 2002: A TechInventory page on Insulated Concrete Forms is added to the ToolBase site.

\section{Baseline and Target Values}

\begin{tabular}{|c|c|c|}
\hline \multicolumn{3}{|c|}{$\begin{array}{l}\text { Metric 1: Percent of new homes in the United States that are built in a location that has } \\
\text { adopted the International Residential Code (IRC) or other building codes that include ICFs }\end{array}$} \\
\hline \multicolumn{3}{|c|}{ Baseline Values: } \\
\hline 1998 & 2003 & 2007 \\
\hline $0 \%$ & $50 \%$ & $77 \%$ \\
\hline \multicolumn{3}{|c|}{$\begin{array}{l}\text { ICFs were adopted into the IRC in } 2000 \text {. Baseline values prior to } 2000 \text { are assumed to be } \\
\text { zero. }\end{array}$} \\
\hline \multicolumn{3}{|c|}{ Target Values: } \\
\hline 2008 & 2013 & 2018 \\
\hline $83 \%$ & $100 \%$ & $100 \%$ \\
\hline
\end{tabular}

\begin{tabular}{|c|c|c|}
\hline \multicolumn{3}{|l|}{ Baseline Values: } \\
\hline 2005 & 2006 & 2007 \\
\hline 3,425 & 3,700 & 4,812 \\
\hline \multicolumn{3}{|c|}{$\begin{array}{l}\text { ICFs were added to the ToolBase Techlnventory in January 2002; page views data provide } \\
\text { by NAHB Research Center. }\end{array}$} \\
\hline \multicolumn{3}{|c|}{ Target Values: } \\
\hline 2008 & 2013 & 2018 \\
\hline 4,400 & 5,800 & 7,100 \\
\hline
\end{tabular}




\begin{tabular}{|c|c|c|}
\hline \multicolumn{3}{|c|}{$\begin{array}{l}\text { Metric 3: Annual percentage growth in the number of Google hits when searching the } \\
\text { following exact phrase: "Partnership for Advancing Technology in Housing" and "Insulating } \\
\text { Concrete Forms" or "ICFs" }\end{array}$} \\
\hline \multicolumn{3}{|c|}{ Baseline Values: } \\
\hline 1998 & 2003 & 2007 \\
\hline NA & NA & NA \\
\hline \multicolumn{3}{|c|}{$\begin{array}{l}\text { Insufficient data are available to establish a baseline value. Data are available from spring } \\
2008 \text { to present, but these are not yet enough to set a baseline. }\end{array}$} \\
\hline \multicolumn{3}{|c|}{ Target Values: } \\
\hline 2008 & 2013 & 2018 \\
\hline TBD & TBD & TBD \\
\hline
\end{tabular}

\begin{tabular}{|c|c|c|}
\hline \multicolumn{3}{|c|}{$\begin{array}{l}\text { Metric 4: ICFs annual production for residential use (in square feet) per million square feet of } \\
\text { all new residential-housing units in the United States per year }\end{array}$} \\
\hline \multicolumn{3}{|c|}{ Baseline Values: } \\
\hline 1998 & 2003 & 2005 \\
\hline 6,908 & 10,890 & 10,448 \\
\hline \multicolumn{3}{|c|}{$\begin{array}{l}\text { This metric measures ICFs production compared to overall new home construction. ICFs } \\
\text { production was compared to total square feet (calculated) of new single-family housing units } \\
\text { completed. }\end{array}$} \\
\hline \multicolumn{3}{|c|}{ Target Values: } \\
\hline 2008 & 2013 & 2018 \\
\hline 14,000 & 18,000 & 22,000 \\
\hline
\end{tabular}

\begin{tabular}{|c|c|c|}
\hline \multicolumn{3}{|c|}{ Baseline Values: } \\
\hline 1998 & 2003 & 2007 \\
\hline 82 & 147 & 199 \\
\hline \multicolumn{3}{|c|}{$\begin{array}{l}\text { Current estimates of ICFA membership in conjunction with trends in the number of square } \\
\text { feet of ICF wall forms shipped were used as a proxy for the number of home builders offering } \\
\text { ICFs. }\end{array}$} \\
\hline \multicolumn{3}{|c|}{ Target Values: } \\
\hline 2008 & 2013 & 2018 \\
\hline 212 & 277 & 342 \\
\hline
\end{tabular}

\begin{tabular}{|c|c|c|}
\hline \multicolumn{3}{|c|}{$\begin{array}{l}\text { Metric 6: Percent of new homes in the United States using ICFs } \\
\text { Baseline Values: }\end{array}$} \\
\hline 1998 & 2003 & 2007 \\
\hline $1.0 \%$ & $4.0 \%$ & $7.4 \%$ \\
\hline \multicolumn{3}{|c|}{$\begin{array}{l}\text { This metric provides an estimate of market penetration and it approximates the range of } \\
\text { coverage of ICFs in new single-family homes. ICF home construction was compared to nen } \\
\text { housing units completed ( } 1 \text { unit single-family). }\end{array}$} \\
\hline \multicolumn{3}{|c|}{ Target Values: } \\
\hline 2008 & 2013 & 2018 \\
\hline $7.8 \%$ & $10.9 \%$ & $14.0 \%$ \\
\hline
\end{tabular}




\section{Guidelines for Developing Metrics, Data Collection, Analysis and Reporting for PATH Subprograms}

The PATH program is undergoing a process of developing and implementing a new set of program metrics. This report discusses the development of high-level metrics that respond to PATH's new mission, goals, and activities, and metrics for individual subprograms. Recommended metrics for five subprograms have been developed, along with data-collection methodologies, baselines, and targets recommendations. PATH may want to conduct similar evaluations for its remaining subprograms. This chapter outlines a general approach and guidelines for developing metrics, collecting data, and analyzing the data to produce baselines and targets.

\section{Developing Metrics}

PATH's development of recommended metrics for its subprograms is based on a welldocumented and widely used approach. This approach follows three basic steps:

1. Develop a logic model for the subprogram

2. Identify potential metrics for the outputs and outcomes in the logic model

3. Recommend metrics for program evaluation

Step 1: Develop a simple logic model of the program activities, outputs, and outcomes. A logic model is a graphical depiction showing how program activities lead to intended outcomes (Figure 6). Developing a logic model is an essential first step because it describes the subprogram's design. In-depth knowledge of the subprogram activities and goals is critical for developing the logic models.

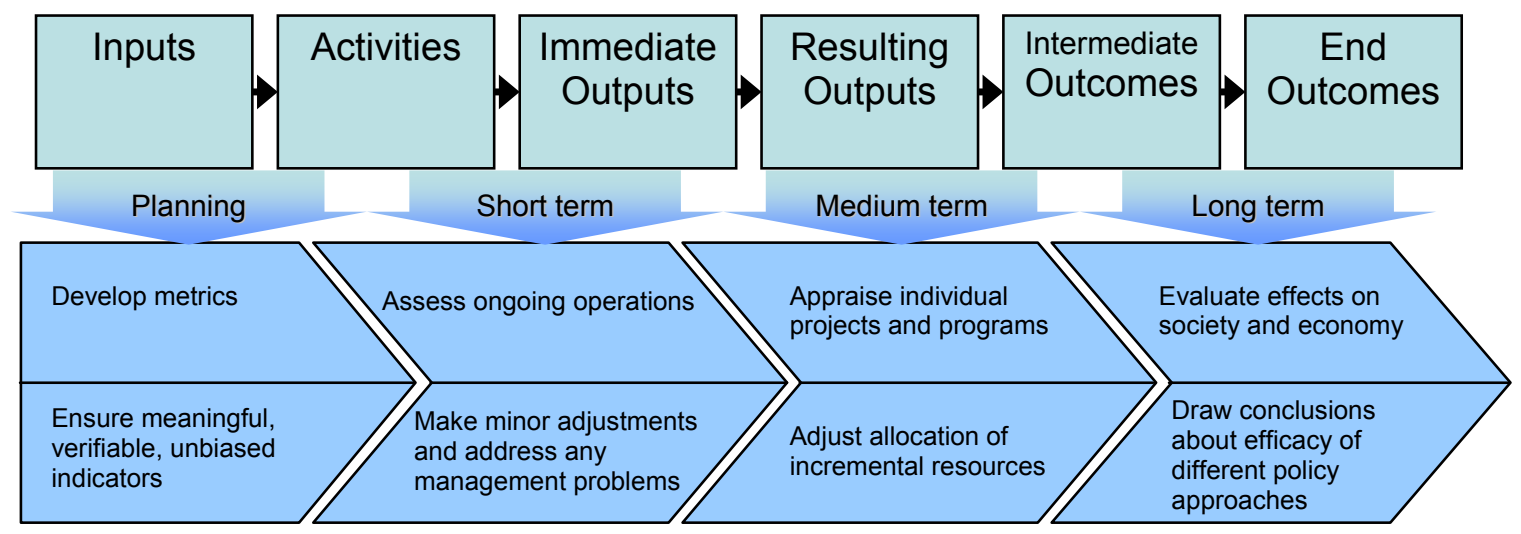

Figure 6. Logic Model Diagram

The logic model translates the program activities and revised goals into a diagram that illustrates how these function collectively while being measurable individually. A vital attribute for any metric is that it shows a clear relationship to the desired goals and objectives, and a logic model provides the conceptual foundation for understanding this relationship. Potential metrics for the PATH program overall have 
already been identified, but the process of developing metrics for individual subprograms within PATH would significantly benefit from such a model.

Step 2: Identify potential metrics based on the logic model. The components of the logic model (outputs and outcomes for each activity) are then used as a framework to identify potential metrics. Potential metrics should cover the breadth of activities, ensuring that every major element of the subprogram is represented. Identifying potential metrics based on the model ensures that the metrics are appropriately matched with the goals and structure of the program. Mapping potential metrics that are aligned with PATH subprogram goals and objectives means that the set of metrics are more likely to cover both the means (activities) and the ends (outcomes), and track the movement of technologies through the innovation cycle.

Step 3: Decide on recommended metrics. This step involves narrowing the list of potential metrics into a set of recommended metrics that measure the subprogram's progress. The set of recommended metrics should be considered for informing a broader assessment of PATH. The process for determining metrics that best represent the progress of the program as well as its specific activities aimed at advancing housing technology and achieving its overall goals is presented in Chapter 2. The framework involves applying a scoring system to the potential metrics based on several key characteristics. These characteristics are used as criteria for scoring potential metrics to refine the set into recommended metrics, and include: understandable, attributable, feasible, and comparable over time. These characteristics and the scoring system are explained in greater detail in Chapter 2.

Determining appropriate metrics also involves applying expert judgment to check that the objective scoring technique generates a set of metrics that are representative of the breadth of PATH activities and includes measures of activities, outputs, and outcomes. If necessary, the set of recommended metrics should be adjusted or rebalanced so that the various criteria required for the evaluation of a multifaceted program such as PATH are met.

\section{Data Collection}

Depending on the individual characteristics of each metric, a data collection plan may need to be developed separately for each metric. For instance, a comprehensive set of metrics will include measurements on a wide range of activities such as Web site hits, promotional activities, market penetration, and others. As such, it is difficult to develop a generalized guidance procedure for data collection applicable to all of PATH's subprograms. Nonetheless, there is at least minimal overlap between data sources and collection methodologies among subprograms. The types of sources and specific examples are provided as follows: 


\section{D\&R International}

D\&R International, PATH's marketing consultant, provides quantitative data on the attendance and frequency of promotional events as well as data on information distribution. D\&R also supplies information on the number of publications and other articles created, and they track the estimated audience reached by such materials.

\section{NAHB Research Center}

The National Association of Home Builders (NAHB) Research Center compiles statistics on Web site use of ToolBase, including number of unique visitors, page views, document downloads, and several others.

\section{Trade Associations}

Trade associations and advocacy organizations can be an excellent source of relevant and timely data. Obtaining data from these organizations can involve time-consuming efforts to connect with the appropriate personnel, but can often result in a wealth of directly relevant and detailed information. Specific examples of trade associations that have been useful for data collection efforts to date include:

\section{Insulating Concrete Form Association (ICFA)}

Insulating Concrete Form Association (ICFA) (http://www.forms.org/) is an organization "dedicated to expanding the use of insulating concrete forms through research, education, promotion, and public affairs work". ICFA provides industry data, such as annual shipment reports showing production trends. ICFA membership lists provide useful proxy data indicating the number of system manufacturers, distributors, contractors, suppliers, etc.

\section{Steel Framing Alliance (SFA)}

The Steel Framing Alliance is a trade association that encourages the widespread use of cold-formed steel framing in residential construction. SFA provides data on steel framing manufacturing, such as number of shipments to the residential industry and market trends data for both single-family site-built and multi-family site-built homes including tons of light-gauge steel framing used and units built. SFA membership lists offer useful data about the number of steel framing residential builders, suppliers/distributors, architects, and related manufacturers such as stud, truss, and component fabricators.

\section{Structural Insulated Panel Association (SIPA)}

The mission of the Structural Insulated Panel Association is to "increase the use and acceptance of SIPs through a strong trade association that provides an industry forum for promotion, communication, education, research, and quality assurance." SIPA provides SIPs production data and data about the number of housing units supplied with SIPs from member companies.

\section{Portland Cement Association (PCA)}

The Portland Cement Association (http://www.cement.org/) is an organization that represents cement companies in the United States and Canada and conducts market 
development, engineering, research, education, and public affairs programs. PCA offers relevant articles about ICFs and a list of known producers.

\section{Census Bureau}

The U.S. Census Bureau publishes a wide range of reliable information about housing in the United States. For example, the Census Bureau reports total square footage of new residential units built per year, a useful data point to normalize fluctuations in implementation of housing technologies due to changes in the U.S. housing market.

\section{Building Code Organizations}

The International Code Council (http://www.iccsafe.org/) lists states and jurisdictions adopting the most widely accepted building codes.

Detailed data-collection methodologies tailored for each metric and subprogram can be found in the Excel worksheets accompanying the "Baseline and Target Memo, Sept 2008."

\section{Analysis and Reporting}

The full set of recommended metrics measure both the means (activities and outputs) and the ends (outcomes) of the program, provide meaningful baselines and target values to gauge future progress, and inform a process for long-term assessment and program improvement.

The difficultly in measuring and analyzing outcomes of research programs, particularly those with a public/private component, has been well-documented in previous reports (e.g., NRC 2003). In the analysis of PATH subprograms, one technique to overcome these difficulties includes emphasizing "intermediate outcomes," as suggested by the section of the 2007 OMB PART guidance titled Categories of Performance Measures. The guidance proposes the use of proxies when such difficulties arise. Proxies were used for several metrics in the evaluation of PATH's five subprograms. The PART guidance offers the following description:

Programs that cannot define a quantifiable outcome measure - such as programs that focus on process-oriented activities (e.g., data collection, administrative duties, or survey work) - may adopt a "proxy" outcome measure. Identification of intermediate steps brings into the PART process an important family of existing results that may lend themselves to qualitative and sometimes quantitative assessment, which can provide useful new data points for reviewers. The terms in which those steps are described depend on the agency, its mission, and the nature and scope of its work.

An important consideration when analyzing metrics involves differentiating between increases in technology adoption as a result of PATH program activities and increases in technology implementation due to external factors. It is particularly challenging for public/private partnerships such as PATH where cooperative activities include both HUD-sponsored elements and private-sector elements. The partnership structure creates 
challenges but does not preclude the use of meaningful outcome metrics that incorporate components of PATH as well as components of external activities from providing useful input toward a comprehensive program evaluation. It is also important that data be considered in the context of the U.S. home-building industry at the time of the measurement. Measured values may fluctuate with changes in demand in the housing market. Such complicating factors should be considered when selecting, analyzing, and reporting metrics.

Another key issue to consider during metrics analysis is the program funding level over time. This is particularly relevant when setting targets for future performance. Budget decisions can have a profound impact on short-, mid-, and long-term performance targets. For example, the scope of the ToolBase program changed significantly in July 2007 when one of the two funding vehicles expired. The program previously had been actively involved with developing new content, promotions, and other enhancements. Following the expiration of one of the funding vehicles, the program switched to a maintenance mode that focuses on ensuring the current site is functioning properly but is not actively promoting the site or adding significant new content. As a result of this change, the recommended metrics covered both the historical period (pre-July 2007) and the current maintenance period. Analysis of the metrics data should consider the changing scope of the program.

The task of analyzing research and public/private partnership programs such as PATH consists of assessing multiple factors and can be complex. The guidance outlined in this memo and detailed in accompanying reports, spreadsheets, and metrics memos offers structured processes that require in-depth knowledge of the program activities, logic models covering outputs and outcomes, an objective metrics-scoring system tailored to program goals, and expert judgment in final selections of metrics and analysis of the metrics. It is important to keep in mind that each PATH subprogram may require a unique approach that may differ from the general guidance outlined here. The individual subprograms should ultimately feed into an overall evaluation of PATH's progress toward achieving its goals. 


\section{Conclusions}

The development of metrics, baselines, and targets for individual PATH programs provides an important step toward generating a long-term comprehensive evaluation of the overall PATH program. Further evaluation and testing will enable the development of an agreed-upon set of metrics and specific numeric targets for PATH as a whole. The recommended metrics presented in this report can be implemented to help measure the progress and impact of the PATH program in the coming years, and contribute to a continuing program assessment.

Recommended metrics for selected programs provide PATH the ability to evaluate program activities and address progress toward achieving its overall goals. These metrics from individual programs can be combined and used to inform higher-level metrics such as those presented in Section 2 of this report - for external program review. Individual program performance measures also can be useful for internal and ongoing management-improvement efforts.

PATH's efforts to refocus its original goals regarding the promotion and development of new technologies and the diffusion of such technologies are evidenced by the intended outcomes of the individual program activities examined in this study. The new program goals align with its overarching mission to advance technology that improves housing performance regarding affordability, durability, sustainability, and safety. This involves encouraging innovation, information dissemination for diffusion of technology, and administering public-private partnerships - all of which are conducted through numerous individual program activities.

The measurement techniques for individual programs presented in this study are intended to allow an evaluation of how well the activities each program undertakes are contributing to outputs and outcomes that help achieve its goals. The recommended metrics (and corresponding baseline and targets) focus on quantity and quality of the results of these activities, and, as much as possible, measure improvements in housing industry innovation that are attributable to PATH.

The limited availability of data that measures the influence of program activities on decision making in the housing industry presents obstacles for program evaluation. Many of the recommended metrics focus on program outputs (e.g., the number of products or Web page hits) rather than directly measuring outcomes (e.g., market penetration of specific PATH technologies) because data for outputs are more readily available. Outcomes metrics are particularly important for gauging how well a program's activities align with high-level PATH goals, but are difficult to obtain. In such instances, proxies are often the best or only option for identifying particular baselines or targets and have been widely used in the recommended metrics.

Attribution also remains a key challenge in measuring program performance. While metrics can demonstrate improvements in the number of participating partners, the frequency of visitors to specific Web pages, or the number of builders in affiliated trade 
groups, determining the influence from PATH involves estimation and professional judgment. Identifying market impacts that are the result of PATH activities (as opposed to impacts that are due to external factors) is particularly difficult for programs with significant public/private partnership involvement. Comprehensive data collection efforts would help improve program attribution. Specifically, data on the rate of diffusion of new housing technologies would enable PATH to better understand the conditions in the marketplace and observe the impacts of the program activities. Such data could be collected through surveys or other sources as part of a continuous, comprehensive program assessment.

Successful long-term PATH program evaluation will benefit from refining and selecting metrics and appropriate targets, expanding data-collection capabilities, and improving attribution of PATH efforts to advancing innovation in housing technology. 


\section{References}

Cohn, M. (ed.) (2006). "Proceedings of a Workshop to Review PATH Strategy, Operating Plan and Performance Measures." Washington, D.C., National Academies Press. Available: http://www.nap.edu/catalog/11661.html

Hassell, S., A. Wong, A. Houser, D. Knopman, and M. Bernstein. (2003). "Building Better Homes: Government Strategies for Promoting Innovation in Housing." Prepared for HUD-PATH by the RAND Science and Technology Policy Institute. Washington, D.C., RAND Corporation.

Housing and Urban Development (HUD). (2003). "Steel Framing Prototype Development: Final Report," December 2003. Available at http://www.huduser.org/Publications/pdf/SteelReport.pdf.

HUD. (2002). Prescriptive Method for Insulating Concrete Forms in Residential Construction, Second Edition," January 2002. Available at http://www.huduser.org/Publications/PDF/icf_2ed.pdf.

HUD. (1997a) "Prescriptive Method for Residential Cold-Formed Steel Framing," November 1997. Accessed 2008 at http://www.huduser.org/publications/destech/pm2.html

HUD. (1997b). "Commentary on the Prescriptive Method for Residential Cold-Formed Steel Framing, Second Edition," November 1997. Accessed 2008 at http://www.huduser.org/publications/destech/commento.html

Martin, C. (2005). "PATH: Program Review \& Strategy, Performance Metrics, \& Operating Plan.” Available in appendices in Cohn 2006.

Martin, C. (2003). "ToolBase Summary.”

McGee, S. (2008). “A History of the ToolBase Portal.” May 2008.

National Renewable Energy Laboratory (NREL). (2008). "Conceptual Soundness and Metric Selection Indicators for the PATH Program," rev April 2008.

National Research Council (NRC). (2008). "Evaluating Research Efficiency." Washington, D.C. The National Academies Press, 2008.

NRC. (2003). "Promoting Innovation: 2002 Assessment of the Partnership for Advancing Technology in Housing. Washington, DC: The National Academies Press. 2003.

National Association of Home Builders (NAHB). (2008) "ToolBase.org: Overview of Past Performance and Future Enhancements." NAHB Research Center, April 22, 2008. 
NAHB. (2007). "SIPs Code Change Lowers Hurdles on the Job Site.” Oct. 8, 2007.

NAHB. (2003). "Steel Framing Prototype Development: Final Report,” December 2003. Available at http://www.toolbase.org/Construction-Methods/ManufacturedHousing/steel-framing-prototype.

NAHB. (2002). "ICFs experience growth in residential market," Walls and Ceilings magazine, December 2002. Accessed 2008 at http://findarticles.com/p/articles/mi_hb5593/is_/ai_n23570727.

Office of Management and Budget (OMB). (2007). "Guide to the Program Assessment Rating Tool (PART).” January 2007

Partnership for Advancing Technology in Housing (PATH). (2007). "PATH Convenes Experts and Innovators to Design Concept Home Charleston," October 26, 2007. Accessed 2008 at http://www.pathnet.org/sp.asp?id=24490.

PATH. (2006a). "Prescriptive Method for Structural Insulated Panels (SIPs) Used In Wall Systems In Residential Construction," June 2006. Accessed 2008 at http://www.pathnet.org/sp.asp?id=19134.

PATH. (2006b). "SIPA and PATH Release Prescriptive Method for Building with Structural Insulated Panels," July 2006. Accessed 2008 at http://www.pathnet.org/sp.asp?id=19133.

PATH. (2006c). "Steel Framing Technology Development and the Steel Framing Alliance," November 2006. Accessed 2008 at http://www.pathnet.org/sp.asp?id=1381.

PATH. (2006d). "HUD Selects Builder and Site for Concept Home Demonstration Project." January 2006. Accessed 2008 at $<$ http://www.pathnet.org/sp.asp?id=17403

PATH. (2004). "PATH Unveils Home of the Future," June 25, 2004. Accessed 2008 at http://www.pathnet.org/sp.asp?id=12066

PATH.. (2003a). "PATH/ToolBase Expands Services for Builders/Remodelers." Accessed 2008 at http://www.pathnet.org/sp.asp?id=1606.

PATH. (2003b). "Hybrid Wood and Steel Details - Builder's Guide.” July 2003. Available at http://www.pathnet.org/sp.asp?id=10230.

PATH. (2003c). "Prescriptive Method for Connecting Cold-Formed Steel Framing to Insulating Concrete Form Walls in Residential Construction.” February 2003. Available at http://www.pathnet.org/sp.asp?id=9092. 
PATH. (2002). "Design for a Cold-Formed Steel Framed Manufactured Home: Technical Support Document," March 2002. Accessed 2008 at http://www.pathnet.org/sp.asp?id=9089.

PATH. (2000). “Strategy and Operating Plan.” Washington, D.C., PATH Program.

PATH (1999). "PATH Teams Up With NAHB Research Center's ToolBase SERVICES . . Awards \$500,000 to Expand Information Services for Builders, Remodelers." Accessed 2008 at http://www.pathnet.org/sp.asp?id=1626.

PATH. (1998). "Prescriptive Method for Insulating Concrete Forms in Residential Construction," May 1998. Available at <http://www.pathnet.org/si.asp?id=440>.

PATH and NAHB. (2008). Personal correspondence with PATH and NAHB Research Center, May 2008.

Portland Cement Association (PCA). (2008). "Insulating Concrete Forms.” Accessed 2008 at http://www.cement.org/homes/ch_bs_icf.asp.

Rogers, E.M. (2003). "Diffusion of Innovations.” New York: Free Press.

Steel Framing Alliance (SFA). (2007). "Framework: Your Gateway to the Steel Framing Industry.” January-Febreuary 2007. Available at http://www.steelframing.org/PDF/framework/0107framework.pdf

SFA. (2003). "Framework: Your Gateway to the Steel Framing Industry." January-March 2003. Available at http://www.steelframing.org/PDF/framework/FameworkJanuary-March-03.pdf.

Structural Insulated Panels Association (SIPA). (2007). "Structural Insulated Panels Adopted into the International Residential Code," May 23, 2007. Accessed 2008 at http://www.sips.org/content/news/index.cfm?PageId=191 


\section{Appendix A. Metrics for Goals}

Individual program metrics align with PATH's revised goals and objectives, as shown in Table A1. Note, however, that the individual program metrics were developed to provide insight into how well an individual program was performing and progressing toward meeting its goals. While individual program goals contribute to addressing PATH's overall goals shown in this table, not every program is intended to directly address a broad range of PATH goals and objectives. Checks were placed in boxes for metrics that most closely align with the overall PATH goals and objectives. Several of the overall goals and objectives are interrelated and metrics are likely to address some of those that are not checked, albeit to a lesser extent. Individual program metrics for these five subprograms and additional programs evaluated in the future may be combined and used to develop higher-level PATH metrics, which may address a wider range of goals and objectives than are checked here. 


\section{Table A1. Objectives Addressed by Metrics}

\begin{tabular}{|c|c|c|c|c|c|c|c|c|c|}
\hline & \multicolumn{3}{|c|}{$\begin{array}{l}\text { Goal 1: Remove barriers and } \\
\text { facilitate technology development } \\
\text { and adoption }\end{array}$} & \multicolumn{3}{|c|}{$\begin{array}{l}\text { Goal 2: Improve technology transfer, } \\
\text { development, and adoption through } \\
\text { information dissemination }\end{array}$} & \multicolumn{3}{|c|}{$\begin{array}{l}\text { Goal 3: Advance housing } \\
\text { technologies' research and foster } \\
\text { development of new technologies }\end{array}$} \\
\hline Objectives: & 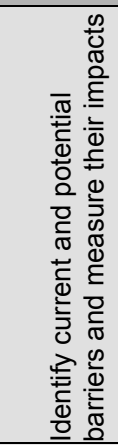 & 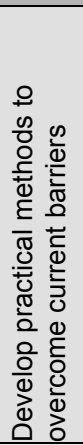 & 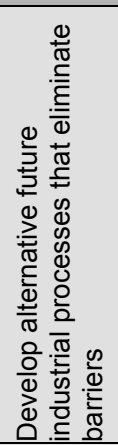 & 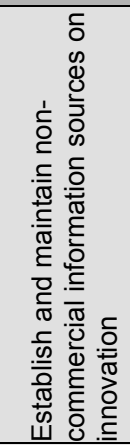 & 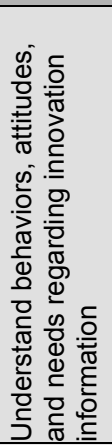 & 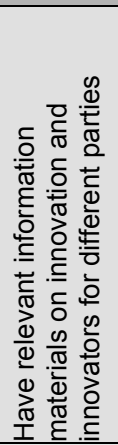 & 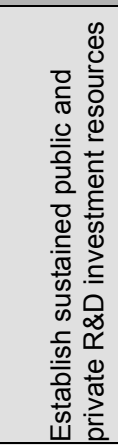 & 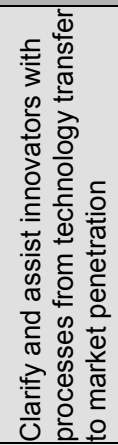 & 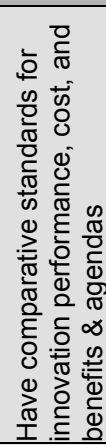 \\
\hline \multicolumn{10}{|l|}{ Concept Home } \\
\hline $\begin{array}{l}\text { Cumulative number of industry partners (such as } \\
\text { designers, builders, technology manufacturers) who } \\
\text { have participated in Concept Home since the inception } \\
\text { of the program }\end{array}$ & & & & & & $x$ & & $x$ & \\
\hline $\begin{array}{l}\text { Cumulative number of technologies that are promoted } \\
\text { by Concept Home and included in completed homes } \\
\text { since the inception of the Concept Home program }\end{array}$ & & & & $x$ & & $x$ & & $x$ & \\
\hline $\begin{array}{l}\text { Cumulative potential audience reached through mass } \\
\text { marketing and press releases (e.g., television } \\
\text { promotions, circulation of newspapers containing } \\
\text { articles about Concept Home) }\end{array}$ & & & & & & $x$ & & $X$ & \\
\hline $\begin{array}{l}\text { Cumulative audience reached via in-person information } \\
\text { events, such as Concept Home promotional events and } \\
\text { open houses }\end{array}$ & & & & & & $x$ & & $x$ & \\
\hline $\begin{array}{l}\text { Average monthly number of Web page hits that contain } \\
\text { information about Concept Home and its technologies } \\
\text { on PATH-sponsored Web sites (i.e., PATHnet, } \\
\text { ToolBase, HUDUser) }\end{array}$ & & & & $x$ & & $x$ & & & \\
\hline
\end{tabular}


Annual percentage growth in the number Google hits when searching the following exact phrase: "Partnership for Advancing Technology in Housing" "Concept Home"

Annual administrative costs as a percentage of total program expenses

Cumulative revenues of products/technologies that

were incorporated into Concept Home (real \$)

Percent of new homes in the U.S. using at least one of

the technologies showcased in the Concept Home

program

\section{ToolBase}

Cumulative number of technologies featured in the

Techlnventory.

Cumulative number of Field Evaluations completed with

results published on ToolBase.

Total number of Techlnventory and Field Evaluations

page views per total number of user visits/sessions in

each month.

Number of broken links in ToolBase.org

Total number of unique visitors to ToolBase.org per

month

Total number of ToolBase.org page views per month

Total number of Techlnventory page views per month

Total number of Field Evaluations page views per

month

Total number of visitors ('visitor sessions') accessing

ToolBase.org per square feet of all new residential-

housing units in the U.S. per month

Average number of page views per session

Average number of repeat visits per month

SIPs

Percent of new homes in the U.S. that are built in a

location that has adopted the International Residentia

Code (IRC) or other building codes that include SIPs

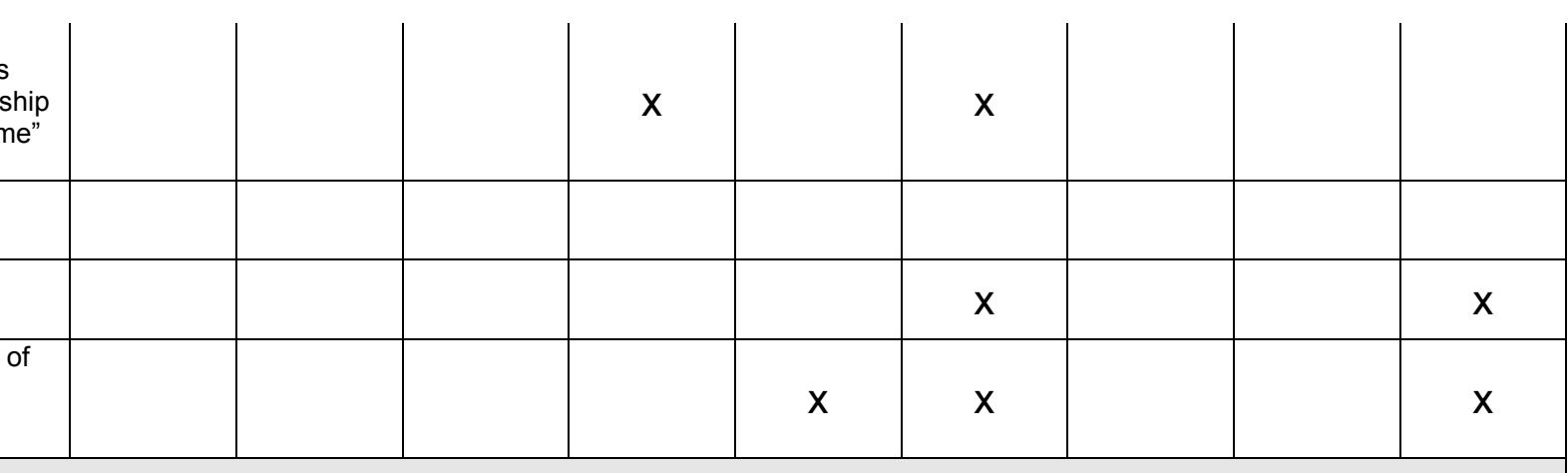

\begin{tabular}{|l|l|l|l|l|} 
& & & & \\
\hline
\end{tabular}

$\mathrm{X}$

\begin{tabular}{|l|l}
\hline & \\
\hline & \\
\hline
\end{tabular}

\begin{tabular}{|l|l|l|l}
\hline$x$ & & & \\
\hline$x$ & & $x$ & \\
\hline
\end{tabular}

\begin{tabular}{|l|l|l|l}
\hline & & & \\
& & & \\
\hline
\end{tabular}

$x$

\begin{tabular}{|l|l|l|l|} 
& & & $x$ \\
\hline & & & $x$ \\
\hline
\end{tabular}

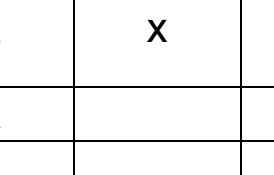

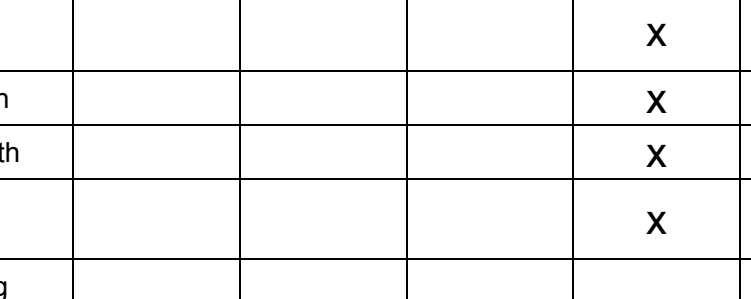

\begin{tabular}{l|l}
$x$ \\
$x$
\end{tabular}




\begin{tabular}{|c|c|c|c|c|c|c|c|}
\hline $\begin{array}{l}\text { Average monthly page views of the ToolBase SIPs } \\
\text { Technology Inventory homepage }\end{array}$ & & & $\mathrm{x}$ & & $\mathrm{X}$ & & \\
\hline $\begin{array}{l}\text { Average monthly downloads of the Structural Insulated } \\
\text { Panels TechSpec (from ToolBase.org site) }\end{array}$ & & & $\mathrm{x}$ & & $\mathrm{X}$ & & \\
\hline $\begin{array}{l}\text { Annual percentage growth in the number of Google hits } \\
\text { when searching the following exact phrase: "Partnership } \\
\text { for Advancing Technology in Housing" \& "Structural } \\
\text { Insulated Panels" OR "SIPS". }\end{array}$ & & & $\mathrm{X}$ & & $\mathrm{X}$ & & \\
\hline Number of home builders offering SIPs & & & & $\mathrm{X}$ & $\mathrm{X}$ & $\mathrm{x}$ & $\mathrm{X}$ \\
\hline Percent of new homes in the U.S. using SIPs & & & & $\mathrm{X}$ & $\mathrm{X}$ & & $\mathrm{X}$ \\
\hline $\begin{array}{l}\text { SIPs annual production for residential use (in square } \\
\text { feet) per million square feet of all new residential- } \\
\text { housing units in the U.S. per year }\end{array}$ & & & & $\mathrm{x}$ & $\mathrm{X}$ & & $\mathrm{x}$ \\
\hline $\begin{array}{l}\text { Number of states that have greater than } 0.5 \% \text { of new } \\
\text { residential-housing units built using SIPs }\end{array}$ & & & & & $\mathrm{X}$ & & $\mathrm{X}$ \\
\hline \multicolumn{8}{|l|}{ Steel Framing } \\
\hline $\begin{array}{l}\text { Percent of new homes in the U.S. that are built in a } \\
\text { location that has adopted the International Residential } \\
\text { Code (IRC) or other building codes that include Steel } \\
\text { Framing }\end{array}$ & $\mathrm{X}$ & $\mathrm{X}$ & & & & $\mathrm{x}$ & \\
\hline $\begin{array}{l}\text { Average monthly page views of the ToolBase Steel } \\
\text { Framing Technology Inventory homepage }\end{array}$ & & & $\mathrm{x}$ & & $\mathrm{X}$ & & \\
\hline $\begin{array}{l}\text { Average monthly downloads of the Cold-Formed Steel } \\
\text { Framing TechSpec (from ToolBase.org site) }\end{array}$ & & & $x$ & & $\mathrm{x}$ & & \\
\hline $\begin{array}{l}\text { Annual percentage growth in the number of Google hits } \\
\text { when searching the following exact phrase: "Partnership } \\
\text { for Advancing Technology in Housing" \& "Steel } \\
\text { Framing" }\end{array}$ & & & $\mathrm{x}$ & & $\mathrm{X}$ & & \\
\hline $\begin{array}{l}\text { Steel framing annual production for residential use (in } \\
\text { tons) per million square feet of all new residential- } \\
\text { housing units in the U.S. per year }\end{array}$ & & & & $\mathrm{x}$ & $\mathrm{X}$ & & $\mathrm{x}$ \\
\hline Number of home builders offering steel framing & & & & $\mathbf{X}$ & $\mathrm{x}$ & $x$ & $x$ \\
\hline Percent of new homes in the U.S. using steel framing & & & & $x$ & $x$ & $x$ & $x$ \\
\hline $\begin{array}{l}\text { Number of states that have greater than } 1.5 \% \text { of new } \\
\text { residential-housing units built using steel framing }\end{array}$ & & & & & $x$ & & $x$ \\
\hline
\end{tabular}




\begin{tabular}{|c|c|c|c|c|c|c|c|}
\hline \multicolumn{8}{|l|}{ ICFs } \\
\hline $\begin{array}{l}\text { Percent of new homes in the U.S. that are built in a } \\
\text { location that has adopted the International Residential } \\
\text { Code (IRC) or other building codes that include ICFs }\end{array}$ & $\mathrm{X}$ & $\mathrm{X}$ & & & & $\mathrm{X}$ & \\
\hline $\begin{array}{l}\text { Average monthly page views of the ToolBase ICFs } \\
\text { Technology Inventory homepage }\end{array}$ & & & $\mathrm{X}$ & & $\mathrm{X}$ & & \\
\hline $\begin{array}{l}\text { Annual percentage growth in the number of Google hits } \\
\text { when searching the following exact phrase: "Partnership } \\
\text { for Advancing Technology in Housing" \& "Insulating } \\
\text { Concrete Forms" OR "ICFs" }\end{array}$ & & & $\mathrm{X}$ & & $\mathrm{X}$ & & \\
\hline $\begin{array}{l}\text { ICFs annual production for residential use (in square } \\
\text { feet) per million square feet of all new residential- } \\
\text { housing units in the U.S. per year }\end{array}$ & & & & $\mathrm{X}$ & $\mathrm{X}$ & & $\mathrm{x}$ \\
\hline Number of home builders offering ICFs & & & & $\mathrm{X}$ & $\mathrm{X}$ & $\mathrm{X}$ & $x$ \\
\hline Percent of new homes in the U.S. using ICFs & & & & $\mathrm{X}$ & $\mathrm{X}$ & & $\mathrm{x}$ \\
\hline $\begin{array}{l}\text { Number of states that have greater than } 2.7 \% \text { of new } \\
\text { residential-housing units built using ICFs }\end{array}$ & & & & & $\mathrm{x}$ & & $\mathrm{X}$ \\
\hline
\end{tabular}




\section{Appendix B. Metrics Scoring for Key Characteristics}

The following tables present the results from applying the "key characteristics" scoring system described in Chapter 2 to the candidate metrics. The scores are used simply to guide the process of refining the candidate set of metrics into a recommended set. The scores provide important input for determining the set of recommended metrics but are not the sole determining factor. Balance across program areas and stages (e.g., activities, outputs, and outcomes) and judgment about measuring the program impacts that are considered essential also represent important criteria for metrics selection.

The scoring system considered four key characteristics (a detailed discussion is provided in Chapter 2), including:

Understandable. The metric should be easily understood by external stakeholders.

Attributable. It should be easy to determine PATH's contribution to the metric's value or result.

Feasible. Reliable data should be available in order to obtain the metric's value.

Comparable over time. The current value of the metric should be able to be directly compared to past and future metric values.

For each metric, and for each of the four characteristics, a score of 0,1 , or 2 is applied. A score of 2 indicates that the metric is highly desirable for a particular characteristic; 0 is undesirable. The four characteristic scores are summed for each metric. It is important to note that the scores are based on current knowledge of the PATH program by the report authors and reviewers. Scores for the candidate metrics should be interpreted as a filter that provides insight into the analysis of possible metrics, helping to create a set of recommended metrics for the program. Scores should not be viewed as a rigid prioritization, and the scores are not the sole indicators for selecting among the candidate metrics - they provide guidance for metrics selection.

After the candidate metrics are scored, the collective set of metrics is considered regarding its representation of the breadth of PATH activities, and intended outputs and outcomes. This final step adds expert judgment to the recommendation process and, if necessary, allows for the set of recommended metrics to be adjusted or rebalanced. It assures that the set of metrics cover the full range of PATH activities, outputs, and outcomes; and that the metrics address the most important intended impacts of the program. Due to this final step, the candidate metrics with the highest "key characteristics" scores do not necessarily become part of the set of recommended metrics. 
Table B1. Concept Home

\begin{tabular}{|c|c|c|c|c|c|c|c|c|c|c|c|c|}
\hline \multirow[b]{2}{*}{ Bin } & \multicolumn{5}{|c|}{$\begin{array}{l}\text { Activity Areas for Concept } \\
\text { Home: }\end{array}$} & \multirow[b]{2}{*}{$\begin{array}{c}\text { Metric } \\
\text { (Recommended metric \# in parentheses) }\end{array}$} & \multirow[b]{2}{*}{$\begin{array}{l}\text { Measures } \\
\text { Input, } \\
\text { Activity, } \\
\text { Output, or } \\
\text { Outcome }\end{array}$} & \multirow[b]{2}{*}{ Understandable } & \multirow[b]{2}{*}{ Attributable } & \multirow[b]{2}{*}{ Feasible } & \multirow[b]{2}{*}{$\begin{array}{l}\text { Comparable } \\
\text { over time }\end{array}$} & \multirow[b]{2}{*}{ Sum } \\
\hline & 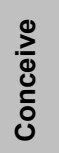 & $\frac{5}{\frac{5}{0}}$ & 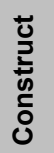 & 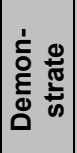 & 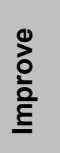 & & & & & & & \\
\hline \multirow{2}{*}{ 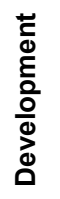 } & $x$ & & & & & Number of Core Concepts identified & Activity & 1 & 2 & 2 & 1 & 6 \\
\hline & $x$ & & & & & $\begin{array}{l}\text { Number of "principles" created to form the } \\
\text { foundation for incorporating innovative } \\
\text { technologies and systems }\end{array}$ & Output & 0 & 2 & 1 & 1 & 4 \\
\hline \multirow{2}{*}{ 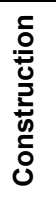 } & & & $x$ & & & $\begin{array}{l}\text { Number of man hours spent constructing the } \\
\text { Concept Home }\end{array}$ & Output & 2 & 0 & 1 & 2 & 5 \\
\hline & & & $x$ & & & $\begin{array}{l}\text { Frequency of testing and evaluation of the home } \\
\text { during all periods of construction }\end{array}$ & Output & 1 & 1 & 1 & 1 & 4 \\
\hline \multirow{4}{*}{ 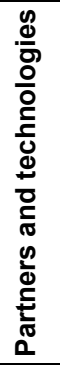 } & & $\mathbf{x}$ & $\mathbf{x}$ & & & Number of industry partners (\#1) & Activity & 2 & 1 & 2 & 2 & 7 \\
\hline & & $\mathbf{x}$ & $\mathbf{x}$ & $\mathbf{x}$ & & $\begin{array}{l}\text { Number of technologies included in and } \\
\text { promoted by the Concept Home (\#2) }\end{array}$ & Output & 2 & 1 & 2 & 2 & 7 \\
\hline & & $x$ & $x$ & & & Number of technology sponsors & Activity & 2 & 1 & 2 & 2 & 7 \\
\hline & & $x$ & & & & $\begin{array}{l}\text { Number of advanced construction technologies } \\
\text { selected to be included in Concept Home }\end{array}$ & Output & 1 & 2 & 1 & 2 & 6 \\
\hline \multirow{4}{*}{ 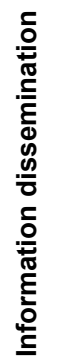 } & & & & $\mathbf{x}$ & & $\begin{array}{l}\text { Number of Web page hits about Concept Home } \\
\text { on PATHnet, ToolBase, or HUDUser (\#5) }\end{array}$ & Output & 2 & 1 & 2 & 2 & 7 \\
\hline & & & & $\mathbf{x}$ & & $\begin{array}{l}\text { Information availability on Concept Home on } \\
\text { the internet (via Web search) (\#6) }\end{array}$ & Output & 1 & 1 & 2 & 2 & 6 \\
\hline & & & & $x$ & & Number of downloads of "Design Guide " & Output & 2 & 1 & 2 & 1 & 6 \\
\hline & & & & $x$ & & Number of open houses per Concept Home & Activity & 2 & 1 & 2 & 1 & 6 \\
\hline
\end{tabular}




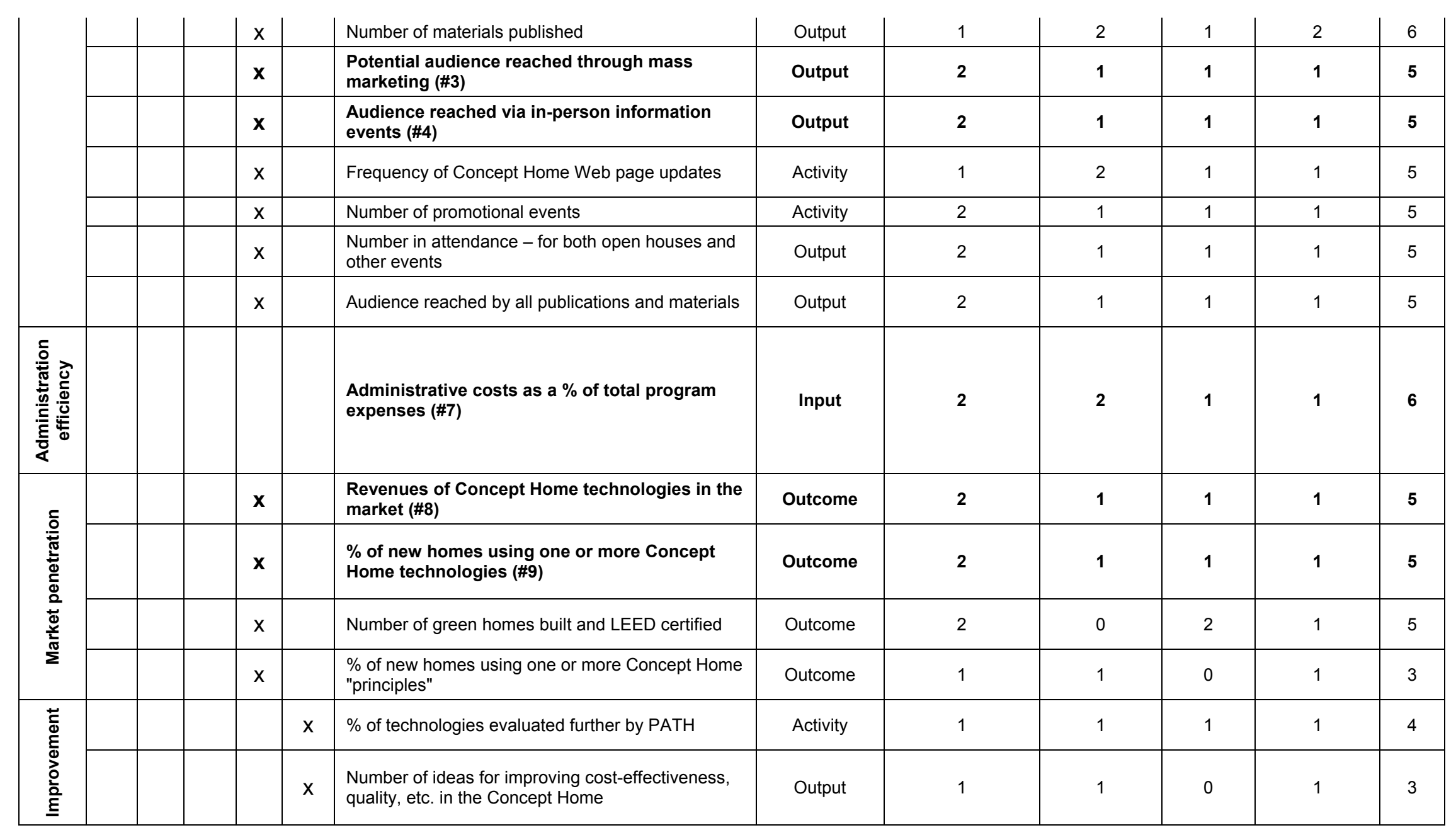


Table B2. ToolBase

\begin{tabular}{|c|c|c|c|c|c|c|c|}
\hline Bin & $\begin{array}{c}\text { Metric } \\
\text { (Recommended metric \# in parentheses) }\end{array}$ & $\begin{array}{l}\text { Measures } \\
\text { Input, } \\
\text { Activity, } \\
\text { Output, or } \\
\text { Outcome }\end{array}$ & Understandable & Attributable & Feasible & $\begin{array}{l}\text { Comparable } \\
\text { over time }\end{array}$ & Sum \\
\hline \multirow{4}{*}{ 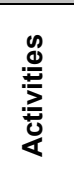 } & Cumulative number of technologies featured in the Techlnventory (\#1) & Activity & 2 & 2 & 2 & 2 & 8 \\
\hline & Cumulative number of Field Evaluations (\#2) & Activity & 1 & 1 & 2 & 2 & 6 \\
\hline & Number of PATH-sponsored promotional events & Activity & 1 & 2 & 1 & 1 & 5 \\
\hline & PATH's cost share of field evaluations & Activity & 1 & 2 & 1 & 1 & 5 \\
\hline \multirow{4}{*}{$\begin{array}{l}0 \\
\frac{1}{0} \\
0 \\
30 \\
3\end{array}$} & Number of broken links in ToolBase.org (\#4) & Output & 1 & 2 & 2 & 1 & 6 \\
\hline & $\begin{array}{l}\text { Techlnventory and Field Evaluations page views per user visit/session } \\
\text { in each month (\#3) }\end{array}$ & Output & 1 & 1 & 2 & 2 & 6 \\
\hline & Frequency of search optimization (for ToolBase.org) conducted & Activity & 1 & 2 & 1 & 1 & 5 \\
\hline & Number of external links to ToolBase.org & Output & 1 & 1 & 1 & 1 & 4 \\
\hline \multirow{6}{*}{ 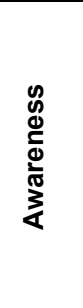 } & Number of ToolBase.org page views per month (\#6) & Output & 2 & 1 & 2 & 2 & 7 \\
\hline & Number of TechInventory page views per month (\#7) & Output & 2 & 1 & 2 & 2 & 7 \\
\hline & Number of Field Evaluations page views per month (\#8) & Output & 2 & 1 & 2 & 2 & 7 \\
\hline & Number of unique visitors to ToolBase.org per month (\#5) & Output & 2 & 1 & 2 & 1 & 6 \\
\hline & $\begin{array}{l}\text { Number of visitors ('visitor sessions') accessing ToolBase.org per } \\
\text { square feet of new residential-housing units in the U.S. per month (\#9) }\end{array}$ & Output & 1 & 1 & 1 & 1 & 4 \\
\hline & Average number of U.S. states represented by site visitors per month & Output & 1 & 0 & 2 & 1 & 4 \\
\hline \multirow{5}{*}{ 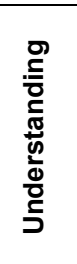 } & Average number of page views per session (\#10) & Output & 1 & 1 & 2 & 2 & 6 \\
\hline & $\begin{array}{l}\text { Average number of repeat visits per month (i.e. Number of visitor } \\
\text { sessions/Number of unique visitors) (\#11) }\end{array}$ & Output & 1 & 1 & 2 & 2 & 6 \\
\hline & Average number of page views per day & Output & 1 & 1 & 2 & 2 & 6 \\
\hline & Average number of new visitors per month & Output & 1 & 1 & 2 & 2 & 6 \\
\hline & Average number of sessions per day & Output & 1 & 1 & 2 & 2 & 6 \\
\hline \multirow{4}{*}{ 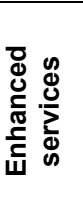 } & Number of promotional events per year (\#12) & Output & 2 & 2 & 1 & 1 & 6 \\
\hline & $\begin{array}{l}\text { Number of news subscribers - including subscribers to E-news, RSS } \\
\text { feeds, and print newsletter mailings (\#13) }\end{array}$ & Output & 2 & 1 & 1 & 1 & 5 \\
\hline & Percentage of E-news subscribers who use a link to access ToolBase & Output & 2 & 1 & 1 & 1 & 5 \\
\hline & Number of press releases about ToolBase & Output & 2 & 1 & 1 & 1 & 5 \\
\hline
\end{tabular}




\begin{tabular}{|c|c|c|c|c|c|c|c|}
\hline & Number of 'email this article' usage per month & Output & 2 & 1 & 1 & 1 & 5 \\
\hline & Audience reached by all promotional events & Output & 2 & 1 & 0 & 1 & 4 \\
\hline 宾 & $\begin{array}{l}\text { Percentage of home builders who are aware of, understand, decide to } \\
\text { use, and finally, confirm their use of a ToolBase technology (\#14) }\end{array}$ & Outcome & 0 & 1 & 0 & 1 & 2 \\
\hline
\end{tabular}

\section{Table B3. Structural Insulated Panels (SIPs)}

\begin{tabular}{|c|c|c|c|c|c|c|c|}
\hline Bin & $\begin{array}{c}\text { Metric } \\
\text { (Recommended metric \# in parentheses) }\end{array}$ & $\begin{array}{l}\text { Measures } \\
\text { Input, } \\
\text { Activity, } \\
\text { Output, or } \\
\text { Outcome }\end{array}$ & $\begin{array}{l}\text { Understand- } \\
\text { able }\end{array}$ & Attributable & Feasible & $\begin{array}{l}\text { Comparable } \\
\text { over time }\end{array}$ & Sum \\
\hline 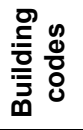 & $\begin{array}{l}\% \text { of new homes built in locations that use the IRC or other building codes } \\
\text { that include SIPs (\#1) }\end{array}$ & Outcome & 2 & 1 & 1 & 2 & 6 \\
\hline \multirow{2}{*}{ 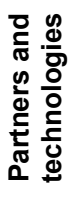 } & $\begin{array}{l}\text { Number of PATH partners (including organizations, builders, or manufacturers) } \\
\text { for SIP project(s) }\end{array}$ & Activity & 2 & 1 & 1 & 2 & 6 \\
\hline & $\%$ of market share that "manufacturer" or "builder" partners represent & Output & 1 & 1 & 1 & 2 & 5 \\
\hline \multirow{4}{*}{ 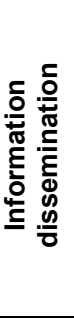 } & $\begin{array}{l}\text { Average monthly page views of the ToolBase SIPs Technology Inventory } \\
\text { homepage (\#2) }\end{array}$ & Output & 2 & 1 & 2 & 2 & 7 \\
\hline & Number of downloads of SIPs TechSpec from ToolBase (\#3) & Output & 2 & 1 & 2 & 2 & 7 \\
\hline & $\begin{array}{l}\text { Information availability on PATH SIPs program on the internet (via Web } \\
\text { search) (\#4) }\end{array}$ & Output & 1 & 1 & 2 & 2 & 6 \\
\hline & $\begin{array}{l}\text { Number of downloads of "Prescriptive Method for SIPs Used In Wall Systems In } \\
\text { Residential Construction" or "Panelized Wall Systems: Making the Connections" } \\
\text { (from PATHnet) }\end{array}$ & Output & 2 & 1 & 2 & 1 & 6 \\
\hline \multirow{5}{*}{ 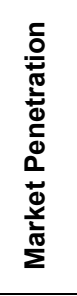 } & Number of home builders offering SIPs (\#5) & Outcome & 2 & 1 & 1 & 2 & 6 \\
\hline & Percent of new homes in the U.S. built using SIPs (\#6) & Outcome & 2 & 1 & 1 & 2 & 6 \\
\hline & $\begin{array}{l}\text { SIPs annual production (sq. ft.) for residential use as a fraction of total } \\
\text { annual residential construction (sq. ft.) (\#7) }\end{array}$ & Outcome & 1 & 1 & 2 & 2 & 6 \\
\hline & $\begin{array}{l}\text { No. of states that have greater than } 0.5 \% \text { of new residential-housing units } \\
\text { built using SIPs (\#8) }\end{array}$ & Outcome & 1 & 1 & 1 & 2 & 5 \\
\hline & Market share of construction companies (e.g. builders) offering SIPs & Outcome & 1 & 0 & 1 & 2 & 4 \\
\hline
\end{tabular}


Table B4. Steel Framing

\begin{tabular}{|c|c|c|c|c|c|c|c|}
\hline Bin & $\begin{array}{c}\text { Metric } \\
\text { (Recommended metric \# in parentheses) }\end{array}$ & $\begin{array}{l}\text { Measures } \\
\text { Input, } \\
\text { Activity, } \\
\text { Output, or } \\
\text { Outcome }\end{array}$ & $\begin{array}{l}\text { Understand- } \\
\text { able }\end{array}$ & Attributable & Feasible & $\begin{array}{l}\text { Comparable } \\
\text { over time }\end{array}$ & Sum \\
\hline 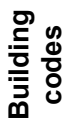 & $\begin{array}{l}\% \text { of new homes built in locations that use the IRC or other building codes } \\
\text { that include steel framing (\#1) }\end{array}$ & Outcome & 2 & 1 & 1 & 2 & 6 \\
\hline \multirow{3}{*}{ 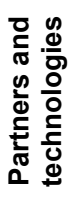 } & $\begin{array}{l}\text { Number of PATH partners (including organizations, builders, or manufacturers) } \\
\text { for steel framing project(s) }\end{array}$ & Activity & 2 & 1 & 1 & 2 & 6 \\
\hline & Number of cooperative agreements with SFA & Output & 1 & 1 & 1 & 1 & 4 \\
\hline & $\%$ of market share that "manufacturer" or "builder" partners represent & Output & 1 & 1 & 1 & 2 & 5 \\
\hline \multirow{4}{*}{ 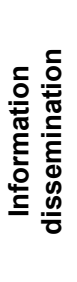 } & $\begin{array}{l}\text { Average monthly page views of the ToolBase Steel Framing Technology } \\
\text { Inventory homepage (\#2) }\end{array}$ & Output & 2 & 1 & 2 & 2 & 7 \\
\hline & $\begin{array}{l}\text { Number of downloads of Cold-formed Steel Framing TechSpec from } \\
\text { ToolBase (\#3) }\end{array}$ & Output & 2 & 1 & 2 & 2 & 7 \\
\hline & $\begin{array}{l}\text { Information availability on PATH steel framing program on the internet (via } \\
\text { Web search) (\#4) }\end{array}$ & Output & 1 & 1 & 2 & 2 & 6 \\
\hline & Number of published technical documents on steel framing and its applications & Output & 2 & 1 & 2 & 1 & 6 \\
\hline \multirow{6}{*}{ 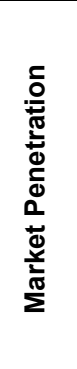 } & $\begin{array}{l}\text { Steel framing annual production (tons) for residential use as a fraction of } \\
\text { total annual residential construction (sq. ft.) (\#5) }\end{array}$ & Outcome & 1 & 1 & 2 & 2 & 6 \\
\hline & Number of home builders offering steel framing (\#6) & Outcome & 2 & 1 & 1 & 2 & 6 \\
\hline & Percent of new homes in the U.S. built using steel framing (\#7) & Outcome & 2 & 1 & 1 & 2 & 6 \\
\hline & $\begin{array}{l}\text { No. of states that have greater than } 1.5 \% \text { of new residential-housing units } \\
\text { built using steel framing }(\# 8)\end{array}$ & Outcome & 1 & 1 & 1 & 2 & 5 \\
\hline & $\begin{array}{l}\text { Number of SFA members (indicating interest in steel framing from } \\
\text { supplier/builder community) }\end{array}$ & Output & 1 & 0 & 2 & 2 & 5 \\
\hline & Market share of construction companies (e.g. builders) offering steel framing & Outcome & 1 & 0 & 1 & 2 & 4 \\
\hline
\end{tabular}


Table B5. Insulated Concrete Forms (ICFs)

\begin{tabular}{|c|c|c|c|c|c|c|c|}
\hline Bin & $\begin{array}{c}\text { Metric } \\
\text { (Recommended metric \# in parentheses) }\end{array}$ & $\begin{array}{l}\text { Measures } \\
\text { Input, } \\
\text { Activity, } \\
\text { Output, or } \\
\text { Outcome }\end{array}$ & $\begin{array}{l}\text { Understand- } \\
\text { able }\end{array}$ & Attributable & Feasible & $\begin{array}{l}\text { Comparable } \\
\text { over time }\end{array}$ & Sum \\
\hline 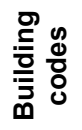 & $\begin{array}{l}\% \text { of new homes built in locations that use the IRC or other building codes } \\
\text { that include ICFs (\#1) }\end{array}$ & Outcome & 2 & 1 & 1 & 2 & 6 \\
\hline \multirow{2}{*}{ 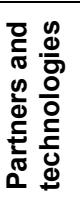 } & $\begin{array}{l}\text { Number of PATH partners (including organizations, builders, or manufacturers) } \\
\text { for ICF project(s) }\end{array}$ & Activity & 2 & 1 & 1 & 2 & 6 \\
\hline & $\%$ of market share that "manufacturer" or "builder" partners represent & Output & 1 & 1 & 1 & 2 & 5 \\
\hline \multirow{4}{*}{ 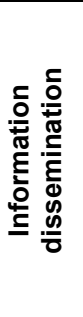 } & $\begin{array}{l}\text { Average monthly page views of the ToolBase ICFs Technology Inventory } \\
\text { homepage (\#2) }\end{array}$ & Output & 2 & 1 & 2 & 2 & 7 \\
\hline & $\begin{array}{l}\text { Information availability on PATH ICFs program on the internet (via Web } \\
\text { search) (\#3) }\end{array}$ & Output & 1 & 1 & 2 & 2 & 6 \\
\hline & $\begin{array}{l}\text { Number of downloads or page views of ICF-related articles and reports on } \\
\text { PATHnet, ToolBase, or HUDUser }\end{array}$ & Output & 2 & 1 & 2 & 1 & 6 \\
\hline & $\begin{array}{l}\text { Number of downloads of ICFs TechSpec from ToolBase (note: this key } \\
\text { document does not appear to be available to download) }\end{array}$ & Output & 2 & 1 & 0 & 2 & 5 \\
\hline \multirow{6}{*}{ 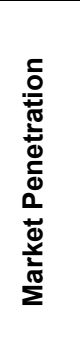 } & $\begin{array}{l}\text { ICFs annual production (sq. ft.) for residential use as a fraction of total } \\
\text { annual residential construction (sq. ft.) (\#4) }\end{array}$ & Outcome & 1 & 1 & 2 & 2 & 6 \\
\hline & Number of home builders offering ICFs (\#5) & Outcome & 2 & 1 & 1 & 2 & 6 \\
\hline & Percent of new homes in the U.S. built using ICFs (\#6) & Outcome & 2 & 1 & 1 & 2 & 6 \\
\hline & $\begin{array}{l}\text { No. of states that have greater than } 2.7 \% \text { of new residential-housing units } \\
\text { built using ICFs (\#7) }\end{array}$ & Outcome & 1 & 1 & 1 & 2 & 5 \\
\hline & $\begin{array}{l}\text { Number of ICFA members (indicating interest in ICFs from supplier/builder } \\
\text { community) }\end{array}$ & Output & 1 & 0 & 2 & 2 & 5 \\
\hline & Market share of construction companies (e.g. builders) offering ICFs & Outcome & 1 & 0 & 1 & 2 & 4 \\
\hline
\end{tabular}




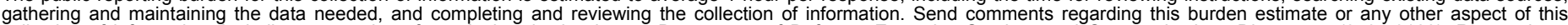

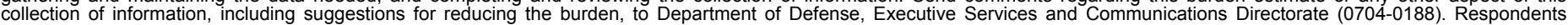

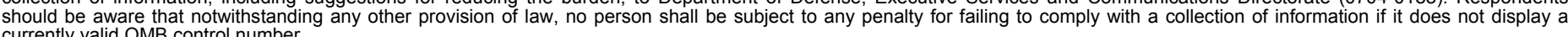

PLEASE DO NOT RETURN YOUR FORM TO THE ABOVE ORGANIZATION.
1. REPORT DATE (DD-MM-YYYY) January 2009
4. TITLE AND SUBTITLE
Conceptual Soundness, Metric Development, Benchmarking, and
Targeting for PATH Subprogram Evaluation

3. DATES COVERED (From - To)

5a. CONTRACT NUMBER

DE-AC36-08-GO28308

5b. GRANT NUMBER

5c. PROGRAM ELEMENT NUMBER

5d. PROJECT NUMBER

NREL/TP-6A2-43822

5e. TASK NUMBER

WF1K.1000

5f. WORK UNIT NUMBER

7. PERFORMING ORGANIZATION NAME(S) AND ADDRESS(ES)

National Renewable Energy Laboratory

1617 Cole Blvd.

Golden, CO 80401-3393
8. PERFORMING ORGANIZATION REPORT NUMBER
NREL/TP-6A2-43822 and
KLCX-4-44453-19

9. SPONSORING/MONITORING AGENCY NAME(S) AND ADDRESS(ES)

10. SPONSOR/MONITOR'S ACRONYM(S) NREL

11. SPONSORING/MONITORING AGENCY REPORT NUMBER

12. DISTRIBUTION AVAILABILITY STATEMENT

National Technical Information Service

U.S. Department of Commerce

5285 Port Royal Road

Springfield, VA 22161

\section{SUPPLEMENTARY NOTES}

\section{ABSTRACT (Maximum 200 Words)}

The objective of this study is to evaluate the conceptual soundness of the U.S. Department of Housing and Urban Development (HUD) Partnership for Advancing Technology in Housing (PATH) program's revised goals and establish and apply a framework to identify and recommend metrics that are the most useful for measuring PATH's progress. This report provides an evaluative review of PATH's revised goals, outlines a structured method for identifying and selecting metrics, proposes metrics and benchmarks for a sampling of individual PATH programs, and discusses other metrics that potentially could be developed that may add value to the evaluation process. The framework and individual program metrics can be used for ongoing management improvement efforts and to inform broader program-level metrics for government reporting requirements.

\section{SUBJECT TERMS}

NREL; U.S. Department of Housing and Urban Development; HUD; Partnership for Advancing Technology in Housing; PATH; Concept Home; ToolBase Program; Structural Insulated Panels Program; Steel Framing Program; Insulating Concrete Forms Program; Energetics

\begin{tabular}{|c|c|c|c|c|}
\hline \multicolumn{3}{|c|}{ 16. SECURITY CLASSIFICATION OF: } & \multirow{2}{*}{$\begin{array}{l}\text { 17. LIMITATION } \\
\text { OF ABSTRACT } \\
\text { UL }\end{array}$} & \multirow{2}{*}{$\begin{array}{ll}\text { 18. } & \text { NUMBER } \\
\text { OF PAGES }\end{array}$} \\
\hline $\begin{array}{l}\text { a. REPORT } \\
\text { Unclassified }\end{array}$ & $\begin{array}{l}\text { b. ABSTRACT } \\
\text { Unclassified }\end{array}$ & $\begin{array}{l}\text { c. THIS PAGE } \\
\text { Unclassified }\end{array}$ & & \\
\hline
\end{tabular}

\begin{tabular}{l} 
19a. NAME OF RESPONSIBLE PERSON \\
\hline 19b. TELEPHONE NUMBER (Include area code)
\end{tabular}

